\title{
AUTUN, MANÉ-VÉCHEN ET VIEUX : L'APPORT DE TROIS SITES MAJEURS À LA CONNAISSANCE DE L'ARTISANAT DU STUC EN GAULE ROMAINE
}

\author{
Autun, Mané-Véchen y Vieux : la aportación de tres \\ importantes yacimientos al conocimiento del artesanado \\ de estuco en la Galia romana
}

\author{
Par Julien Boislève ${ }^{1}$
}

Recibido el 3 de abril de 2012. Aprobado el 1 de mayo de 2012

Résumé : La découverte et l'étude récente d'importants lots de stucs sur les sites de la villa de Mané-Véchen en Plouhinec (Morbihan) et du "palais" urbain du centre hospitalier à Autun (Saône-et-Loire) constituent un apport considérable à notre connaissance d'un artisanat relativement méconnu en Gaule : le stuc. Parallèlement, le réexamen de collections plus anciennes sur la domus de Vieux (Calvados) a permis la réinterprétation de décors laissant une place considérable et parfois inattendue au relief. Relativement complets, et pour certains restituables, ces décors éclairent un usage du stuc assez différent de celui connu en Italie et permettent d'identifier certaines modes décoratives typiquement provinciales.

Mots clés : décor, stuc, enduit peint, dorure, imitation de marbre, villa, domus, Gaule romaine.

Resumen: El descubrimiento y el reciente estudio de importantes conjuntos de estucos hallados en la villa de Mané-Vechen en Plouhinec (Morbihan) y en el "palacio" urbano del hospitalario en Autun (Saône-et-Loire) constituyen una considerable aportación al conocimiento de un artesanado relativamente desconocido en la Galia: el estuco. Paralelamente, la revisión de las antiguas colecciones de la domus de Vieux (Calvados) ha permitido la reinterpretación de las decoraciones en las que el relieve juega un rol considerable $y_{\text {, en }}$ ocasiones, inesperado. Relativamente completas y, en algunos casos, susceptibles de una restitución, estas decoraciones esclarecen un uso del estuco bastante diferente al conocido en Italia y permiten identificar ciertas modas decorativas típicamente provinciales.

Palabras clave: decoración, estuco, pinturas, pan de oro, imitación de mármol, villa, domus, Galia romana.

\section{INTRODUCTION}

Le stuc est certes présent sur de très nombreux décors, connus à peu près partout sur le territoire des Gaules, mais le plus souvent limité à l'application de corniches sommitales couronnant un décor peint ou, dans une moindre mesure, de moulures séparatives rythmant la paroi. II n'occupe alors qu'une surface restreinte.
Pourtant, plusieurs indices, pour une bonne part objets de découvertes anciennes, laissaient déjà entrevoir des décors où le relief prend une place plus importante, allant peut-être jusqu'à constituer la dominante principale de la composition. Plusieurs éléments modelés et figurés se rattachent probablement à ce type de schéma décoratif, mais nombre d'entre eux demeurent des éléments isolés conservés dans quelques réserves de musées. C'est le cas par exemple

(1) Chargé d'études spécialisées sur les peintures et stucs d'époque romaine. La Bonnemais, 35590 La Chapelle Thouarault, France. boislevejulien@yahoo.fr 
de plusieurs têtes du musée Rolin à Autun (Saône-et-Loire), d'un petit visage d'Eros à Clermont-Ferrand (Puy-de-Dôme) ou encore d'un protomé de taureau provenant d'Alésia (Côte-d'Or). L'absence de lots conséquents interdit bien sûr toute lecture globale du décor et donc toute réflexion sur la place des reliefs dans la composition.

La faible quantité de décors stuqués connus en Gaule ne peut s'expliquer par la seule fragilité d'un matériau qui, s'il est effectivement souvent impossible à prélever en fouille, s'avère dans certains cas particulièrement résistant. Le corpus, limité en nombre, reflète bien la relative rareté de ce type de décor, sans qu'il soit évident d'en établir la raison précise : diffusion moins large des modèles stylistiques, coût plus élevé, présence moindre d'artisans qualifiés, destination réservée à des espaces d'apparat,...

\section{LE STUC EN GAULE, LES NOUVELLES DÉCOUVERTES}

L'amélioration des méthodes de fouilles et de la prise en compte des vestiges peints et stuqués à l'occasion des fouilles, aussi bien programmées que préventives, ont per- mis ces dernières années de mettre au jour puis d'étudier plusieurs ensembles de stucs dont la qualité, la particularité ou simplement la bonne conservation offrent une lecture renouvelée de la place de cet artisanat en Gaule romaine. De styles très différents, les divers décors qui nous intéresseront ici sont issus de trois sites importants.

\subsection{Les décors de la villa de Mané-Véchen (Morbihan)}

Le premier est une riche demeure située sur la côte sud la Bretagne (Provost 2007) (fig. 1). Sise sur un petit promontoire rocheux à quelques encablures de l'océan atlantique, la villa de Mané-Véchen en Plouhinec développe en plan en U fermant une cour ouverte sur la ria d'Etel, vaste vallée fluviale ennoyée par la mer $^{2}$. Construite dans le dernier quart du II s. ap. J.-C., la riche habitation jouit d'un panorama remarquable et s'apparente à une villa maritima, un lieu de villégiature tel que ceux connus sur les côtes italiennes. L'ensemble architectural subit peu de modifications durant son occupation et connaît un abandon brutal en $282^{3}$, sans doute lié aux troubles et aux pirateries auxquels les villae côtières sont particulièrement vulnérables. L'aile méridionale

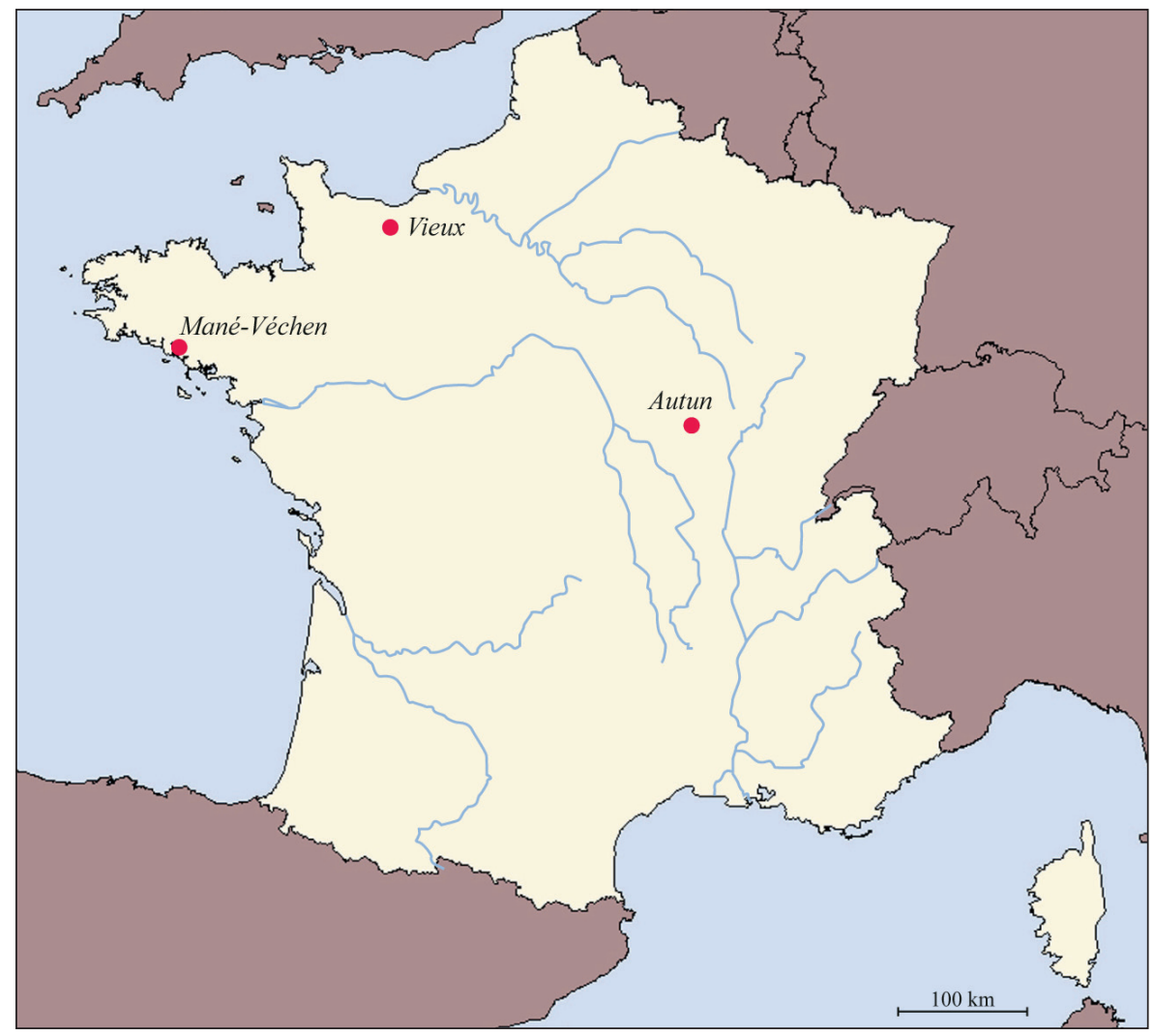

Fig. 1. Carte de localisation des sites.

(2) Propriété de l'État, le site a fait l'objet d'une fouille programmée dirigée par A. Provost de 2000 à 2007. Les décors prélevés sous la responsabilité de J. Boislève dans les salles BF et AB ont été étudiés au CEPMR de Soissons, également sous la responsabilité de l'auteur (Boislève 2006 et Boislève 2009).

(3) Cette date précise correspond au dernier apport identifié dans un important trésor monétaire enfoui dans l'aile sud du bâtiment (André 2003). 


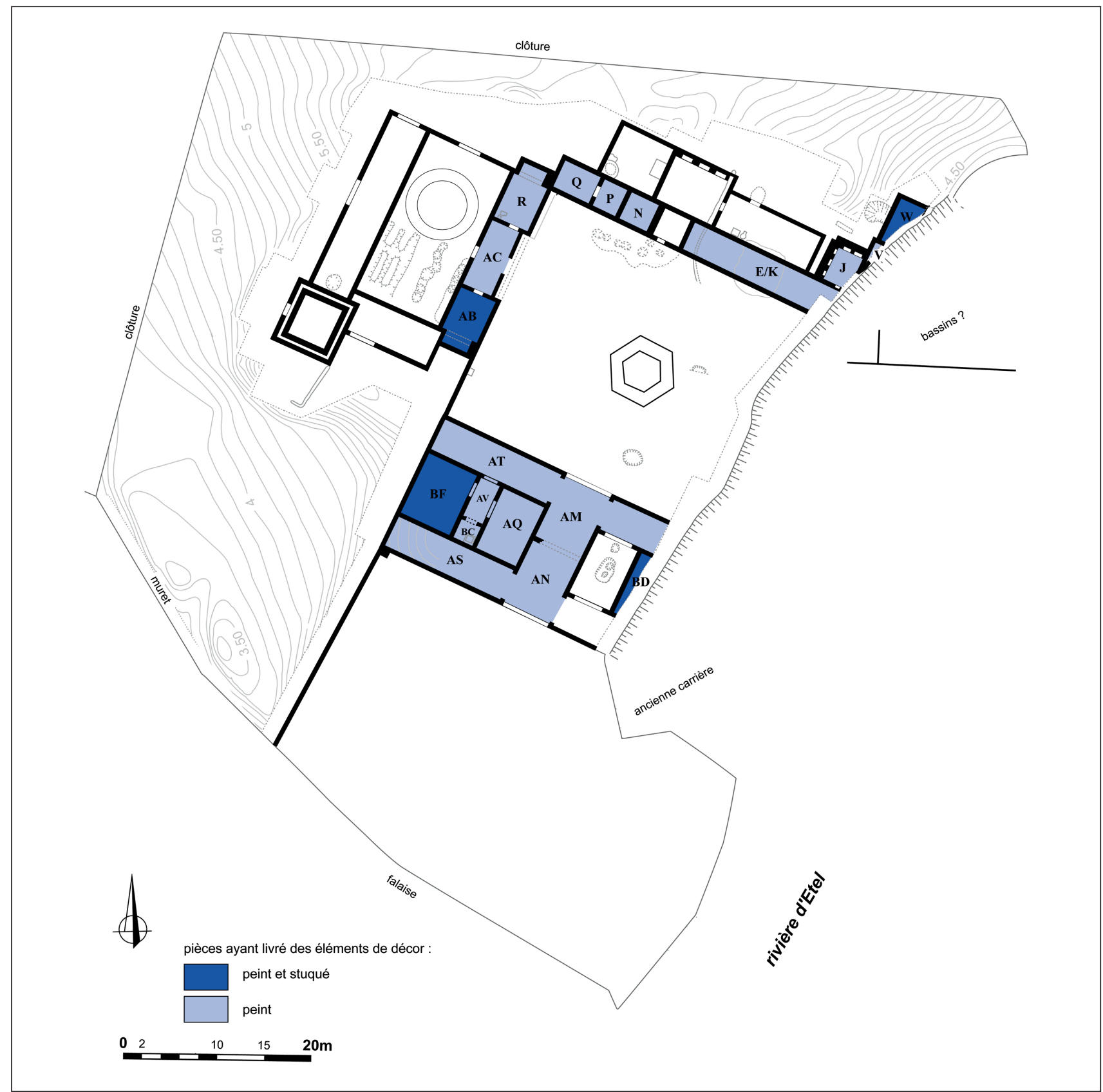

\ Fig. 2. Plan de la villa de Mané-Véchen avec localisation des salles peintes et stuquées (d'après un plan de A. Provost).

de l'édifice est détruite dans un incendie tandis que les deux autres sont réoccupées de façon plus anarchique et sans entretien notable. Toitures, murs et décors se ruinent donc progressivement jusqu'à l'abandon complet vers $321^{4}$.

\subsubsection{La place du stuc, répartition spatiale et fonctionnelle}

Les couches de démolition et d'effondrement des décors, présentes dans une bonne partie des pièces de la villa, autorisent une assez bonne restitution d'ensemble du pro- gramme décoratif. Dans cette demeure, quatre pièces arboraient des décors stuqués (les salles $B F, B D, A B$ et $W$ ) (fig. 2). Leur répartition révèle la place particulière réservée au stuc et le rôle de ce choix décoratif dans l'apparat des lieux.

Ainsi, dans l'aile méridionale, qui constitue l'aile principale de la villa, à la fois celle par laquelle on accédait aux lieux, mais également celle dont toutes les parois étaient ornées, deux pièces livrent un décor stuqué. II s'agit des vastes salles sises à chacune des extrémités du corps de bâtiment

(4) Après l'abandon par les propriétaires légitimes en 282, le site fait l'objet de réoccupations limitées, souvent directement sur les couches de démolition et sans entretien ou réfections massives des bâtiments. 


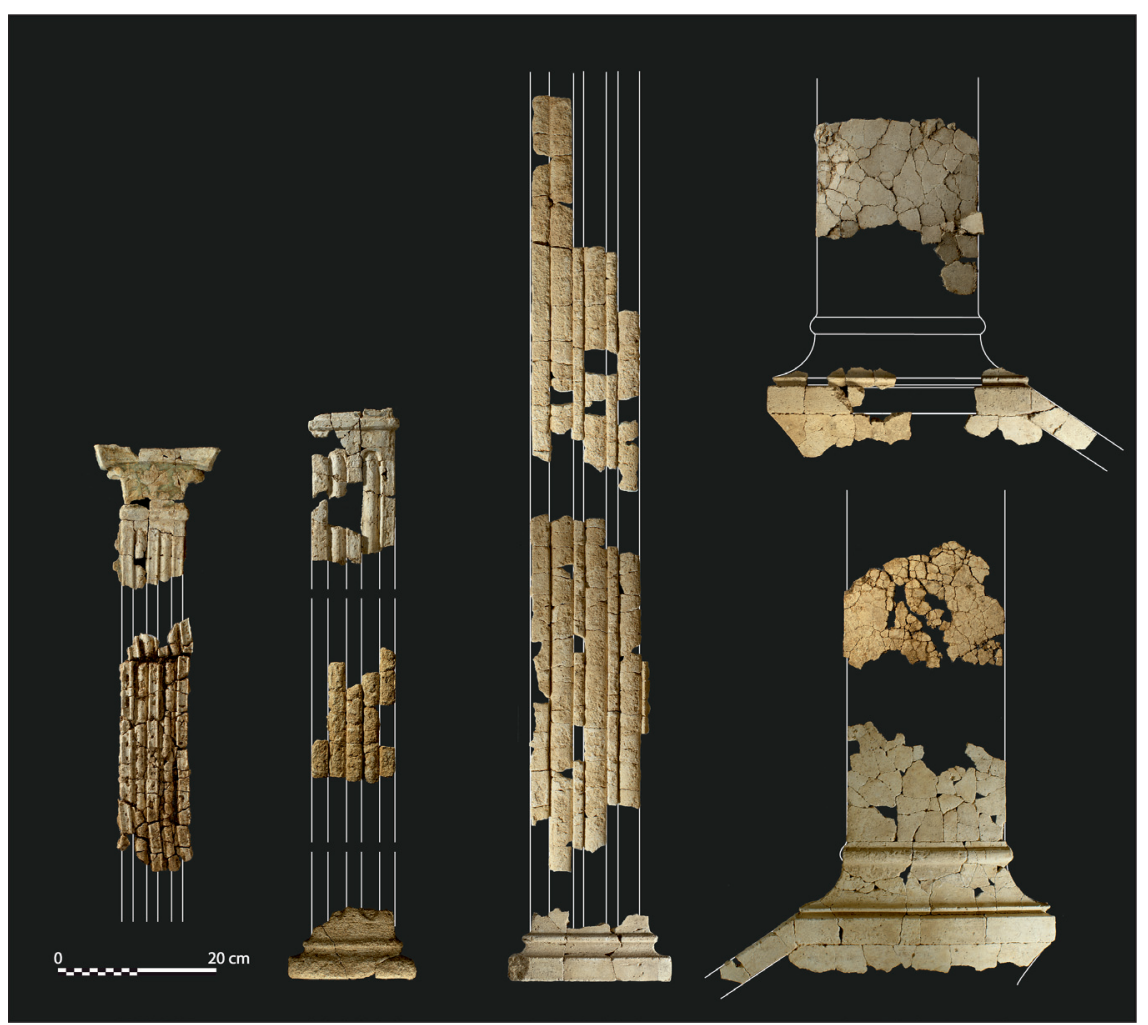

A Fig. 3. Mané-Véchen, salle BF, différents types de pilastres (clichés J. Boislève, CEPMR).

et considérées comme des salons d'apparat. Elles révèlent les seuls ensembles de stucs figurés du site. Au nord, avec une situation privilégiée en façade maritime, la salle BD a été en grande partie détruite par l'avancée du front de mer, accentuée par l'exploitation du granite à cet endroit. Seule une infime partie subsistait donc, qui a fait l'objet de fouilles déjà anciennes, dans les années $70^{5}$. Elles ont livré quelques éléments de stucs malheureusement perdus mais dont subsistent deux moulages de plâtre, quelques photos et surtout une publication dans l'étude des stucs de Gaule menée par M. Frizot (Frizot 1977 : 194-197). Au sud, la salle BF est la parfaite symétrie de la précédente et bénéficie d'un système de chauffage par hypocauste à conduits.

Dans l'aile centrale, le stuc prend place dans la salle $A B$, une pièce en façade sur cour dont l'architecture ménage une exèdre rectangulaire. Elle est également, en plan, l'exacte symétrie de la salle $R$ dont elle est séparée par un vestibule (salle $A C$ ). Cette seconde pièce à exèdre est dépourvue d'élément de stucs dans sa décoration mais privilégie tout de même l'emploi du relief par l'incrustation de coquillages (Boislève et al. 2011 : 27).

Enfin, dans l'aile septentrionale, c'est la salle $W$, une petite pièce chauffée par hypocauste et située en façade maritime, qui livre quelques éléments de stucs. En grande partie détruite par l'érosion marine, sa surface conservée n'offre que quelques indices de sa décoration.
Associée aux décors uniquement peints et aux salles dépourvues d'ornementation, la lecture du programme décoratif révèle donc toute la hiérarchie des pièces et, ainsi, l'importance statutaire du stuc. Le relief, qui plus est modelé et figuré, est alors réservé aux deux pièces les plus importantes de l'aile principale dont l'ensemble des salles, murs et plafonds, était décoré. Dans les autres ailes, le stuc est également choisi pour des espaces dont la fonction, l'emplacement ou les aménagements de confort sont essentiels. II prend place dans les salles chauffées, pourvues d'une exèdre et jouissant d'une situation idéale en façade sur cour ou sur le panorama maritime. Le stuc est donc clairement identifié ici comme un élément de luxe et d'apparat supérieur aux seuls décors peints et donc dévolu aux espaces majeurs de l'entité architecturale (Boislève sous presse).

\subsubsection{La salle BF, description du décor mural}

Dans cette pièce le décor, de loin le plus riche de la villa, réservait une place prépondérante au stuc, aussi bien pour l'ornementation murale que pour le plafond qui a pu être clairement identifié (Boislève 2009). Malheureusement, si les éléments en reliefs présentent un assez bon état de conservation lié à la solidité remarquable des mortiers, l'enduit de support sur lequel ils étaient posés à presque

(5) Fouille de P. André en 1972. 


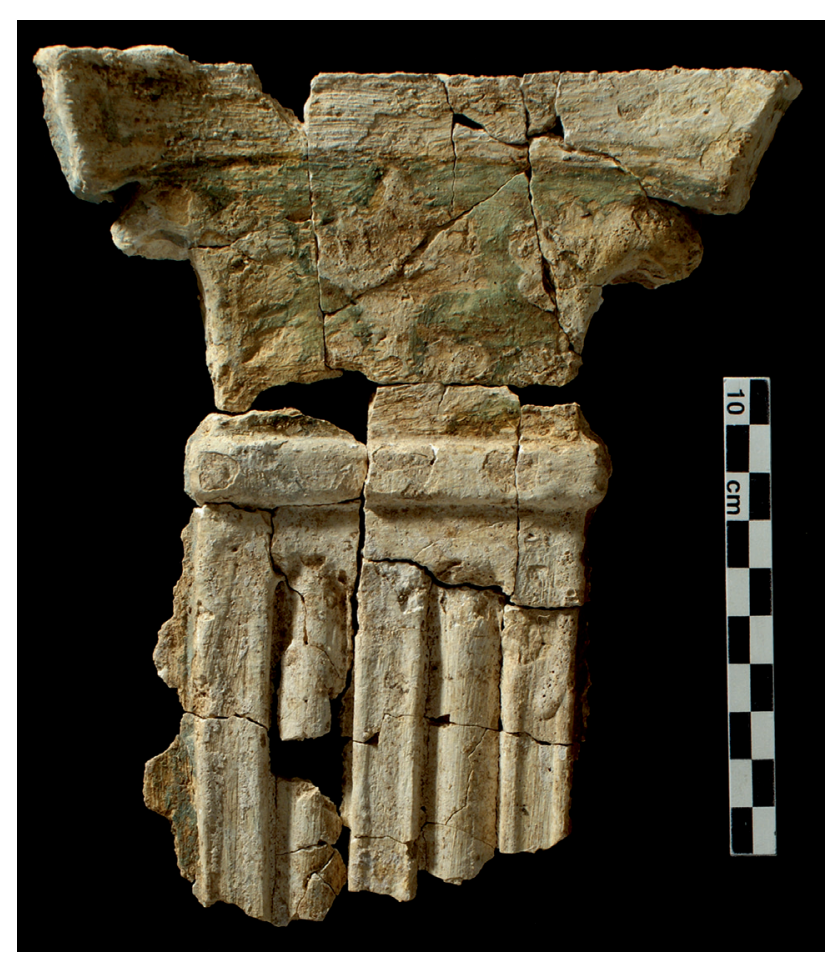

A FIg. 4. Mané-Véchen, salle BF, chapiteau peint (cliché J. Boislève, CEPMR).

totalement disparu ${ }^{6}$. Constitué d'un mortier sableux sans doute assez terreux, il a littéralement fondu, ne laissant à la fouille qu'une couche de sable. Dès lors, les éléments du relief demeurent des pièces isolées qu'il est impossible, en l'absence des fonds, de rattacher les unes aux autres.

La zone inférieure devait être entièrement peinte comme l'indique une petite partie du décor in situ sur la paroi nord. Au-dessus d'une plinthe violacée, des compartiments à encadrement de veinures bleues, peut-être des imitations de marbres, alternent avec des inter-compartiments jaunes.

Les reliefs qui prenaient donc place en zone médiane et peut-être supérieure, présentent une large variété de formes puisées dans un vocabulaire architectural, végétal, mais aussi figuré.

De grands personnages en forte saillie devaient se détacher sur des fonds colorés rouges (comme en témoigne la trace de couleur à la base des stucs) et prendre place dans des niches, arcades ou autres architectures qui rythmaient la paroi et étaient pour certaines également bordées de fonds bleus (Boislève 2010 b).

Quatre types de pilastres sont ainsi identifiés (fig. 3). Trois sont des fûts rudentés dont les dimensions ou la nature exacte des profils diffèrent. En relief d'environ $1 \mathrm{~cm}$ sur la paroi, ils sont pourvus de bases à profil lisse et de chapiteaux dont la ciselure des feuilles d'acanthes est rendue par un motif peint en vert (fig. 4). Le quatrième type, très différent s'apparente peut-être à un piédestal plutôt qu'à un pilastre. II présente également une base lisse, plus large que celles des pilastres rudentés, surmontée d'un fût lisse et plat de faible épaisseur $(0,5$ à 0,8 cm). Au niveau de la base, une découpe angulaire d'un côté et la prolongation d'un bandeau en oblique de l'autre suggèrent une probable perspective.

Ces différents pilastres servaient logiquement de support à divers éléments d'architecture dont des arcades qui sont clairement identifiées. II s'agit d'une moulure à profil lisse (listel, ressaut angulaire, talon et double côte angulaire) tirée en arc de cercle d'un diamètre extérieur de l'ordre de $175 \mathrm{~cm}$ (fig. 5), créant donc un cadre de dimension conséquente susceptible d'accueillir les plus grandes figures. Parmi les autres éléments évoquant l'architecture, divers moulures à bord droit d'un côté et angle oblique de l'autre correspondent sans doute à des modillons vus en perspective. Les nombreuses occurrences de ce type, avec l'angle biais à droite ou à gauche, invitent à proposer une perspective axiale. Par ailleurs, trois types de moulures à profil lisse constituent sans doute des éléments d'encadrement. L'une d'entre elle au moins présente un angle à $90^{\circ}$ qui confirmerait cette fonction.

Tous ces éléments créent donc un cadre à dominante architecturale, très présent, qui doit rythmer et diviser strictement la paroi en panneaux ou registres où se placent les nombreuses figures. Là encore, la variété est de mise. Elle se perçoit d'abord dans les différences d'échelle de représentation (fig. 6). Les plus grandes figures avoisinent ainsi avec la taille réelle tandis que d'autres ne mesurent que quelques centimètres. Plutôt que des scènes à personnages multiples où divers plans expliqueraient ces variations, il faut envisager des registres ou des compartiments différents où les divinités primordiales sont représentées à grande échelle tandis que des personnages annexes sont de taille réduite. Si aucune figure n'est complète, nous savons, par les diverses parties de corps retrouvées, qu'elles étaient figurées en pied.

La variété s'exprime aussi dans le mode de représentation. Les grandes figures, très soignées, bénéficient d'un modelé rigoureux, où les volumes et les détails de l'anatomie sont rendus avec le plus grand naturalisme (fig. 7). Elles sont laissées blanches. À l'inverse, les plus petits personnages sont d'exécution plus rapide et moins détaillée. La couleur couvre souvent les vêtements mais aussi les visages comme en témoigne une oreille et une main à la carnation rose (fig. 8). La polychromie contribuait sans doute à parfaire le rendu final d'une réalisation plus rapide. Parmi les personnages retrouvés nous identifions le dieu Silène connu par le bas d'un visage caractérisé par une moustache torsadée (fig. 9). Un autre visage, aux traits enfantins et à la chevelure bou-

(6) À l'exception d'une petite plaque conservée in situ sur le mur nord de la pièce et qui livre quelques informations sur le soubassement du décor. Cf. infra. 


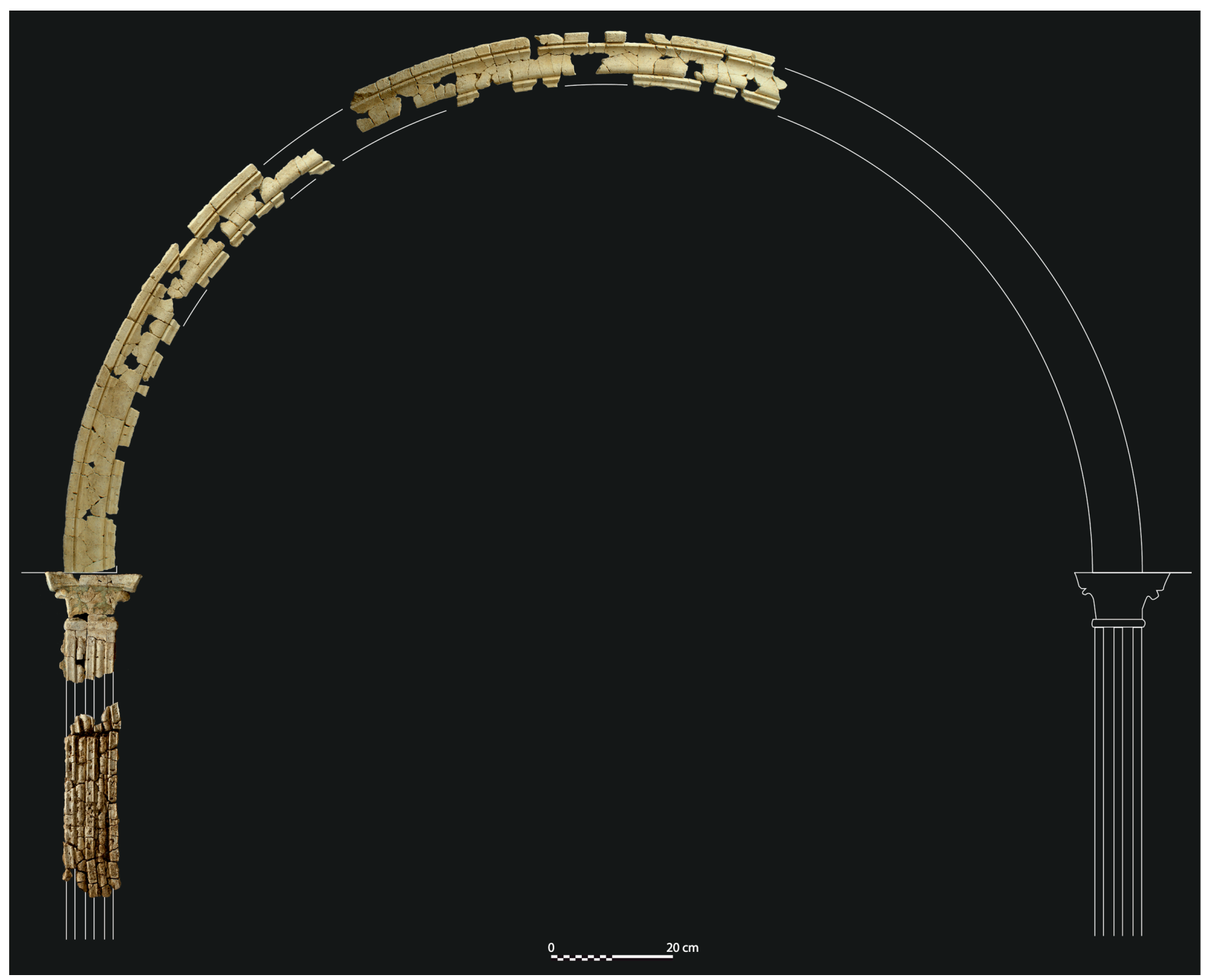

\ FIG. 5. Mané-Véchen, salle BF, proposition de restitution d'une arcade (DAO et cliché J. Boislève, CEPMR).

clée évoque Éros (fig. 10). Plusieurs faunes ou satyres sont identifiés par des traits biens marqués. Crâne chauve, lèvre supérieure épaisse et arcades sourcilières très prononcées et en accent circonflexe marquent ainsi l'une des têtes. Deux autres présentent des traitements différents. La première offre un faciès presque animal avec un nez épaté et des arcades sourcilières prononcées. La chevelure est traitée de manière étonnante, évoquant presque des mèches crépues. La seconde a des traits proches du grotesque avec menton en galoche, joues proéminentes et arcades plissées au niveau du nez. Les yeux en amande sont grand ouverts (fig. 11).

Les plus petits visages demeurent en revanche plus difficiles à identifier en l'absence de traits caractéristiques.

Outre ces têtes, plusieurs membres ou parties de corps identifient d'autres divinités. On note ainsi trois mains ou bras de grande taille et de très belle facture tenant cha- cune un objet longiligne qui correspond au sceptre identifiant le dieu. Seul l'un d'entre eux, plus complet, a permis de reconnaître le caducée d'Hermès (fig. 12) tandis qu'une autre main tient une probable bourse appartenant sans doute à la même divinité. Un torse nu est celui d'un satyre, aux pectoraux marqués et portant sur l'épaule gauche sa probable nébride. Le pedum qu'il tient contre son épaule apparaît aussi sur quelques centimètres (fig. 13). L'un des grands personnages était vêtu d'un long vêtement plissé (toge ?) dont le stucateur rend avec un incroyable talent tout le volume et le mouvement, jouant avec des reliefs parfois considérables qui marquent assurément une divinité de premier plan.

Enfin, associés aux stucs ornant les parois, il faut intégrer des coquillages qui étaient incrustés dans le mortier. II s'agit de grosses coques à côtes radiales prononcées. Deux

(7) Les identifications sont dues à Catherine Dupont, malacologue à l'université Rennes 1, UMR 6566 du CNRS. CREAAH "Centre de Recherche en Archéologie Archéosciences Histoire". 


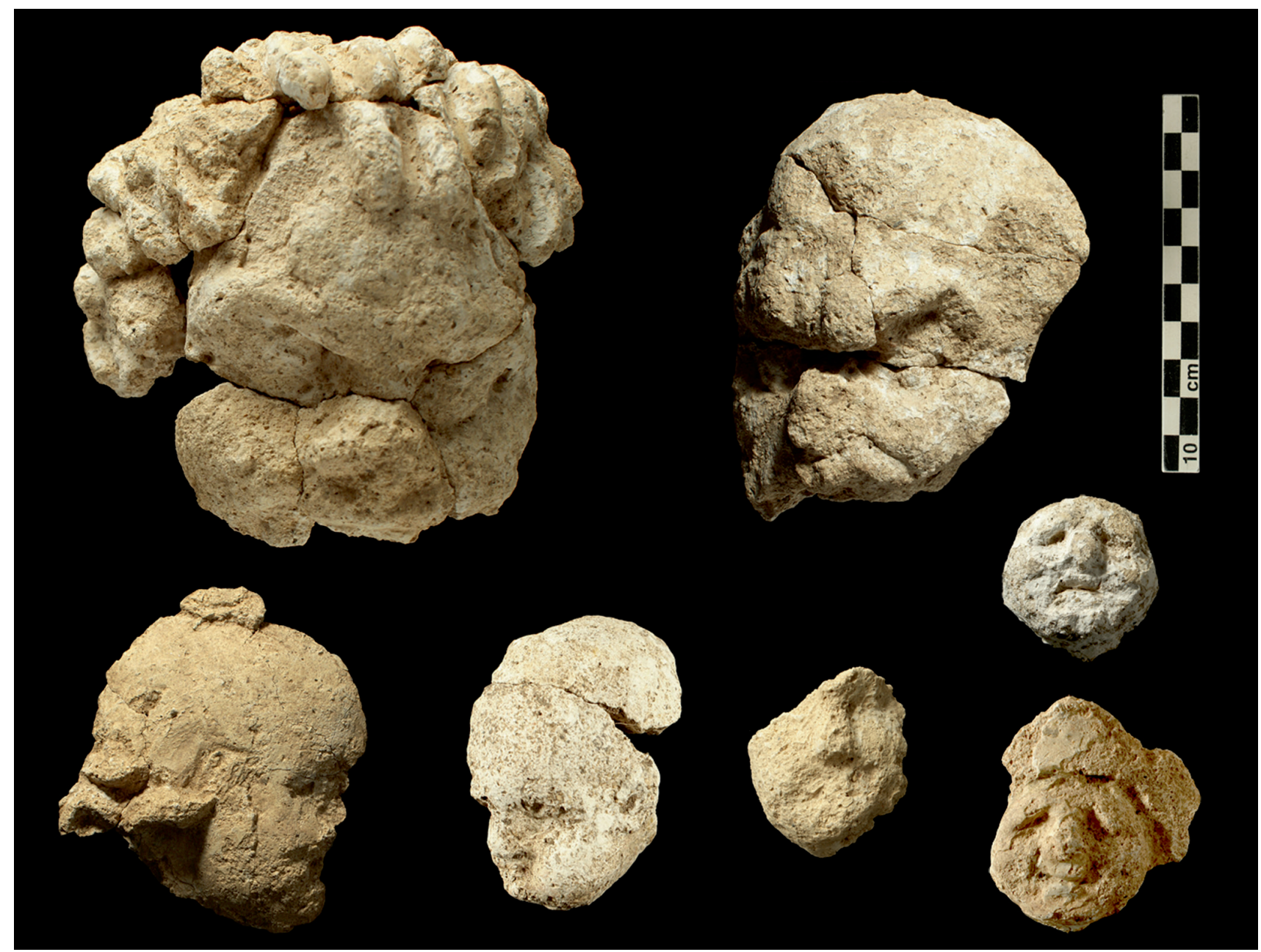

A FIG. 6. Mané-Véchen, salle BF, différentes têtes (clichés J. Boislève, CEPMR).

espèces sont présentes ${ }^{7}$, Cerastoderma edule pour les plus petites et Acanthocardia tuberculata pour les plus grandes. Disposés comme souvent en rang continu, ils pouvaient constituer des encadrements ou marquer quelques lignes de force de l'architecture (bord de fenêtre, angle d'une niche,...).

\subsubsection{La salle BF, description du décor de plafond}

L'incendie des charpentes et l'effondrement de la toiture qui en découle a permis de bien discerner, en stratigraphie, les éléments du décor de plafond, scellés par les tuiles, de ceux du décor mural reposant sur elles. Par ailleurs, la chauffe à induré la terre de support sur laquelle des empreintes de fagots de brindilles sont lisibles, confirmant la présence d'un plafond orné de stucs.

La correspondance stylistique entre mur et plafond est évidente à plusieurs titres. Tout d'abord les choix chromatiques sont identiques, avec des reliefs blancs se détachant sur des fonds bleus et rouges même s'il est vrai que ces deux couleurs sont canoniquement associées au stuc. Ensuite, les moulures du plafond présentent strictement le même profil que celles des parois, mais développé à une échelle bien inférieure (5,3 cm au plafond contre $8,5 \mathrm{~cm}$ en paroi) (fig. 14).
La thématique crée également le lien puisque quelques figurations sont identifiées au plafond dont le corps d'un satyre en érection, sans doute tourné vers une ménade ou une nymphe (fig. 15). Par ailleurs, une végétation abondante de pampres et de grappes de raisins semble couvrir l'essentiel de la surface et crée bien sûr un cadre aux intonations bachiques évidentes. Si les grappes (fig. 16) sont nettement en relief (des petites boulettes assemblées sur un support d'enduit frais), tous les feuillages sont parfaitement plats et de faible épaisseur (environ 0,4 cm). Assez finement découpés, ils sont rehaussés d'incisions de surface qui créent les nervures centrales. Divers modèles sont présents (fig. 17) mais chacun est répété plusieurs fois, peut-être dans une composition savamment orchestrée. L'élément le plus étonnant de ce décor réside dans la présence systématique d'une dorure à la feuille sur tous les feuillages tandis que les grappes, les moulures et les personnages sont laissés blancs.

Le décor de cette pièce, où le relief est partout présent, prononcé, varié dans ses traitements, coloré ou au contraire dont la blancheur se détache sur des fonds saturés, devait imposer au visiteur le poids de son abondance. La symbolique mythologique, la taille des représentations, la finesse de la 


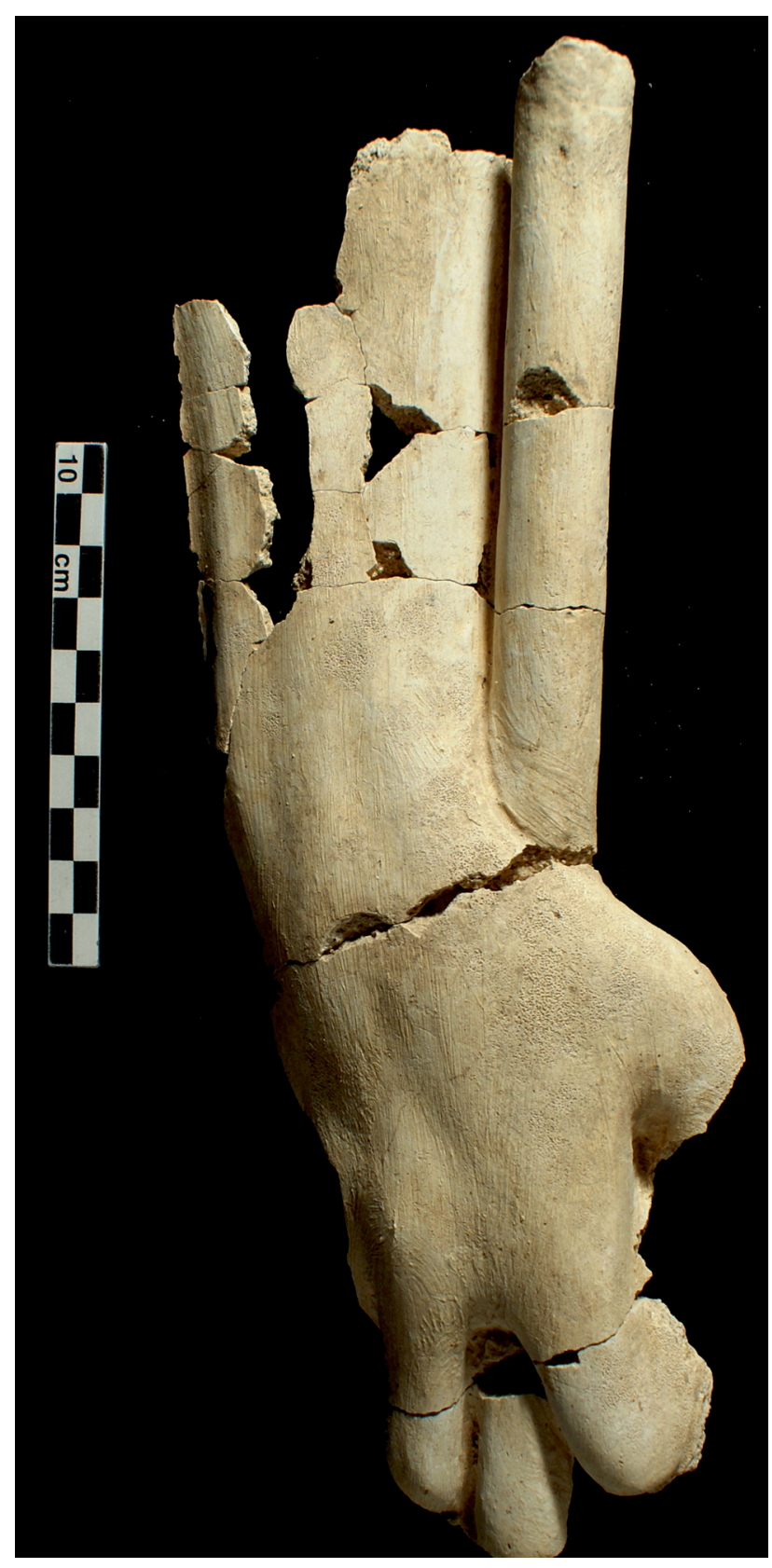

A FIG. 7. Mané-Véchen, salle BF, avant-bras et main tenant un sceptre (cliché J. Boislève, CEPMR).

réalisation égalant le rendu des plus fines statues de marbre blanc, autant que l'éclat des dorures, définissaient certainement une pièce majeure clairement dévolue à l'apparat.

\subsubsection{La salle $B D$, description du décor}

Si la salle BD est, en plan, la parfaite symétrie de la salle $B F$, les quelques éléments de son décor présagent d'une étonnante similitude puisque l'ensemble livre également les indices d'un riche décor stuqué (Boislève y Provost 2011). Parmi les fragments exhumés lors des fouilles des années 70 se trouvent ainsi des stucs figurés d'assez belle facture dont une petite tête d'enfant qui pourrait correspondre à un Éros (fig. 18). Le registre animalier est avéré par deux fragments, I'un représentant une panthère bondissante dont la crinière est fortement développée, l'autre laissant seulement deviner la patte arrière d'un animal placé au-dessus d'une moulure (Frizot 1977 : 169). Divers fragments de corps, de feuillages, ainsi qu'une petite variété de moulures et corniches complètent ce décor.

Les observations des fouilleurs mentionnent certains stucs reposant sur une couche de mortier elle-même fixée à une couche de terre rubéfiée conservant au revers l'empreinte de baguettes de bois. Cet indice essentiel confirme, comme dans la salle BF, la présence de stuc en couvrement de pièce, en plus des éléments de paroi. On peut donc envisager une seconde pièce au riche décor à dominante stuquée et offrant aussi des scènes figurées.

\subsubsection{La salle $A B$, description du décor}

Dans cette salle à exèdre l'effondrement en place d'une partie du décor autorise une restitution complète ${ }^{8}$ de la paroi (Boislève 2006). Les quatre murs principaux de la pièce présentent un même décor où le stuc participe à l'illusion de placages de marbres assez élaborés. L'exèdre livre en revanche une ornementation figurée. L'imitation de marbre couvre toute la hauteur de la paroi (fig. 19). Au-dessus d'une plinthe gris-noir mouchetée de blanc, la zone médiane accueille des orthostates en léger relief $(0,7 \mathrm{~cm})$, peints d'une imitation de marbre aux veinures grises et violacées, rehaussée d'un mouchetis blanc. Ils sont séparés les uns des autres par une lésène à quatre petits compartiments rectangulaires superposés, également en faible relief et qui se détachent sur un fond à imitation de porphyre vert. Une moulure simple à profil lisse couronne la zone médiane et assure la transition avec une zone supérieure organisée en trois registres superposés et séparés les uns des autres par une corniche stuquée également peinte en imitation de marbre. Le registre inférieur alterne des compartiments rectangulaires, au-dessus des orthostates, et des compartiments carrés au niveau des lésènes. Ils sont séparés les uns des autres par une fine baguette verticale stuquée dont seul l'arrachement est connu. Les rectangles sont peints d'un encadrement à bande grise finement mouchetée de blanc et, au centre, d'un rectangle de porphyre vert agrémenté des découpes à redans ménageant, aux extrémités, deux petits rectangles ornés chacun d'un losange dressé peint en imitation de brèche jaune orangé (fig. 20). Entre les deux, un motif couché, de taille plus importante et surtout travaillé en relief, était aussi peint d'une imitation de roche ${ }^{9}$. Il peut s'agir d'un losange, d'un rectangle ou

${ }^{(8)}$ Seule la restitution de la zone inférieure demeure sujette à caution, notamment dans ses dimensions, du fait des faibles indices retrouvés

$\left({ }^{9}\right)$ Du fait du séchage rapide de cette mince couche de mortier, la couche d'épiderme supportant le pigment a semble-t-il mal adhéré et presque totalement disparu. Seuls quelques indices très localisés permettent donc de prouver que l'ensemble était peint. 


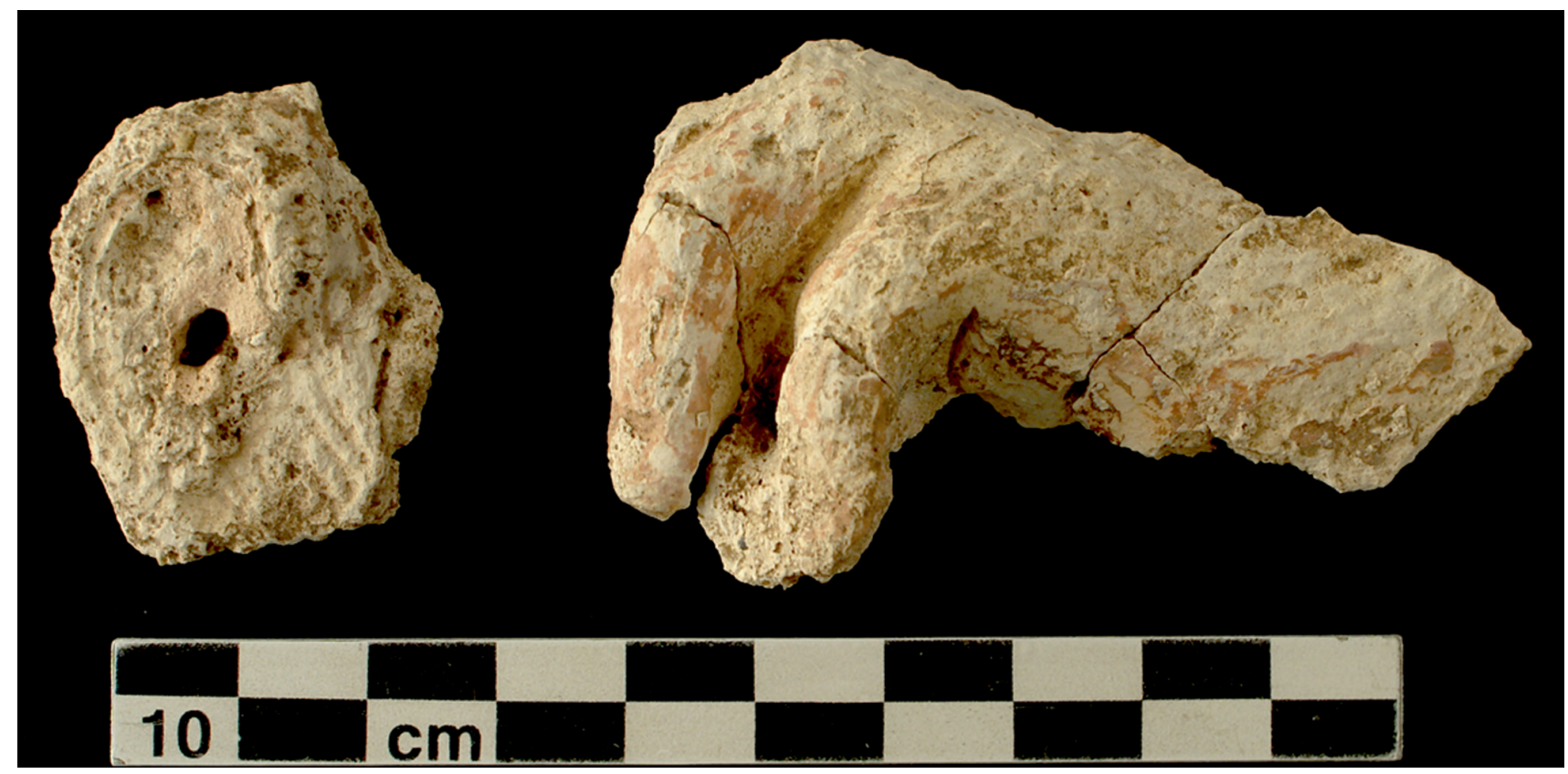

ム FIG. 8. Mané-Véchen, salle BF, oreille et main rehaussées de rose (cliché J. Boislève, CEPMR).

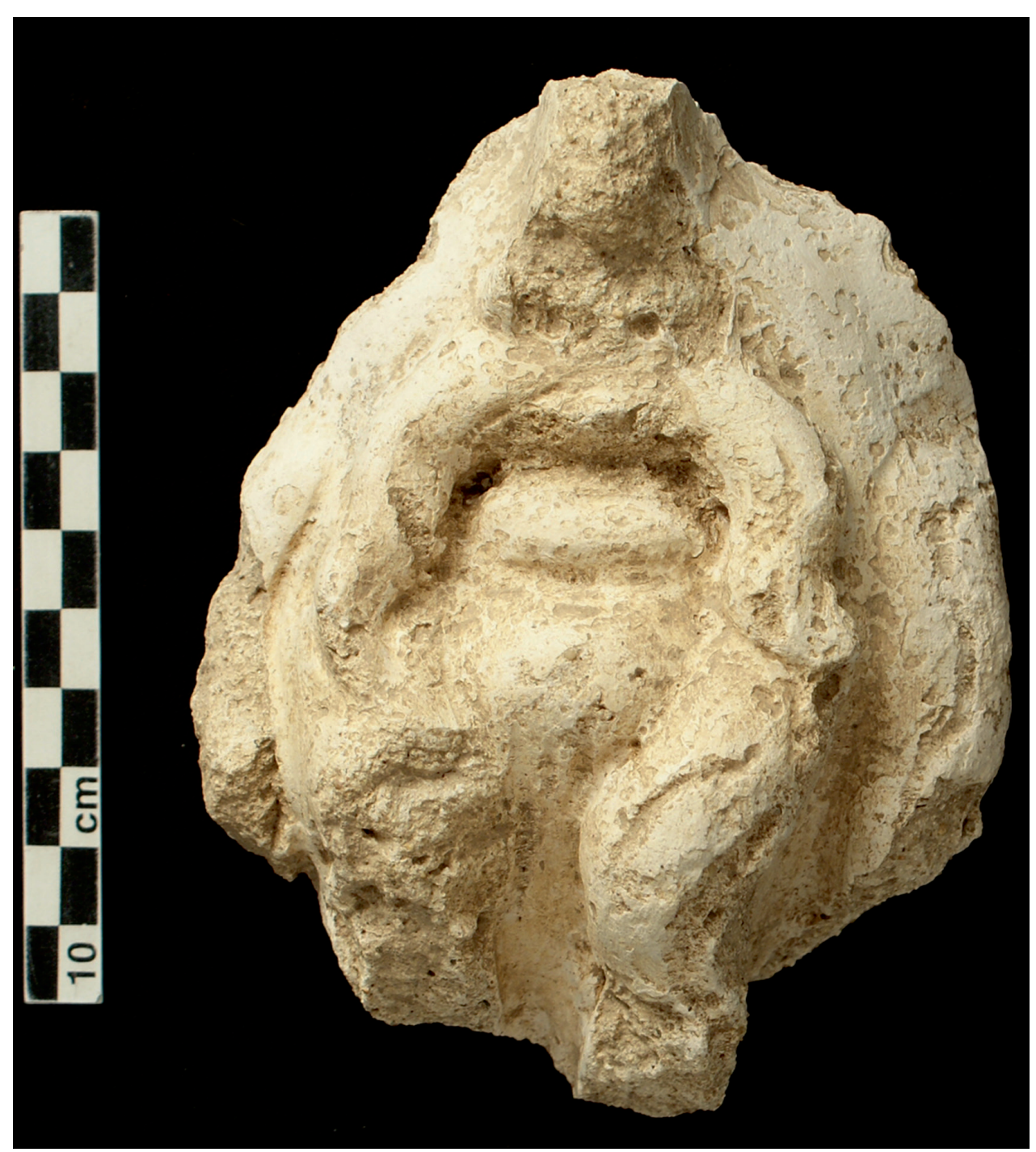

4 Fig. 9. Mané-Véchen, salle $\mathrm{BF}$, bas du visage d'un Silène (cliché J. Boislève, CEPMR). 


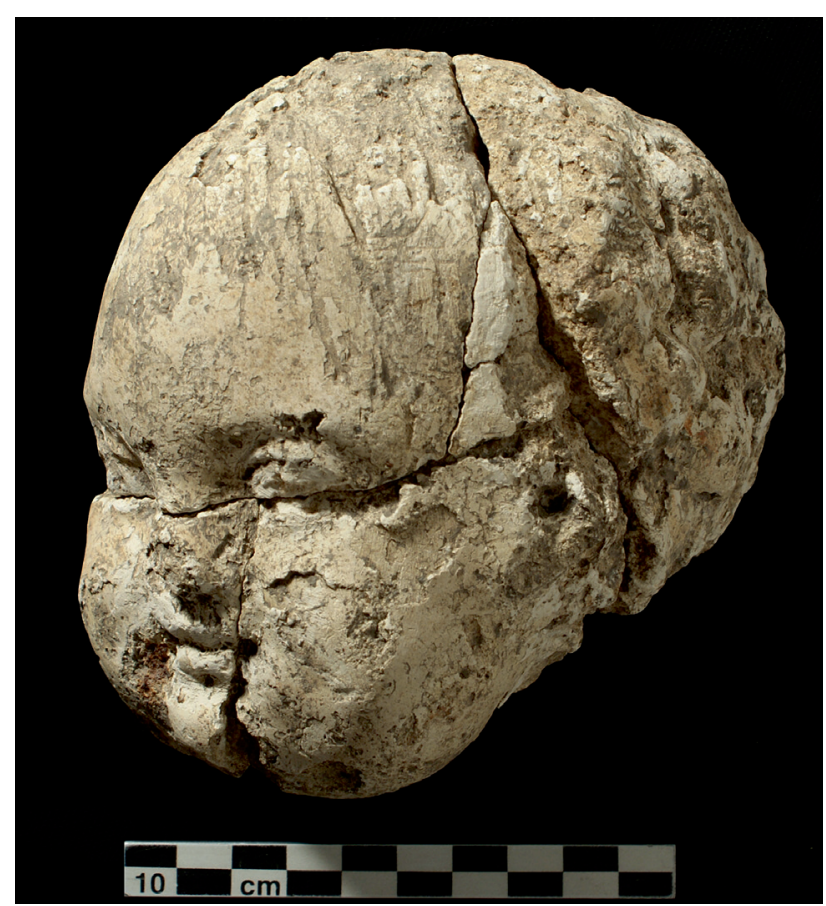

A FIg. 10. Mané-Véchen, salle BF, visage d'Eros (cliché J. Boislève, CEPMR).

d'un scutum, selon un rythme qui n'est pas certain. Dans les compartiments carrés le principe est le même mais la bande d'encadrement est en imitation de porphyre rouge et le motif en relief se détachant sur un carré de porphyre vert peut être soit un disque, soit un carré sur la pointe.

Le registre médian est plus simple, alternant des compartiments rectangulaires couchés à imitation de marbre vert foncé à gros nodules blancs, et des compartiments rectangulaires dressés et en relief, ornés d'une imitation de marbre de Chemtou (Tunisie). Enfin, sur le registre supérieur, le stuc disparaît totalement. Seules subsistent l'alternance de rectangles et de carrés et, dans une moindre mesure, les imitations de marbres. Elles se cantonnent toutefois à de petites surfaces, des plaques carrées intégrées à un méandre à svastikas noir sur fond blanc, et des bandes d'encadrement mouchetées de blanc sur un fond dégradé de gris à rouge imitant probablement la diorite noire. Un compartiment carré, orné d'un carré sur pointe, marque le centre de la paroi et interrompt la longue frise du méandre.

Dans l'exèdre, l'illusion marmoréenne est encore présente au niveau des parties inférieures du décor, mais le relief a lui totalement disparu, remplacé par des corniches fictives peintes qui assurent la continuité du décor avec les murs principaux de la pièce (fig. 21). L'espace est surtout dévolu à des représentations figurées dont une partie est connue. Ainsi, un grand buste de Vénus est peint sur la voûte en berceau incliné, éclairée par une large fenêtre percée dans le mur de fond d'exèdre. Se détachant sur un fond bleu, elle est figurée en majesté, portant une cou-

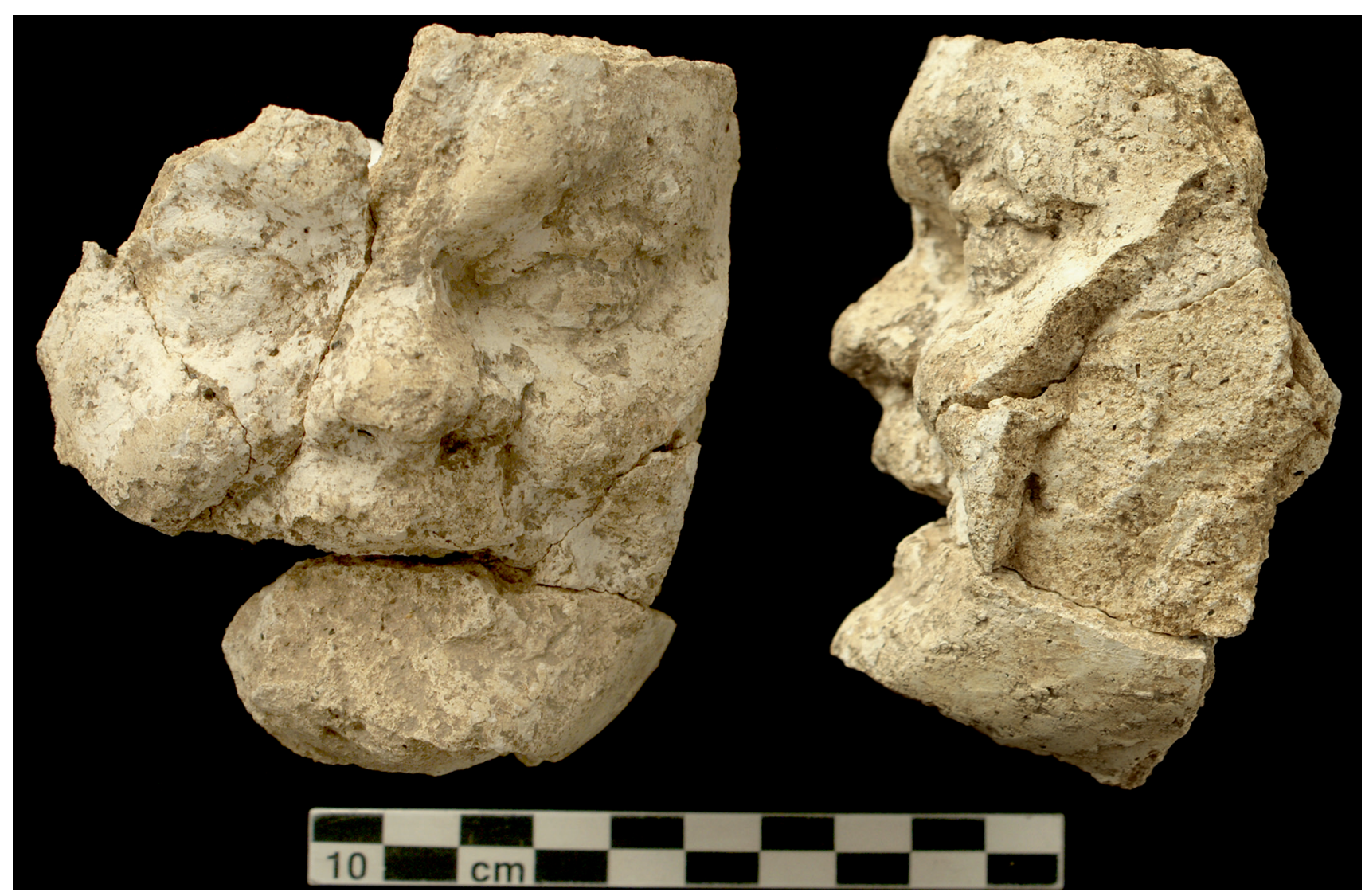

A FIG. 11. Mané-Véchen, salle BF, face et profil d'un visage de satyre (cliché J. Boislève, CEPMR). 


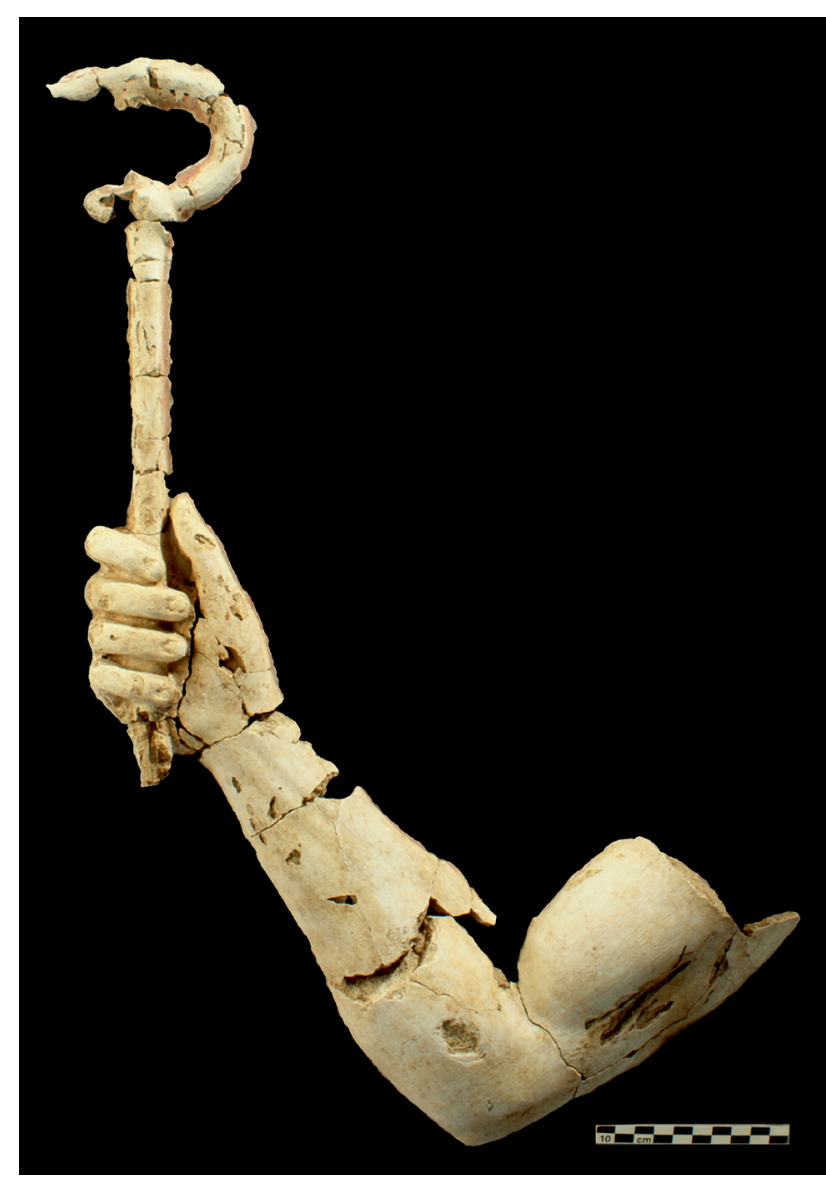

A Fig. 12. Mané-Véchen, salle BF, bras d'Hermès (cliché J. Boislève, CEPMR).

ronne, nimbée d'un disque bleu clair, vêtue d'un lourd manteau en dégradé de bleu à violet et d'une tunique blanche, arborant plusieurs rangs de colliers dont un de perles et d'émeraudes, et tenant un flabellum (fig. 22). Deux Amours flottants tiennent un drapé au-dessus de sa tête tandis que l'un apporte également un coffret à bijoux. Deux autres Amours se trouvent dans de petits compartiments en écoinçons de part et d'autre de la fenêtre (fig. 23). Sur les murs latéraux, quelques fragments indiquent d'autres représentations figurées dont un personnage aux cheveux blonds et bouclés et une fine corbeille remplie de fleurs roses.

Dans cette salle le décor est donc particulièrement soigné. L'architecture est mise en valeur par une ornementation qui différencie nettement l'exèdre et contribue justement à attirer l'attention sur cette partie. Les parois intégralement marmoréennes se veulent la parfaite illusion d'un placage de marbre. Les imitations sont fines et détaillées de sorte que chaque roche est fidèlement représentée et identifiable. Le stuc contribue à accentuer cet effet en donnant au mur les reliefs des véritables placages. L'ensemble constitue un luxueux écrin pour la divinité représentée dans l'exèdre.

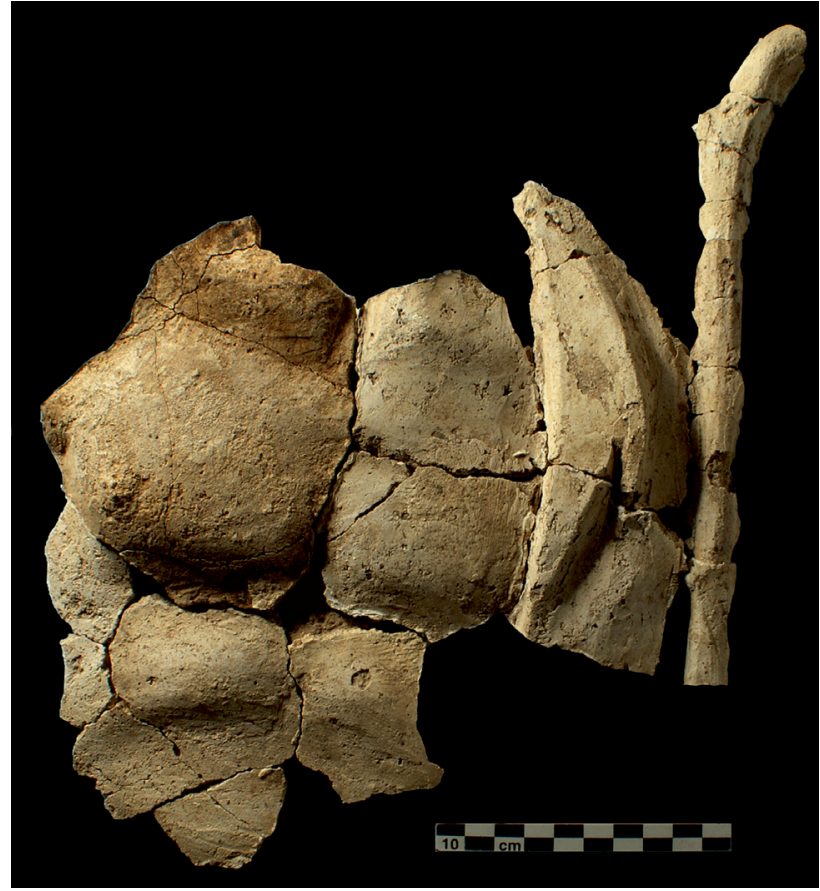

A Fig. 13. Mané-Véchen, salle BF, torse de faune (cliché J. Boislève, CEPMR).

\subsubsection{La salle $W$, quelques indices du décor}

Les quelques centimètres carrés de cette pièce qui n'ont pas été emportés par le front maritime ont permis de mettre au jour de maigres indices d'un décor associant également peinture à imitation de marbre et stucs. On trouve ainsi une certaine variété de moulures et corniches en stucs accompagnant des imitations de roches très proches de celles de la salle $A B$ ainsi que des pilastres fictifs peints. Parmi les stucs, on retiendra quelques formes géométriques en faible épaisseur qui s'apparentent aux motifs du premier registre supérieur du décor de la salle $A B$. II est dès lors probable que le même atelier a réalisé le décor de la salle $W$, dans un esprit sans doute assez similaire à celui de la pièce $A B$.

\subsection{Les décors de la maison au Grand Péristyle à Vieux}

Le site de Vieux se trouve dans le département du Calvados, situé à quelques kilomètres de Caen dans la plaine. L'antique ville d'Aregenua, capitale de la cité des Viducasses, prenait place sur les bords du petit vallon où coule la Guigne. Dans un îlot jouxtant immédiatement le forum, et en limite sud de la trame urbaine, une vaste domus, dite maison au Grand Péristyle, a été fouillée de 1988 à $1991^{10}$ (Vipard 1998 et 2002). Construite à la toute fin du II $\mathrm{s}$. ou au début du IIIe ap. J.-C., la demeure s'étend sur $1420 \mathrm{~m}^{2}$ et résulte du réaménagement d'une domus précédente, la

${ }^{10}$ La fouille a été menée par le Service Archéologie du Conseil général du Calvados sous la direction de P. Vipard. 


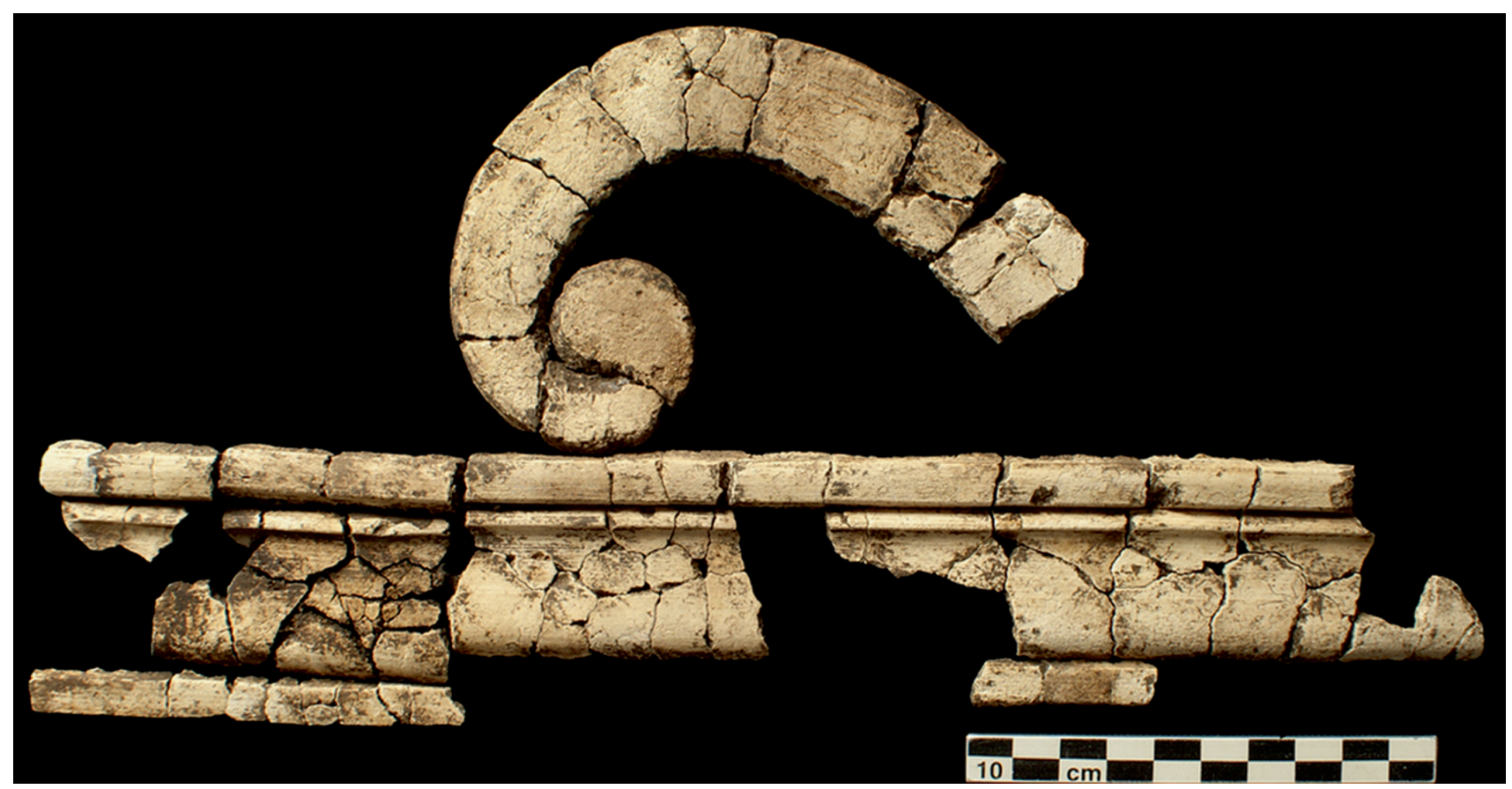

\ FIg. 14. Mané-Véchen, salle BF, élément de moulure et volute du plafond (cliché J. Boislève, CEPMR).

maison au Petit Péristyle, édifiée vers 170. Elle s'organise autour d'un grand péristyle à colonnes sculptées de thèmes bachiques qui encadrent un espace de jardin agrémenté d'un bassin central (fig. 24). L'ensemble des décors exhumés lors de la fouille a fait l'objet d'un réexamen récent apportant une nouvelle lecture de certains ensembles ${ }^{11}$.

\subsubsection{La place du stuc, répartition spatiale et fonctionnelle}

Le recours au relief au sein des décors de cette riche demeure est sans surprise assez large. Le stuc est présent dans de nombreuses pièces, mais se cantonne pour une part d'entre elles à des corniches, d'ailleurs plus ou moins élaborées, qui rythment les diverses zones de la paroi quand elles ne se limitent pas à la couronner. Nous retiendrons ici deux décors où le relief joue un rôle beaucoup plus conséquent (Boislève 2012). Le premier se trouve dans la plus vaste pièce de la domus (pièce III), une salle de $72 \mathrm{~m}^{2}$ située au cœur de l'aile occidentale. Considérée comme un salon de réception, cette pièce jouxte une seconde salle au décor riche avec mosaïque de sol et peintures murales présentant des tableaux mythologiques de très grande qualité (pièce II). Le second décor de stucs prend place dans une petite pièce chauffée par hypocauste à pilettes (pièce XV), sise à l'extrémité de l'aile orientale, dans l'angle du péristyle. De façon certes moins évidente qu'à Mané-Véchen, l'observation de la répartition spatiale et fonctionnelle de la place des décors de stucs dans le bâti révèle encore ici un statut important pour ce type de décor qui est donc réservé à une salle de confort chauffée par hypocauste et à une seconde salle de réception dont les dimensions en font une pièce d'importance.

\subsubsection{La pièce III, description du décor}

Le décor présente une zone inférieure particulièrement développée qui s'apparente à un imposant soubassement d'imitation de placage de marbre à motifs complexes, dont l'effet est renforcé par une utilisation pour le moins originale du relief (fig. 25). La base du mur est pourvue d'un quart-de-rond d'étanchéité en tuileau au-dessus duquel se développe une plinthe marron et noire de $20 \mathrm{~cm}$ de hauteur. Elle est couronnée par une double bande rouge bordeaux et rouge ocre. Au-dessus, la zone inférieure présente une organisation élaborée, du fait du recours aux jeux de relief. On observe une bande de $6 \mathrm{~cm}$ à veinures bleues sur fond blanc qui couvrent un bord chanfreiné au-delà duquel s'amorce, en retrait, le fond vert foncé des compartiments principaux. L'encadrement vertical des compartiments est assuré par des sortes de "piliers", inter-compartiments en relief (de 1,5 à $2 \mathrm{~cm}$ ), larges de $52 \mathrm{~cm}$ et pourvus, à $6,5 \mathrm{~cm}$ de chaque côté vertical, d'une baguette à profil arrondie et rehaussée de rouge (fig. 26). La bande en relief sur laquelle elle se dégage est peinte des mêmes veinures bleues que sur l'encadrement du côté inférieur des compartiments. Elle présente un même bord chanfreiné vers le panneau mais un bord droit vers l'intérieur de l'inter-compartiment qui est en

(11) Etude menée par J. Boislève, rapport d'étude inédit. Une première étude avait été menée partiellement en 1996 par B. Amadéi dans le cadre de son travail de mémoire de maîtrise. 


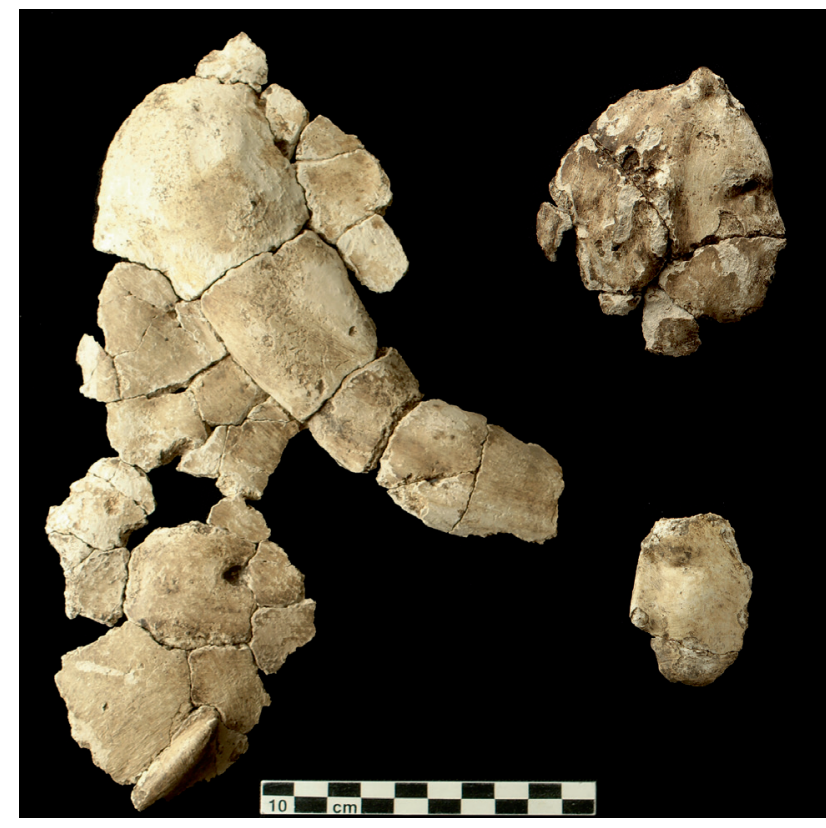

\ Fig. 15. Mané-Véchen, salle BF, éléments figurés du plafond, satyre en érection et visage féminin (cliché J. Boislève, CEPMR).

creux et ménage un fond à imitation de marbre vert foncé avec une découpe centrale à redans (deux décrochements rectangulaires ménagés en relief dans le bandeau d'encadrement). Au centre des compartiments, se dégageant sur un fond d'imitation de marbre vert, on identifie un motif de croix de scuta stuqué. Chaque scutum est dégagé par un bandeau de 5 à $6 \mathrm{~cm}$ de large, en relief de 1,3 à $2 \mathrm{~cm}$, qui dessine son contour. Les deux extrémités sont marquées d'un arc de cercle et le centre du scutum vertical, qui se trouve au premier plan dans la croix, est orné d'un ovale suggérant l'umbo, relié aux arcs de cercles par un rayon s'évasant vers le centre du bouclier (fig. 27). Les plaques conservées assurent une disposition d'au moins trois scuta, mais il n'est pas impossible d'envisager un motif à quatre boucliers. Les contours en relief sont également traités en imitation de marbre, soit une roche à gros nodules jaunes et petites veinures marron se détachant sur un fond rouge bordeaux (fig. 28), soit une variante similaire mais à nodules roses.

Le couvrement des compartiments est assuré par une bande en relief à imitation de marbres à veinures bleue avec quelques touches roses ou vert kaki. Elle est surmontée d'une corniche en stuc dont le profil se compose d'un listel, d'une doucine et d'un bandeau sommital. Cette dernière, continue sur la paroi, assurait le couronnement de la zone inférieure (fig. 29).

La zone médiane, uniquement peinte, retrouve une composition au schéma beaucoup plus classique pour la Gaule. De grands panneaux rouges à bandes d'encadrement multiples sont séparés par un inter-panneau assez large $(51 \mathrm{~cm})$, à fond noir et orné d'un candélabre végétalisant avec figure sommitale. II s'agit dans un cas d'un personnage féminin tenant des cymbales.

\subsubsection{La pièce $X V$, description du décor mural}

Cette petite pièce chauffée, dont la fonction n'est pas clairement établie, livre un décor étonnamment luxueux où le stuc trouve sa place aussi bien aux murs qu'au plafond.

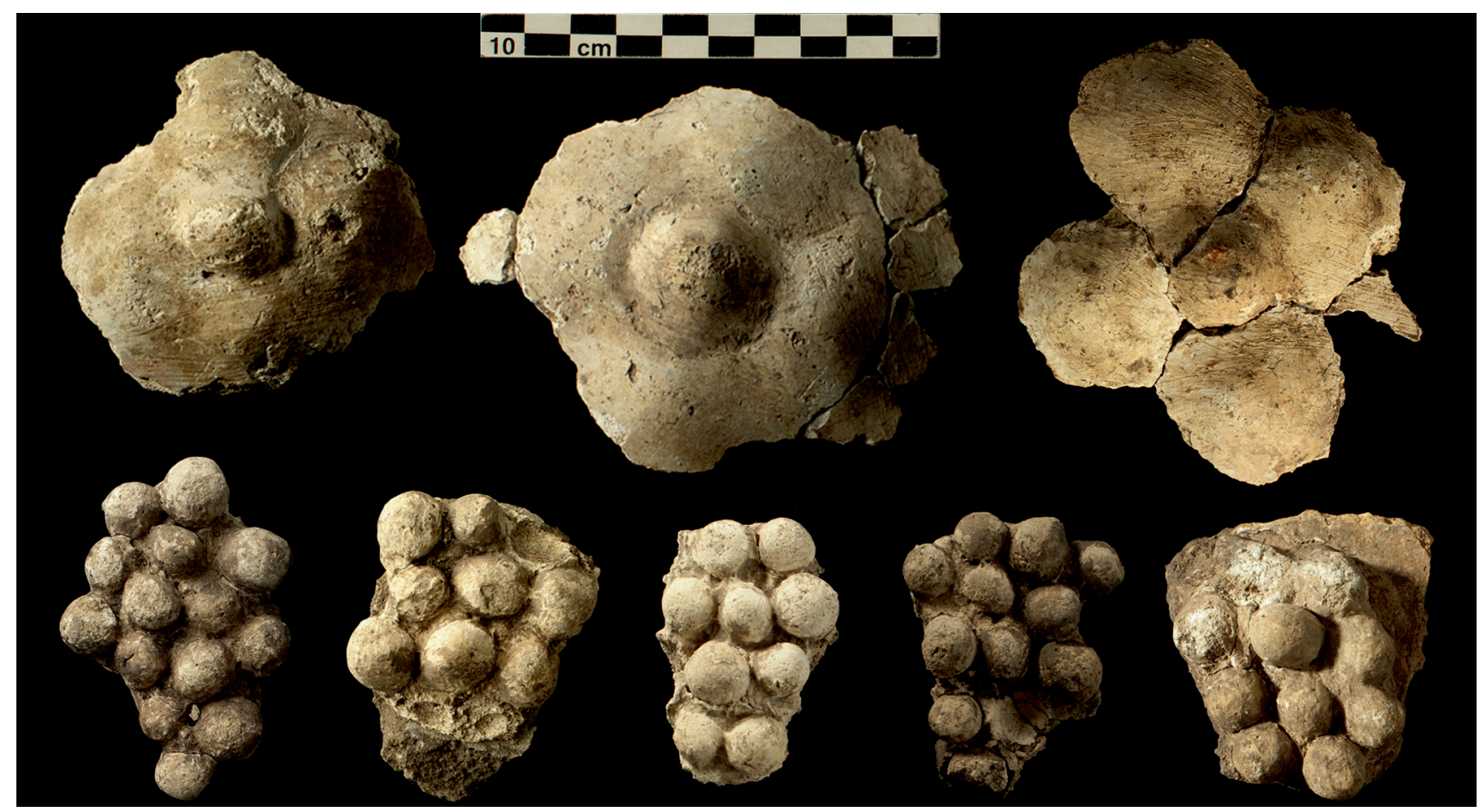

A FIg. 16. Mané-Véchen, salle BF, éléments de grappes de raisins et fleurons du plafond (cliché J. Boislève, CEPMR). 


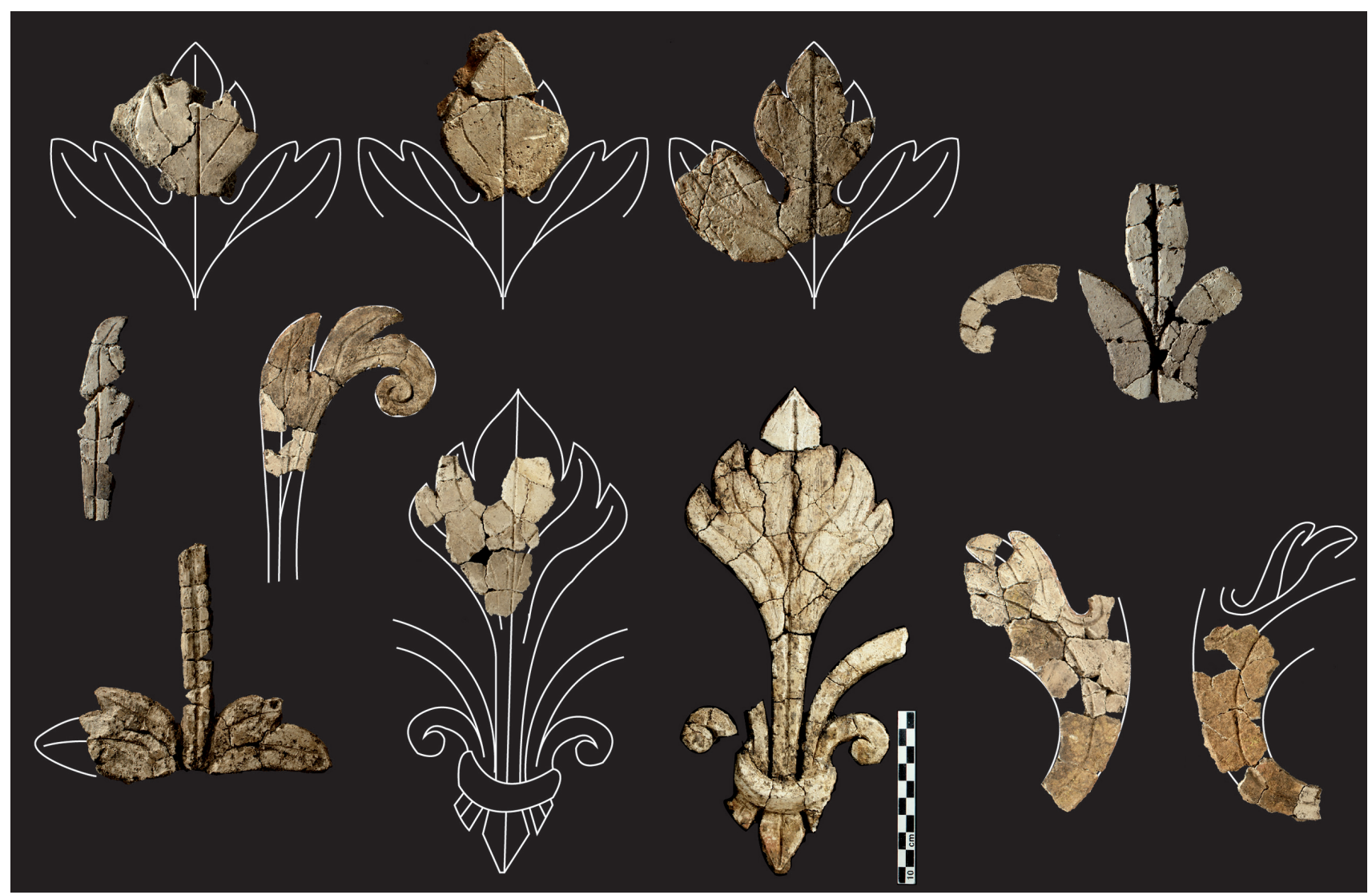

\ FIg. 17. Mané-Véchen, salle BF, divers feuillages appartenant au plafond (DAO et clichés J. Boislève, CEPMR).

En paroi, la peinture occupe l'essentiel de la composition mais le relief y tient une place non négligeable qui n'est malheureusement connue, la plupart du temps, que par la seule empreinte des arrachements des moulures et corniches (fig. 30). La zone inférieure, à imitation de marbres, est une succession de panneaux de marbre vert, limités par une bande blanche bordée de filets noirs et encadrés par une bande à imitation de marbre jaune. La transition avec la zone médiane est assurée par une corniche stuquée à profil lisse constituée d'un filet droit, d'un listel et d'une doucine droite (fig. 33g). Elle est surmontée d'une bande noire.

La zone médiane est divisée en panneaux rouge vermillon alternant avec des inter-panneaux rouge bordeaux dont ils sont séparés par des moulures de stuc. Les panneaux sont ornés d'un double encadrement intérieur constitué de deux filets jaunes agrémentés d'un gros point dans les angles. La bordure est la succession d'une bande bleu clair $(1 \mathrm{~cm})$, d'un filet blanc $(0,6 \mathrm{~cm})$ et d'une bande noir azuré $(3,5$ à $4 \mathrm{~cm})$. Des vignettes agrémentaient le centre des fonds vermillon, petites scènes figurées livrant plusieurs exemplaires d'Amours volant ou flottant dont l'un tient une étoffe verte. Le couronnement des panneaux n'est connu que par une plaque clé qui indique un traitement en fronton triangulaire bordé d'éléments stuqués dont il n'a pas été possible de comprendre la nature.
Les inter-panneaux, larges de 32 à $33 \mathrm{~cm}$, sont limités par une bande verte de 3,6 cm bordée d'un filet blanc. Ils sont pourvus d'un encadrement intérieur constitué d'un filet jaune. Au centre, un filet de même couleur marque la hampe d'un candélabre agrémenté de divers objets accrochés par un ruban dont on distingue les nœuds à coques et les pans qui retombent. Deux objets sont connus, l'un est une sorte d'oscillum ou de tympanon au cœur noir cerné de jaune. L'autre, plus énigmatique et incomplet, rappelle la forme d'une toupie noire dont la pointe est rehaussée de touches jaunes.

Sur l'un des panneaux, devait prendre place un important personnage en stuc figurant une divinité que le bonnet phrygien a identifié à un dieu oriental, peut être Attis (fig. 31). La figure devait être en pied, pour une hauteur estimée entre $1 \mathrm{~m}$ et $1,20 \mathrm{~m}$. Le relief assez important est assez grossièrement dégagé, les traits du visage laissant apparaître les coups vifs de la spatule ayant servi au modelage. Chevelure et bonnet phrygien sont rehaussés d'une couleur ocre jaune à rouge (fig. 32 ).

\subsubsection{La pièce $X V$, description du décor de plafond}

Parmi les nombreux éléments de décors retrouvés dans les niveaux de démolition de cette pièce figuraient une grande quantité de fragments de stucs variés qui ne correspondent pas aux arrachements perçus sur le décor mural 


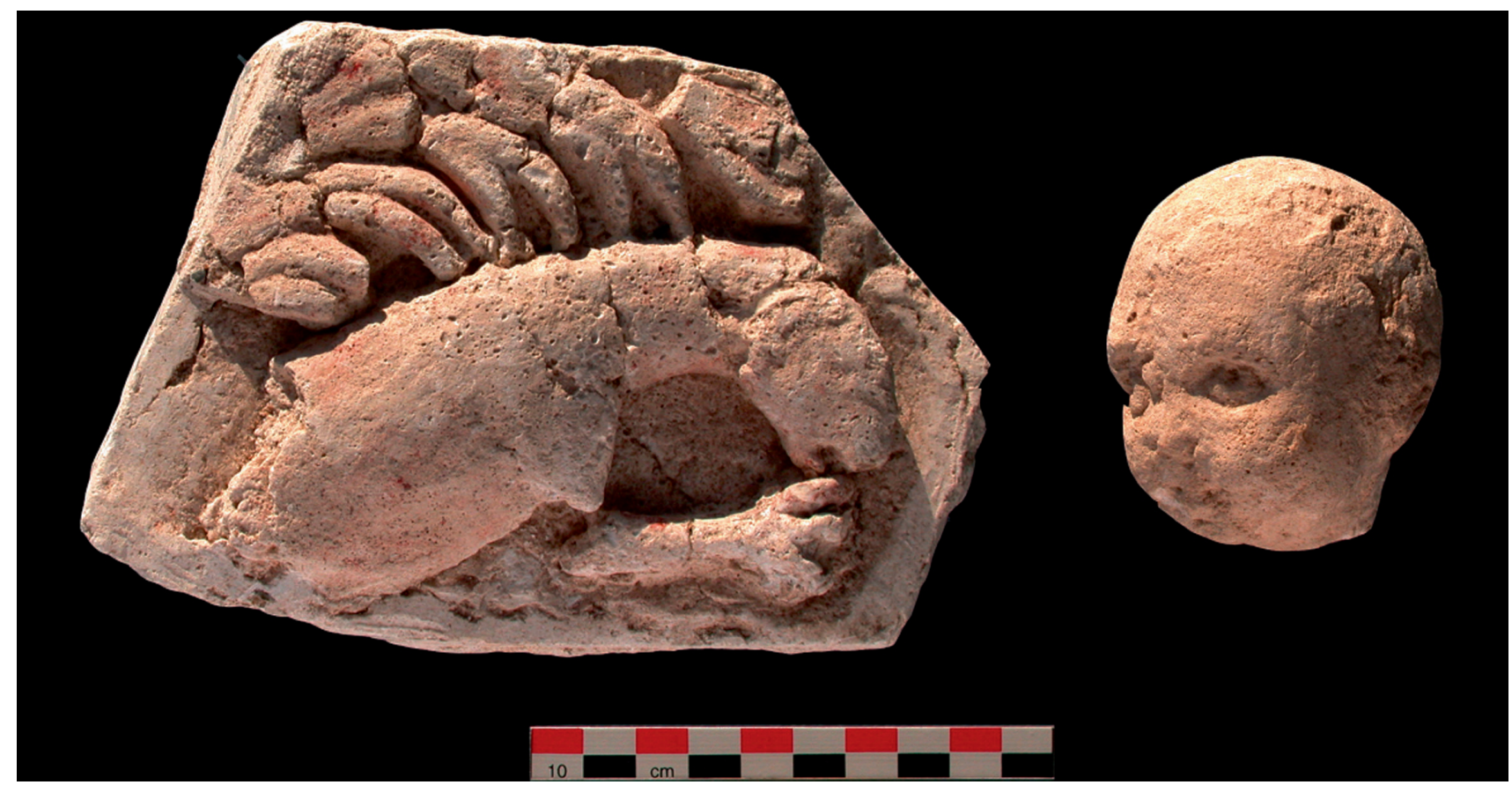

\ FIg. 18. Mané-Véchen, salle BD, moulage des éléments stuqués disparus (cliché J. Boislève).

et doivent donc appartenir au plafond même si aucun élément de support n'a été retrouvé (fig. 33). Peut-être faut-il envisager une application sur enduit de terre ayant dès lors totalement disparu ? On note tout d'abord une multitude de moulures à profil lisse (listel, filet, doucine et baguette arrondie) et tirées en arc de cercles (fig. 33a). Elles définissent des cercles de $47 \mathrm{~cm}$ de diamètres dont la fréquence suggère une composition à réseau. Des traces de peinture rouge, à la base de chaque moulure, témoignent de la couleur du fond sur lequel se détachait la blancheur du stuc. Des moulures droites (fig. 33i) (côte angulaire centrale bordée de baguettes arrondies au relief moins prononcé) ainsi que des fleurons modelés (fig. 33e et f) dont plusieurs indices témoignent qu'ils se plaçaient à l'intersection de deux moulures droites selon un angle qui interdit la restitution d'une trame orthonormée (fig. 34). Les médaillons circulaires pouvaient donc constituer le remplissage de losanges définis par les moulures droites. Mais, dans ce système, d'autres éléments stuqués ne trouvent pas leur place. On retiendra notamment de nombreux fragments de colonnettes de feuilles (fig. 33b), moulure à profil semi-circulaire dont la surface est modelée et incisée pour créer un rythme de feuilles disposées en quinconce. La largeur de ces colonnettes $(8 \mathrm{~cm})$ correspond bien à l'arrachement observé sur le décor mural, mais la présence de clous de fixation, de stries au revers ainsi que le contour irrégulier du relief interdit cette hypothèse et renvoit donc aussi cet élément en décor de plafond. Quelques autres fragments de stucs modelés correspondent à de gros fleurons à quatre pétales nervurés et découpés ainsi que divers types de feuilles plus ou moins bombées (fig. 33c et d).

Dans cette pièce, le relief participe donc d'un décor luxueux comme en témoigne l'emploi du cinabre en grands à-plats pour le fond des panneaux. La facture des moulures et feuillages modelés est assez variée et soignée, ce qui tranche avec les traits vigoureux et peu naturalistes du personnage, laissant supposer un artisan mal à l'aise avec la représentation humaine.

\subsection{Le décor monumental du "palais" d'Autun}

La fouille préventive menée à l'emplacement du nouvel hôpital d'Autun ${ }^{12}$ (Bet 2006) a permis aux archéologues de suivre l'évolution d'un îlot inséré dans la trame viaire de I'antique Augustodunum, de sa fondation jusqu'à son déclin. L'ensemble se situe dans le quart nord-ouest de la ville, à proximité immédiate de l'enceinte, non loin de la porte Saint-Andoche. À l'implantation d'un premier habitat de bois et de torchis, vers la fin du règne d'Auguste, succèdent de nombreux réaménagement qui révèlent au fil des siècles, une installation artisanale, un quartier d'habitat érigé en pierre et diverses évolutions jusqu'à la construction, vers la fin du III s. ap. J.-C., d'un vaste édifice qui restructure tout l'espace et rassemble en une seule propriété des parcelles jusqu'alors séparées (fig. 35). Le bâtiment s'organise autour de deux longs couloirs axiaux qui s'étendent sur au moins

(12) Fouille menée par I'Inrap en 2001, sous la responsabilité d'opération de Ph. Bet. 


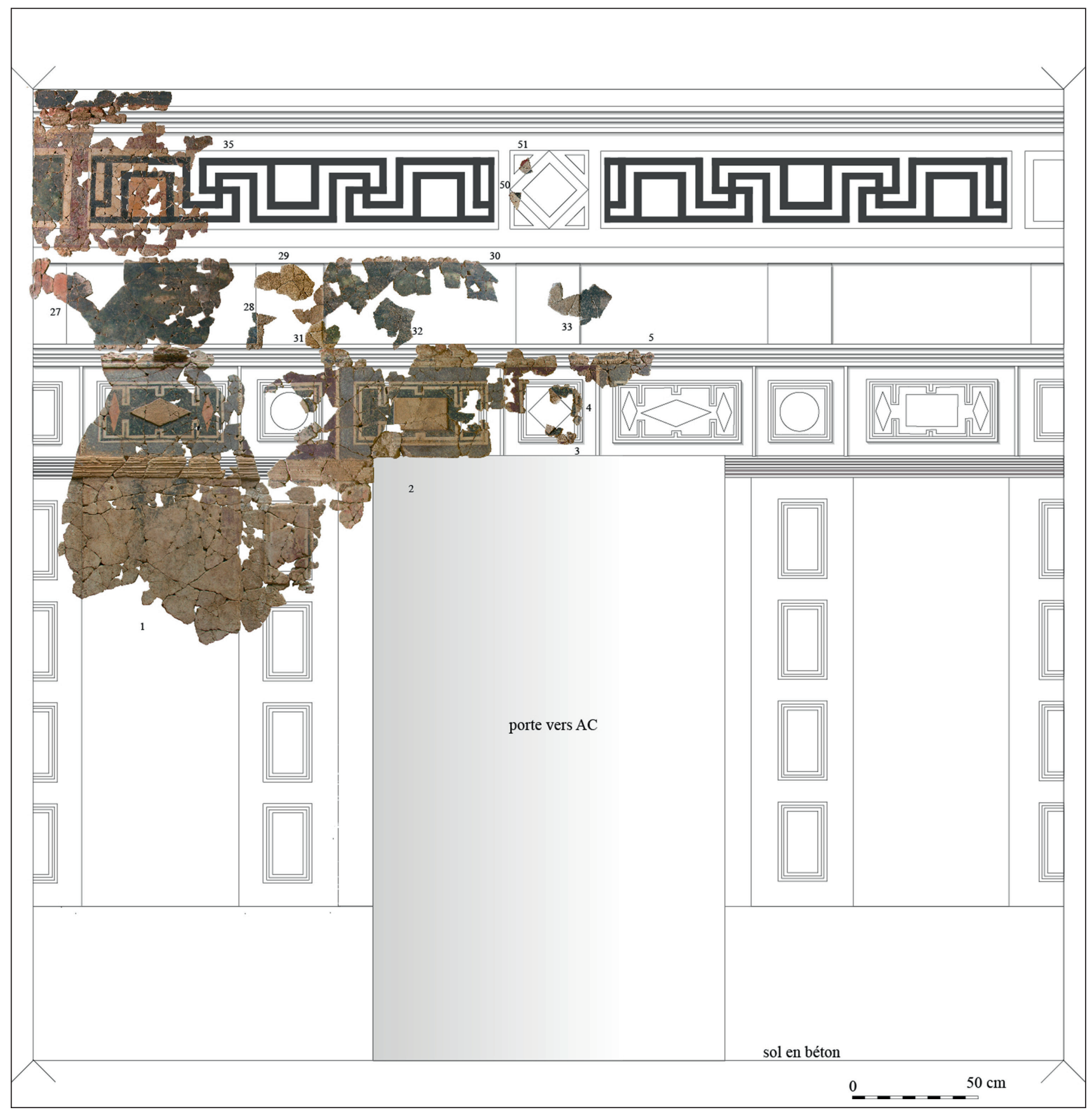

\ FIG. 19. Mané-Véchen, salle AB, restitution du décor de la paroi nord (DAO J.-F. Lefèvre, restitution et clichés J. Boislève, CEPMR).

$40 \mathrm{~m}$ de long. Ils desservent des pièces centrales en enfilade et débouchent sur une vaste abside qui termine le bâtiment à une extrémité. On estime la superficie totale du bâti à au moins $5000 \mathrm{~m}^{2}$ ce qui, avec les nombreuses pièces chauffées et la capacité du commanditaire d'empiéter en partie sur l'espace public dévolu au rempart, en fait un véritable palais dont il demeure impossible de dire s'il est à vocation publique ou privée. C'est dans le comblement de l'infrastruc- ture d'une des pièces à hypocauste qu'ont été trouvés les stucs (espace 13). Ils ont été placés au rebut dans cet espace lors de la phase de récupération des matériaux de construction. Si leur emplacement d'origine est incertain, il semble acquis qu'ils proviennent bien de ce grand édifice. La quantité importante de fragments et leur bon état de conservation ont permis des remontages conséquents qui autorisent une restitution complète du décor ${ }^{13}$ (Boislève 2007).

(13) Etude menée au CEPMR de Soissons sous la direction de J. Boislève et avec la participation de C. Allonsius, C. Allag, F. Monier, L. Déodat. Dessins au point et infographies de J.-F. Lefèvre, photographies de Ph. Delangle (CNRS-ENS/UMR 8546) et restitution 3D de L. Espinasse (Archéotransfert/Ausonius). 


\subsubsection{Le décor des parois, description}

La recomposition révèle le décor de deux murs à angle droit (fig. 36). Si la zone inférieure est similaire sur les deux parois, l'organisation de la composition diffère pour les zones médianes et supérieures. La plus grande paroi (dite paroi A) développe une série d'arcades tandis que la seconde (paroi B) est percée de trois fenêtre hautes (Boislève y Allag 2011).

La zone inférieure, stuquée, est la partie la plus mal connue du décor. Elle est uniformément blanche et le motif n'est dégagé que par des moulures. Ces dernières définissent des compartiments encadrés d'un bandeau plat $(7,5 \mathrm{~cm}$ de large pour $0,4 \mathrm{~cm}$ de relief) bordé de part et d'autre d'une doucine et d'un ressaut $(2,8 \mathrm{~cm}$ de large). Un décrochement carré, vers l'intérieur du compartiment, ornait le centre des côtés verticaux. Le système était peut-être répété sur les côtés horizontaux. Ornant les compartiments, deux motifs géométriques sont connus, qui se répartissaient peutêtre en alternance d'un compartiment à l'autre (Boislève 2011 : 526). Le premier est un fleuron basé sur un disque de $17 \mathrm{~cm}$ de diamètre et pourvu de pétales oblongs et de sépales

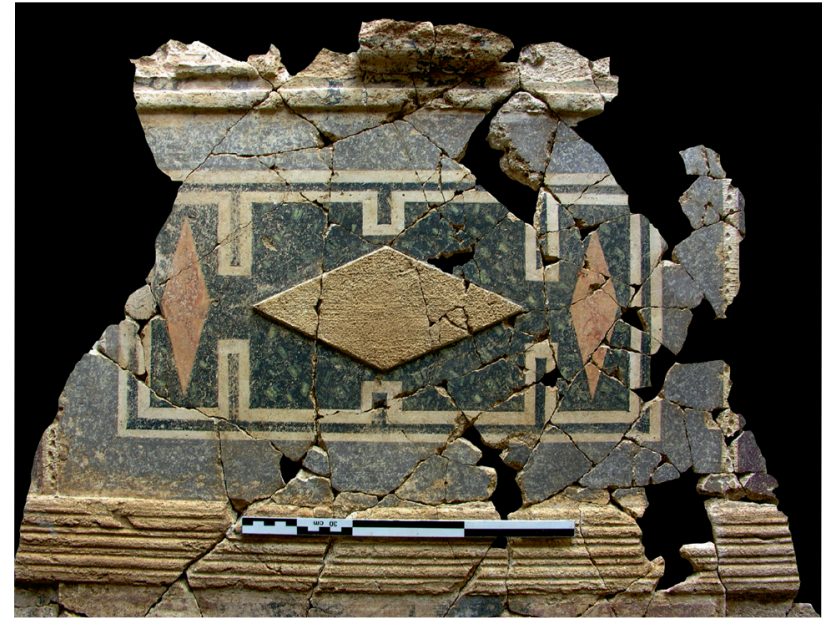

$\Delta$ Fig. 20. Mané-Véchen, salle AB, détail du registre inférieur (cliché J. Boislève, CEPMR).

en forme de dard. Le second est une croix de deux scuta disposés autour d'un disque central de $21 \mathrm{~cm}$ de diamètre. Ces deux motifs sont dessinés par des moulures simples. La zone inférieure est couronnée par une large corniche $(27 \mathrm{~cm})$ qui

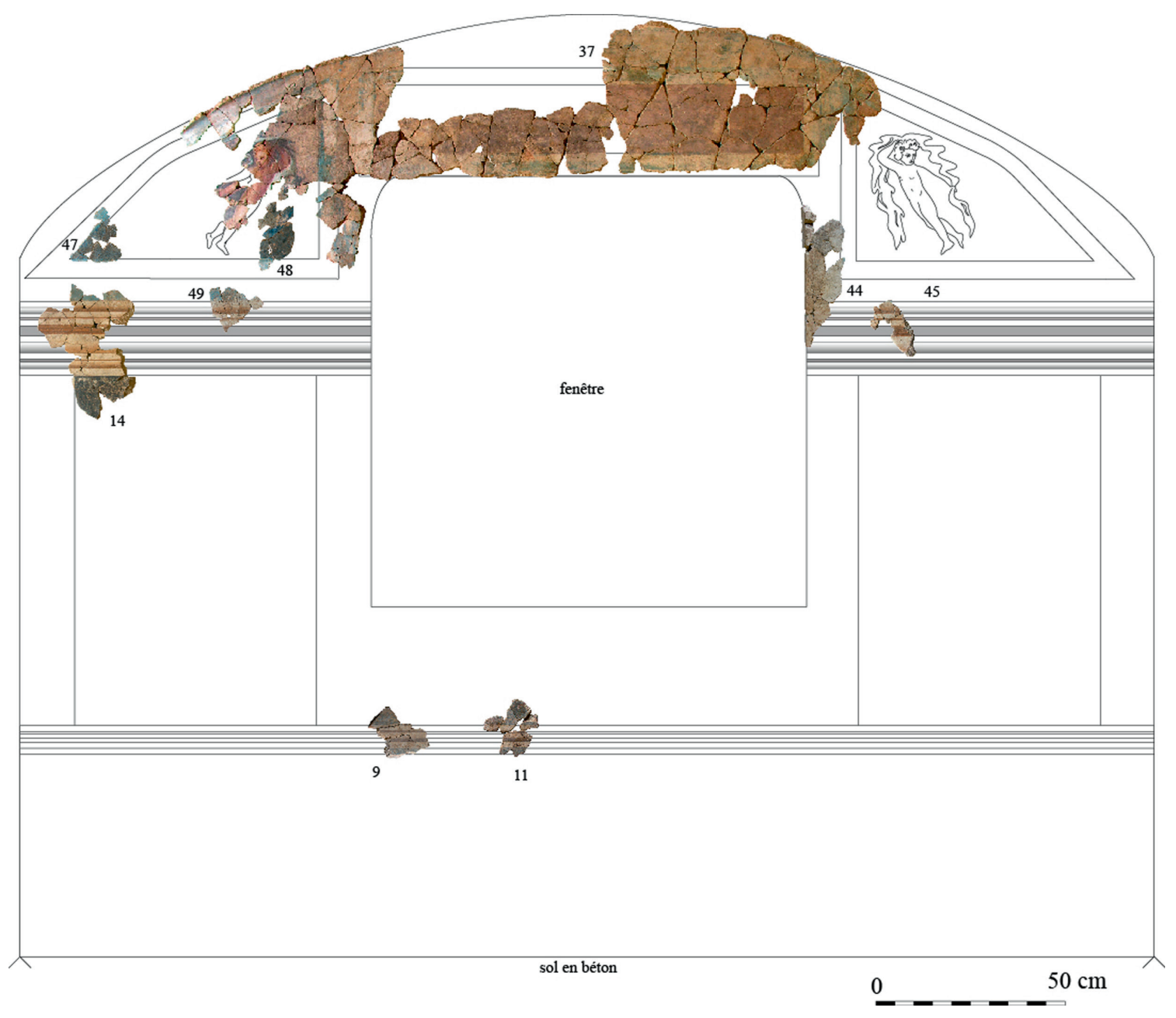

A Fig. 21. Mané-Véchen, salle AB, restitution du décor du mur de fond d'exèdre (DAO J.-F. Lefèvre, restitution et clichés J. Boislève, CEPMR). 


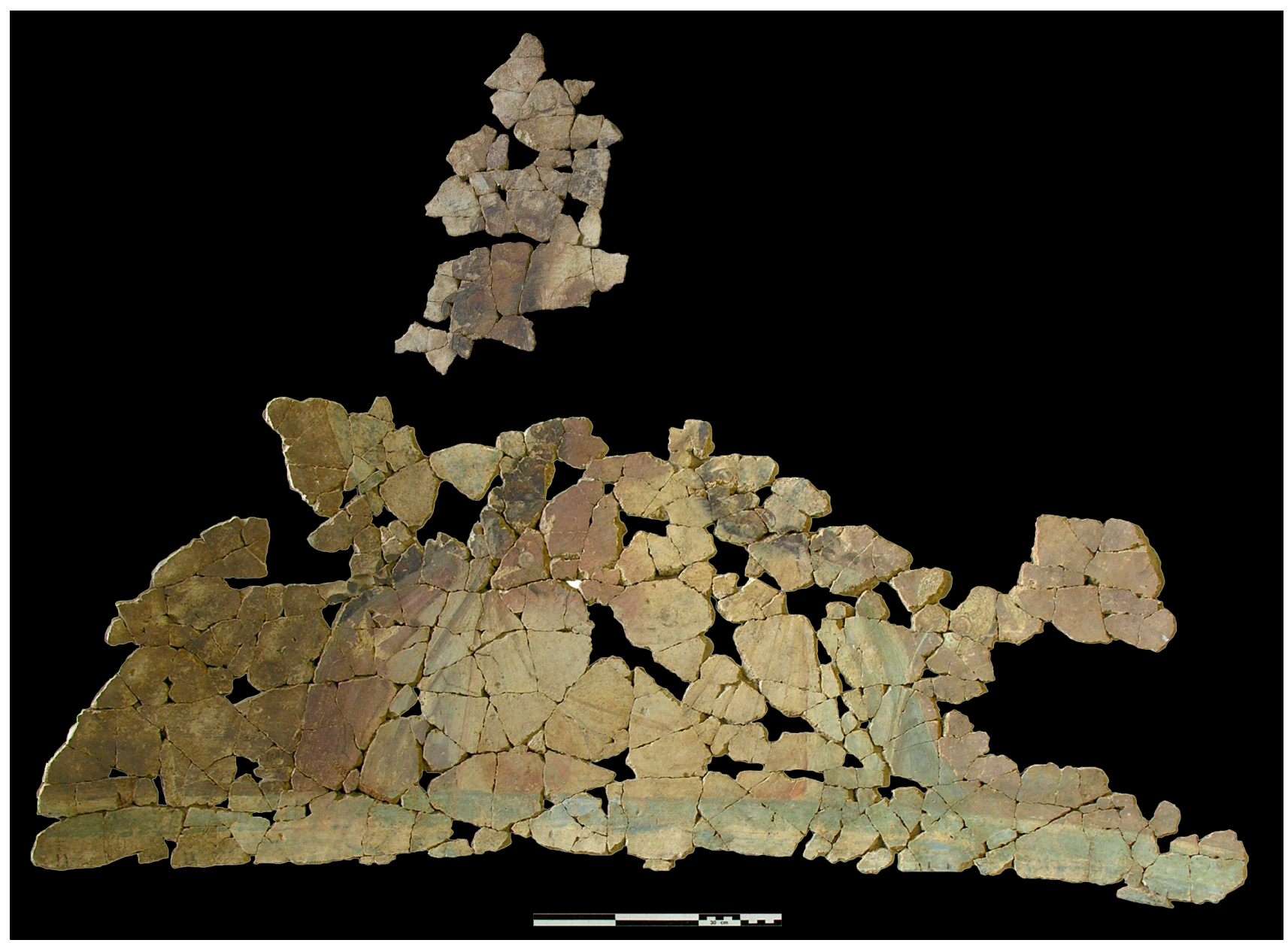

\ FIg. 22. Mané-Véchen, salle AB, Vénus en majesté sur la voûte de l'exèdre (cliché J. Boislève, CEPMR).

court en continu d'un mur à l'autre (fig. 37). Elle est constituée de trois frises superposées à motifs estampés : un rang d'oves, une frise de bucranes et protomés séparés par une guirlande pendante et une frise de coquilles encadrées de dauphins dressés et opposés.

Au-dessus de cette corniche intermédiaire, le mur A présente de hautes arcatures aveugles qui jouent toutefois sur un véritable relief (fig. 38). Des pilastres larges de $52,5 \mathrm{~cm}$, construits sur une structure de tubuli portent des arcs en plein cintre d'un diamètre interne compris entre 128,5 et $135,5 \mathrm{~cm}$. Ils ménagent ainsi des niches en retrait de quelques $15 \mathrm{~cm}$. La face des pilastres est ornée de cadres moulurés soulignés intérieurement d'une double bande alternativement rouge et rose ou bleu foncé et bleu clair. La moulure est simple, composée d'un bandeau, d'un rang de grands oves avec coquille et fer de lance, d'une baguette arrondie, d'une bande renflée rehaussée de points roses et terminée par un ressaut angulaire découpé de triangles. Les pilastres sont couronnés par une corniche à profil lisse qui joue le rôle d'imposte et suit le profil de la paroi pour régner en continu sur toute sa longueur. Elle se retrouve donc également dans les niches qui accueillent un cadre constitué de la même moulure que sur les pilastres et bordé de part et d'autre de bandes bleues ou rouges en alternance. De chaque côté du cadre, on note également une colonnette stuquée, à base lisse, fût cannelé et chapiteau modelé. La corniche d'imposte marque également la transition entre la zone médiane et la zone supérieure qui accueille les arcades ; ces dernières sont bordées d'une moulure assez similaire aux précédentes mais pourvues de deux rangs d'oves (fig. 39). Comme ailleurs sur la paroi, elles sont soulignées des couleurs en opposition, rouge d'un côté et bleu de l'autre. Entre deux arcs, l'écoinçon est occupé par un rinceau modelé à volutes alternées qui naît d'un culot d'acanthe posé sur l'imposte et se développe en deux tiges longeant le bord de chaque arc. Au sommet de la paroi, une corniche à deux registres couronne le mur. Elle présente des motifs de feuillages stylisés qui sont incisés au couteau et laissent apparaître la couleur rose d'un mortier de tuileau sous-jacent. Dans les niches, le dispositif est assez similaire puisque la même moulure à deux rangs d'oves y est répétée. Le tympan ainsi formé est en revanche occupé par des pans de rubans en festons et tombant droit qui naissent d'un nœud à coques accroché au centre de la moulure.

Sur la paroi $B$, le vocabulaire décoratif est identique mais développé au sein d'une organisation toute autre du décor (fig. 40). Zones médiane et supérieure sont cette fois nette- 


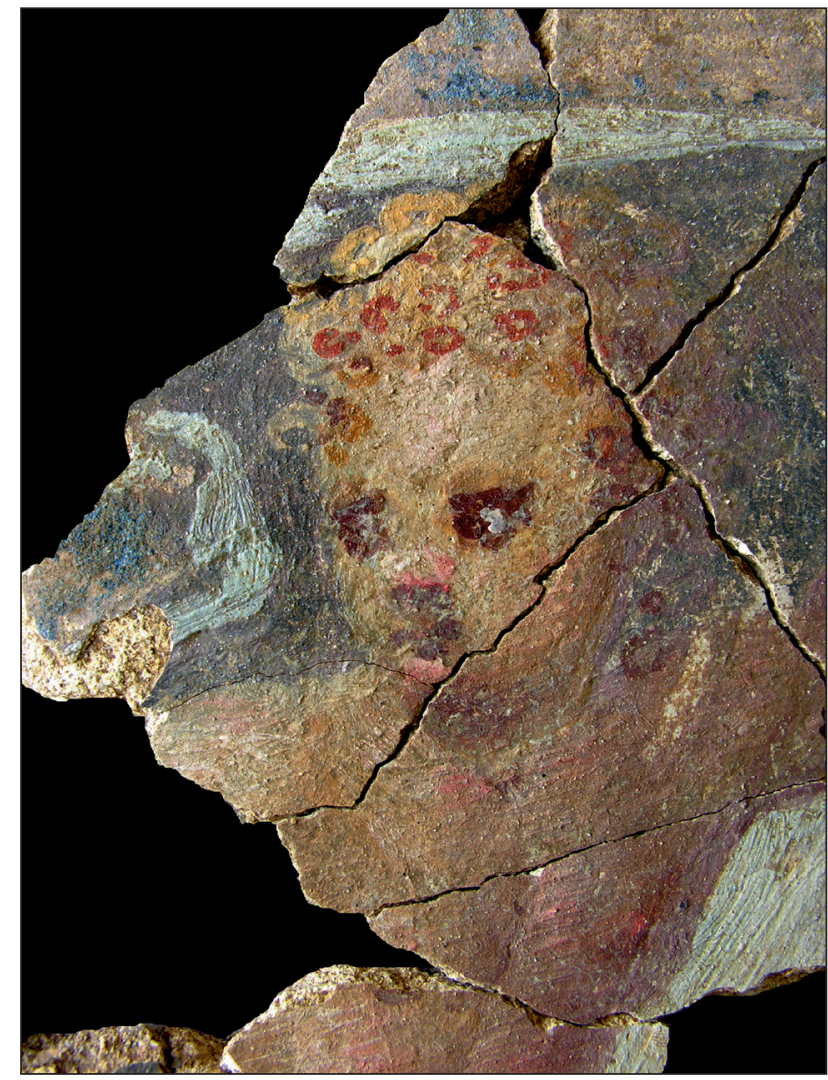

A FIg. 23. Mané-Véchen, salle AB, détail de l'Amour sur le mur de fond d'exèdre (cliché J. Boislève, CEPMR). ment différenciées. La première est marquée de deux grands caissons profonds de $15 \mathrm{~cm}$, ménageant un pilier central de $52 \mathrm{~cm}$ et dont le fond est travaillé comme des panneaux encadrés d'une moulure de stuc sur trois côtés. On retrouve ici la moulure à rang d'oves unique, bande renflée pointée et découpée de triangles. Elle est soulignée d'une bande simple, rouge ou bleue, à l'extérieur et d'une double bande, rouge et rose ou bleu foncé et bleu clair, en opposition, à l'intérieur. Une bordure ajourée à motif bleu clair alternant avec un motif violet sur filet de même couleur complète cet encadrement.

La bordure des caissons présente la même moulure d'encadrement soulignée de couleur seulement sur son côté externe. La zone supérieure est occupée par une succession de trois fenêtres hautes à ébrasures. Tableaux latéraux et appuis sont ornés d'un cadre stuqué, toujours constitué avec le même profil de moulure et souligné des mêmes couleurs en opposition.

\subsubsection{Les indices d'un plafond stuqué}

Un autre groupe, mêlé au même remplissage de I'hypocauste et appartenant selon toute vraisemblance au décor de la même pièce n'a pu permettre des remontages suffisamment conséquent pour discerner la trame du décor. II s'agit d'un enduit fixé sur briques plates et striées de $3,5 \mathrm{~cm}$ d'épaisseur ce qui semble caractériser un plafond avec système d'armature suspendue, ce que confirmeraient les nombreuses fiches métalliques en T associées à cette US.

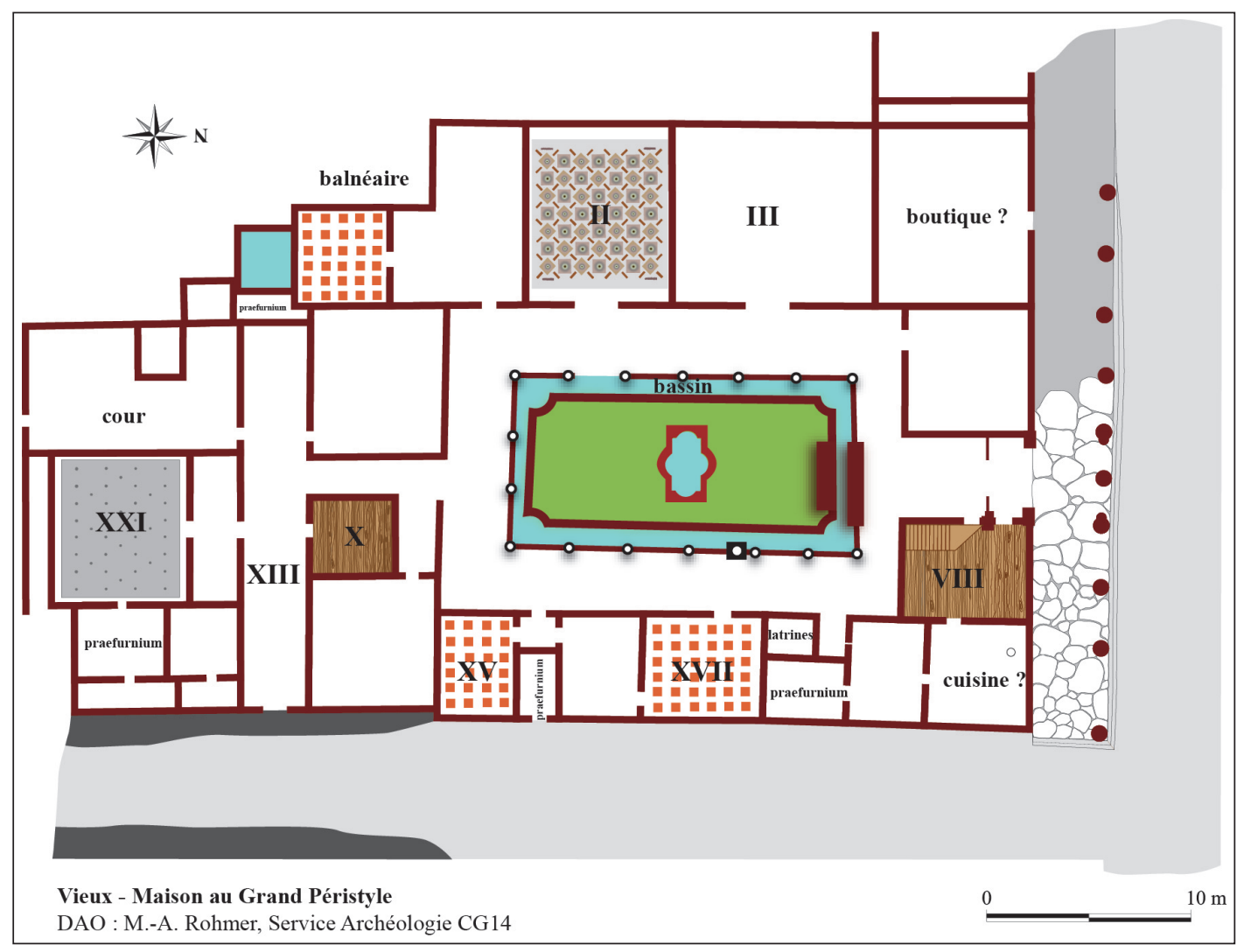

ム Fig. 24. Vieux, Maison au grand Péristyle, plan de la domus (DA0 M.-A. Rohmer, CG14). 
Le décor est marqué par des moulures en stuc soulignées de la même alternance de bleu et de rouge que sur les parois (fig. 41), si ce n'est que le rouge employé ici est toujours un vermillon. On note une moulure droite à profil lisse et un motif de deux demi-cercles inscrits et tangents définis par une moulure à rang d'oves de profil différent de ceux des moulures de paroi. II faut ajouter au décor de ce plafond des cabochons en forme de pétales trilobés qui prenaient place sur les moulures estampées comme en témoignent les empreintes au revers.

\section{LE STUC EN GAULE : ÉTAT DES CONNAISSANCES}

Ces ensembles de stucs, parmi les plus complets connus à ce jour en France, éclairent notre connaissance de ce type de décor, notamment en précisant des compositions qui ne pouvaient jusqu'alors être comprises. Ainsi, on retiendra que les décors où le stuc est un élément déterminant de la composition, sinon un élément dominant, voire le seul objet du décor, tout au moins sur une zone, comme sur un décor inédit de Marquion ${ }^{14}$ (Pas-de-Calais), sur celui de la villa de La Pierre à Maladières (Jura) (collectif 1991 : 17-23) et sur une voûte d'Autun ${ }^{15}$ (Allag et al. 2011 : 516), sont particulièrement rares. Nous en dénombrons sur moins d'une vingtaine de sites en France. Au sein de ces décors l'usage du stuc peut se répartir en quelques groupes principaux avec toutefois une finalité commune, celle de faire illusion, d'imiter les plus nobles matériaux. Le stuc permet ainsi de créer un placage de marbre des plus réalistes, de donner l'apparence d'une noble architecture d'arcatures à une pièce haute, ou encore d'exposer une galerie de sculptures dont la finesse



\ FIg. 25. Vieux, Maison au grand Péristyle, salle III, restitution hypothétique du décor (DA0, cliché et restitution J. Boislève, CG14).

(14) Cet ensemble issu d'une fouille menée par l'Inrap est en cours d'étude au CEPMR sous la direction de C. Allonsius. II présente, tout au moins pour une zone, sinon pour toute la surface ornée, un décor monochrome blanc dont le motif n'est dégagé que par le seul recours au relief.

(15) Site de la Clinique du Parc, rapport inédit de S. Groetembril, CEPMR, 1993. 


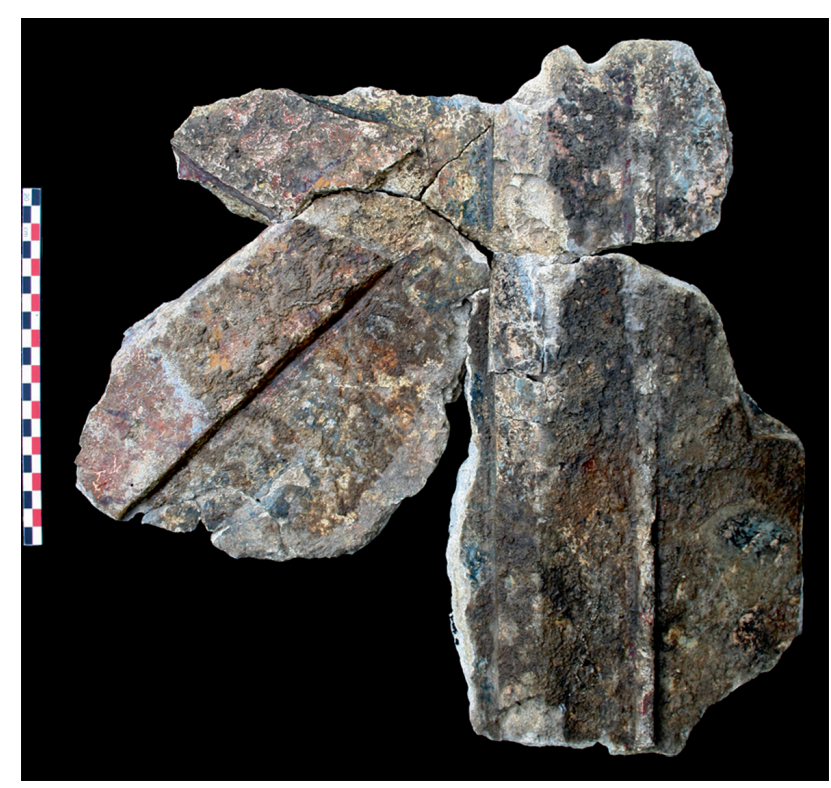

A FIg. 26. Vieux, Maison au grand Péristyle, salle III, élément de bord du compartiment avec amorce d'un scutum oblique (cliché J. Boislève, CG14).

du modelé et la blancheur rappellent les plus belles statues de marbre même si le matériaux limite l'exercice d'imitation au seul haut-relief, bien que cherchant au maximum à augmenter la saillie de la figure sur la paroi. Tant par les matériaux imités que par la nature des décors, le stuc vise donc à imiter les plus riches modes décoratifs (placages, sculptures, grand appareil) et à donner justement l'illusion de cette richesse. II semble toutefois judicieux de distinguer quatre natures différentes de décors ${ }^{16}$ : ceux d'inspiration architecturale, ceux où le stuc participe à l'illusion de placages de marbres, ceux ayant recours à la figuration se rapprochant de la sculpture et enfin, un peu à part, les décors destinés aux couvrements des pièces. Certains ensembles, comme nous l'avons vu à Mané-Véchen peuvent rassembler plusieurs de ces composantes principales.

\subsection{Le stuc au sein des imitations de placages de marbres}

L'usage du stuc au sein de décors à imitations de marbre est une véritable nouveauté mise en lumière par la restitution du décor de la salle $A B$ de Mané-Véchen et par le réexamen du décor de la pièce III de Vieux où la restitution initiale en plafond avait considérablement induit les chercheurs en erreur. Depuis, d'autres ensembles inédits ou beaucoup plus fragmentaires, et jusqu'alors incompris, se rattachent à ce

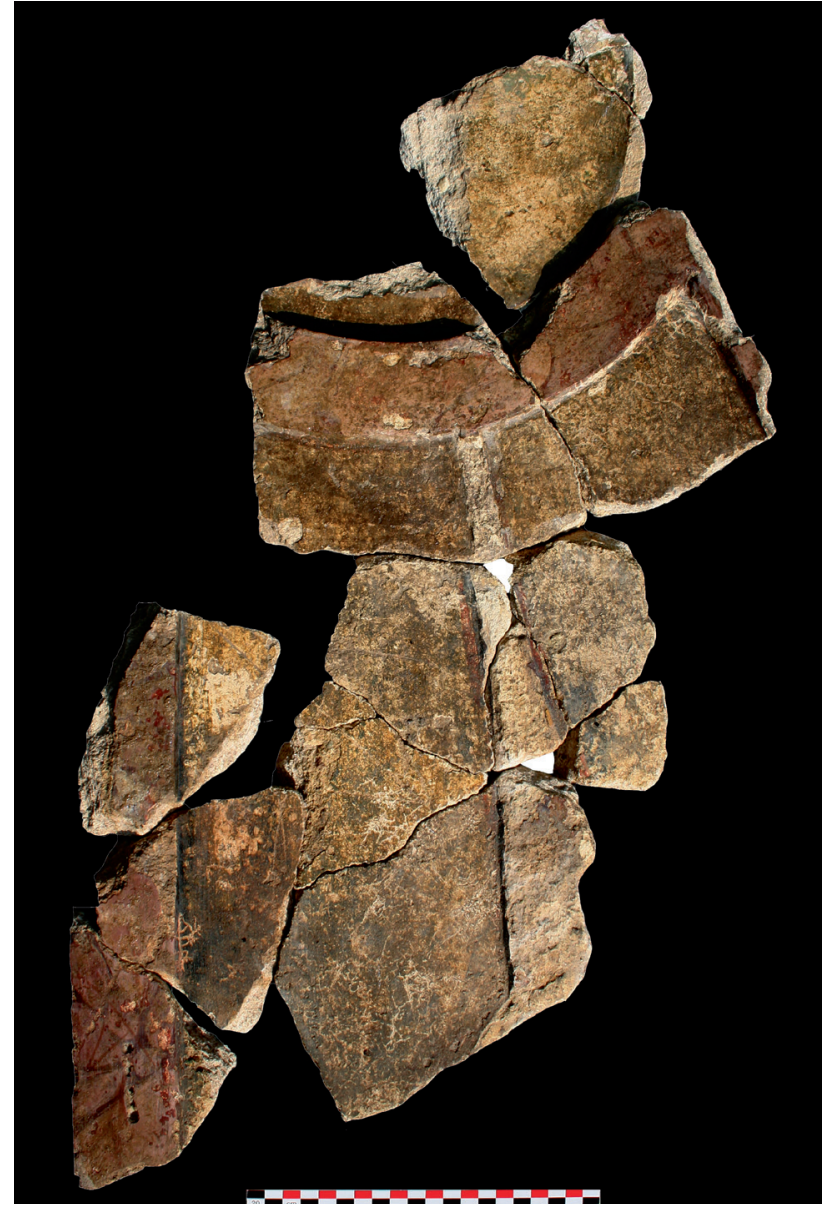

A Fig. 27. Vieux, Maison au grand Péristyle, salle III, scutum dressé (cliché J. Boislève, CG14).

groupe. C'est ainsi le cas de quelques fragments trouvés à Corseul (Côtes-d'Armor) (fig. 42, Boislève sous presse) et d'ensembles d'Argentomagus (Saint-Marcel, Indre) (fig. 43, Boislève sous presse) qui sont en attente d'étude ${ }^{17}$. Citons encore un décor tout récemment fouillé à Grand ${ }^{18}$ et dont quelques éléments ont d'ores et déjà été présentés avant étude.

La polychromie du stuc est déjà en soit une rareté, si on excepte toutefois les orthostates peints des décors les plus précoces, se rattachant au ${ }^{\text {er }}$ style et dont de rares exemples sont connus sur quelques sites de Gaule Narbonnaise (par exemple sur l'ile-Sainte Margueritte (Barbet 2008 : 37-39). Le plus souvent laissé blanc, le relief est, dans les cas qui nous concernent, entièrement peint de veinures, mouchetures et autres projections qui permettent d'évoquer les roches les plus diverses. L'imitation couvre, dans chacun des ensembles de ces sites, les formes géométriques en relief

${ }^{(16)}$ Une classification assez similaire a été proposée dans Allag et al. 2011. Signalons que nous ne reprenons pas ici les stucs liés au style structural ou au $1^{\text {er }}$ style pompéien, les décors de nos trois sites n'apportant pas de données nouvelles concernant ce groupe.

$\left.{ }^{17}\right)$ Les fragments de Corseul ont été identifiés lors d'un inventaire du mobilier mené par J. Boislève et F. Labaune, ceux d'Argentomagus lors d'un inventaire mené par J. Boislève, J.-F. Flécher et F. Monier. Inédit.

${ }^{(18)}$ Quelques photos visibles sur le site de l'Inrap (www.inrap.fr). Ces éléments ont été partiellement présentés par N. Froeliger et M. Mondy lors du dernier séminaire de l'AFPMA tenu à Paris en 2011. 


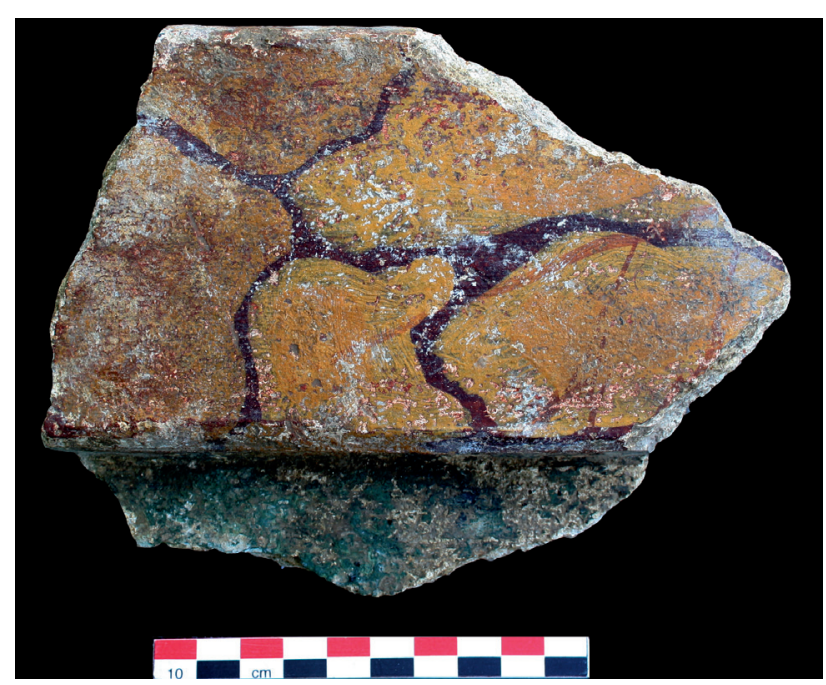

A FIg. 28. Vieux, Maison au grand Péristyle, salle III, détail du motif d'imitation de marbre (cliché J. Boislève, CG14).

mais gagne aussi, tout au moins à Mané-Véchen et à Corseul, la surface des corniches, ces deux exemples constituant les seuls cas de cette pratique avérés à ce jour.

Le rôle du relief dans ces imitations de sectilia est de mettre en évidence des motifs géométriques plus ou moins complexes qui sont littéralement mis en avant par une légère saillie de l'ordre du demi-centimètre, allant toutefois jusqu'à $2 \mathrm{~cm}$ dans le cas de Vieux. À Corseul, Mané-Véchen et Argentomagus, le motif géométrique en relief (rectangle, losange, disque, carré sur pointe, carré à côtés concaves,...) est toujours un motif plein dont la surface est parfaitement plane et traitée en une seule imitation de roche, chaque motif faisant donc l'illusion d'une seule et même plaque insérée dans une marqueterie plus élaborée que peut suggérer la peinture (voir par exemple les découpes à redans sur les compartiments du bandeau inférieur de la salle $A B$ à ManéVéchen). À Vieux l'usage est un peu différent car le relief constitue le contour du motif de bouclier et la composition joue davantage sur la notion de pleins et de creux pour faire ressortir l'imposante croix de scuta.

La finesse de traitement du décor de Mané-Véchen pouvait laisser penser que l'intégration d'éléments stuqués visait à accroitre le degré de réalisme du placage de marbres, à parfaire l'illusion. Toutefois, la saillie de certains éléments n'est pas une évidence sur les véritables sectilia et l'exemple de Vieux tendrait également à invalider cette hypothèse. En effet, dans la pièce III, si le soubassement d'imitation est imposant en taille et en termes de composition, l'imitation de roche demeure assez rapide, sinon grossière, mais en aucun cas naturaliste. Les roches suggérées évoquent à la rigueur des brèches, des marbres verts ou quelque marbre blanc veiné, mais la volonté de faire référence à une roche précise n'est pas là. Le recours au relief est donc plutôt à chercher dans une évolution stylistique plus large et qui semble caractéristique de l'époque sévérienne.

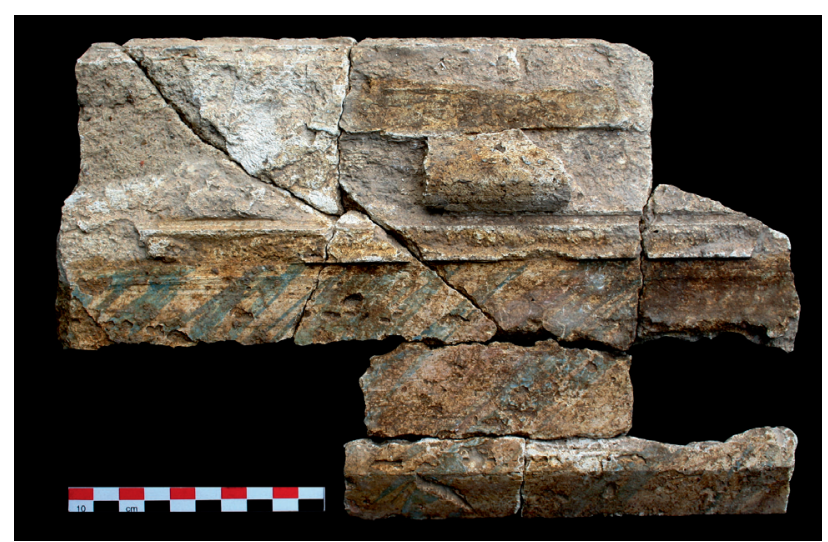

A FIg. 29. Vieux, Maison au grand Péristyle, salle III, moulure de couronnement de la zone inférieure (cliché J. Boislève, CG14).

Ce petit groupe d'imitation de marbres à motifs géométriques en relief s'inscrit en effet dans une mouvance plus vaste observée déjà dans les compositions peintes. Ainsi, il apparaît qu'à partir de la fin du $\|^{e}$ s. ap. J.-C., les imitations d'opus sectile reviennent en force et l'époque signe le retour à une certaine complexité des motifs. Les découpages des formes sont plus variés et les imbrications des différentes roches plus nombreuses. Ainsi, on identifie en peinture une série de décors typiques de cette époque et comportant un registre étroit à compartiments d'opus sectile riche et détaillé. C'est le cas par exemple des peintures de Genainville (Val-d'Oise) (Berthier 1980), Lisieux (Calvados) (Allag y Bartel 1985), Arnouvilleles-Gonesse (Val-d'Oise) (Flécher 1980), Charleville-Mézières (Ardennes) (Allag et al. 2011 : 511) ou Carhaix (Finistère) (Boislève y Labaune-Jean 2011) qui ont en commun un registre détaillé en couronnement de zone inférieure également à imitation de marbre. Le décor de la salle $A B$, bien qu'en partie traité en relief, se rattache parfaitement à ce groupe.

L'usage du relief dans ces décors apparaît donc comme un degré supplémentaire dans une évolution stylistique du genre, qui tend vers un accroissement du détail, de la variété et de la complexité des motifs.

\subsection{Les décors d'inspiration architectonique}

Ce groupe est sans surprise le plus représenté et pourrait finalement inclure toutes les corniches intégrées aux décors peints si nous n'avions choisi de considéré uniquement les ensembles à dominante stuquée. II correspond à un type de décor où le stuc évoque des éléments d'architecture, du simple édicule à l'arcature monumentale développée sur toute une paroi. Les moulures servent d'encadrement de panneaux comme on l'observe à Autun tandis que les corniches répétées à plusieurs niveaux de la paroi permettent de la diviser en zones distinctes. Le stuc permet d'accentuer l'effet de l'architecture fictive en lui donnant un relief qui l'extrait de la paroi et autorise davantage de jeux de profondeur et de plans successifs. Certains décors proposent de simple édi- 


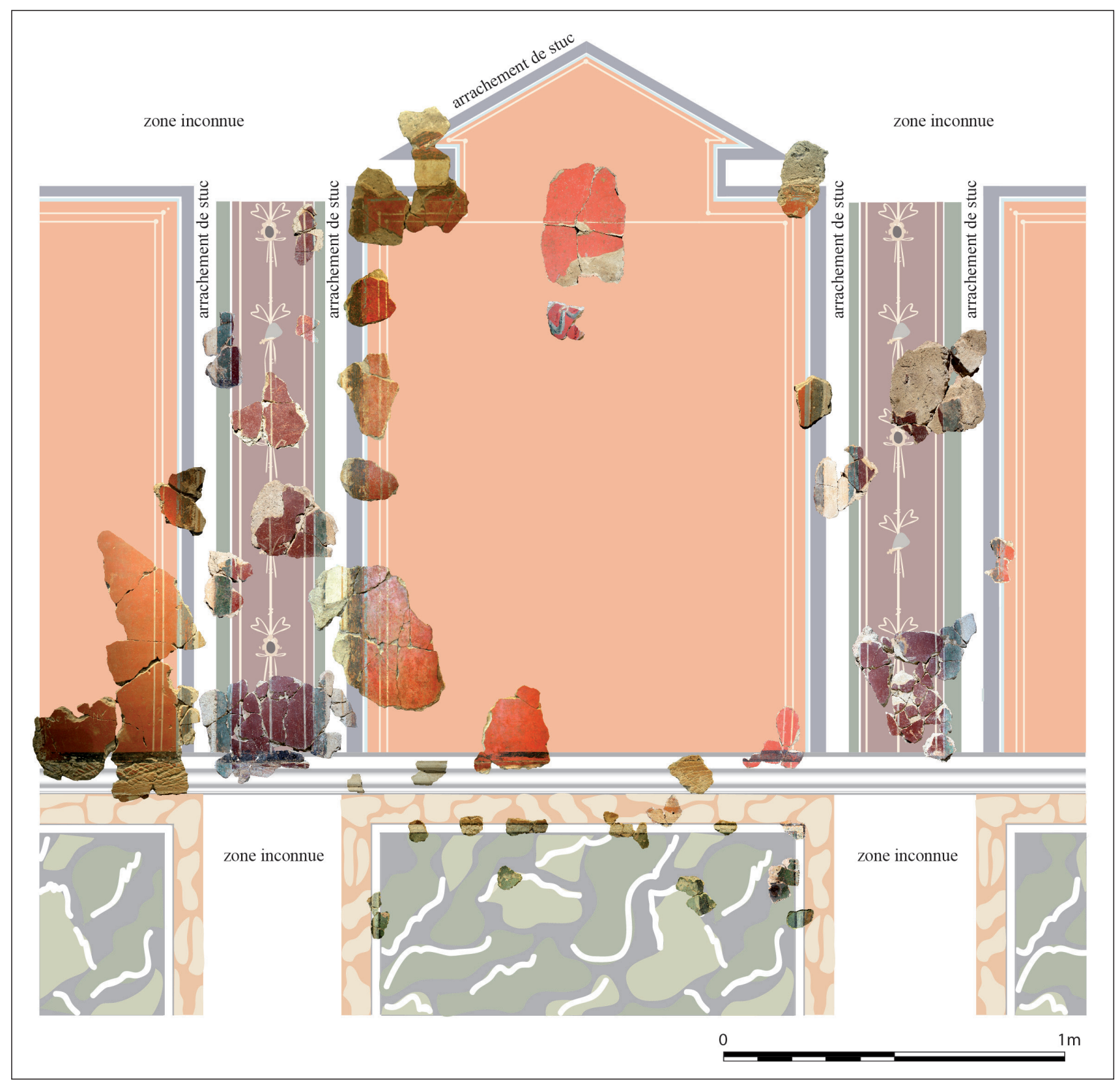

\ FIg. 30. Vieux, Maison au grand Péristyle, salle XV, restitution hypothétique du décor (DAO, clichés et restitution J. Boislève, CG14).

cules dans une vue très axiale où le relief suffit à évoquer la profondeur. On peut rattacher à cette pratique les éléments de fronton triangulaire, d'arcade et de pilastres cannelés provenant de Bavilliers (Territoire de Belfort) (Billerey 2009) et dans une moindre mesure le décor des parois de la salle $\mathrm{XV}$ où les arrachements des stucs suggèrent des colonnettes ou pilastres et tout au moins l'amorce d'un fronton triangulaire. Mais dans ce dernier cas, la dimension des éléments et surtout la persistance du système peint à panneaux et inter-panneaux auxquels le stuc ne fait que s'additionner, conditionne les reliefs à un rôle plus proche de l'encadrement que de la création d'une véritable évocation d'architecture.

Dans bien d'autres cas, on note davantage cette volonté d'imiter une architecture et les artisans ont d'ailleurs souvent recours à la perspective quand bien même ils disposent d'un matériau modelable en trois dimensions. On l'observe ainsi à Mané-Véchen où des modillons ou consoles sont clairement traitées avec un effet de perspective. On le remarque encore plus nettement dans la villa de La Pierre à Maladières (collectif 1991) où le décor, proposé pour une zone supérieure, forme un pavillon ou un édicule. Les colonnettes cannelées portent un entablement et un fronton triangulaire dont le contour est dégagé par des moulures retravaillées au couteau. Sur les côtés de l'édicule central, ainsi que sous l'entablement, des lignes de fuite incisées créent une perspective et la profondeur d'un soffite à caissons. L'aboutissement ultime de cette tentative de faire de la paroi une structure architecturée se trouve probablement dans le décor d'Autun 


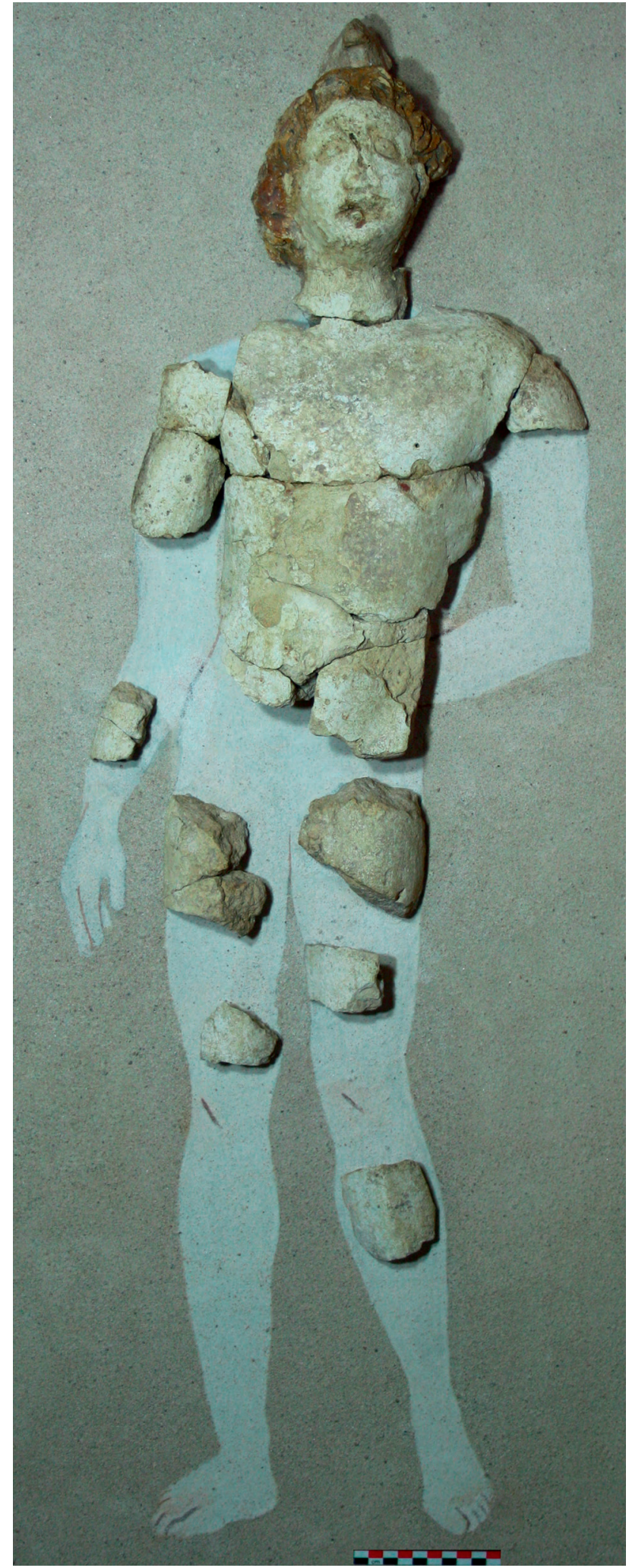

A FIg. 31. Vieux, Maison au grand Péristyle, salle XV, vue de l'Attis en stuc (cliché J. Boislève, CG14).

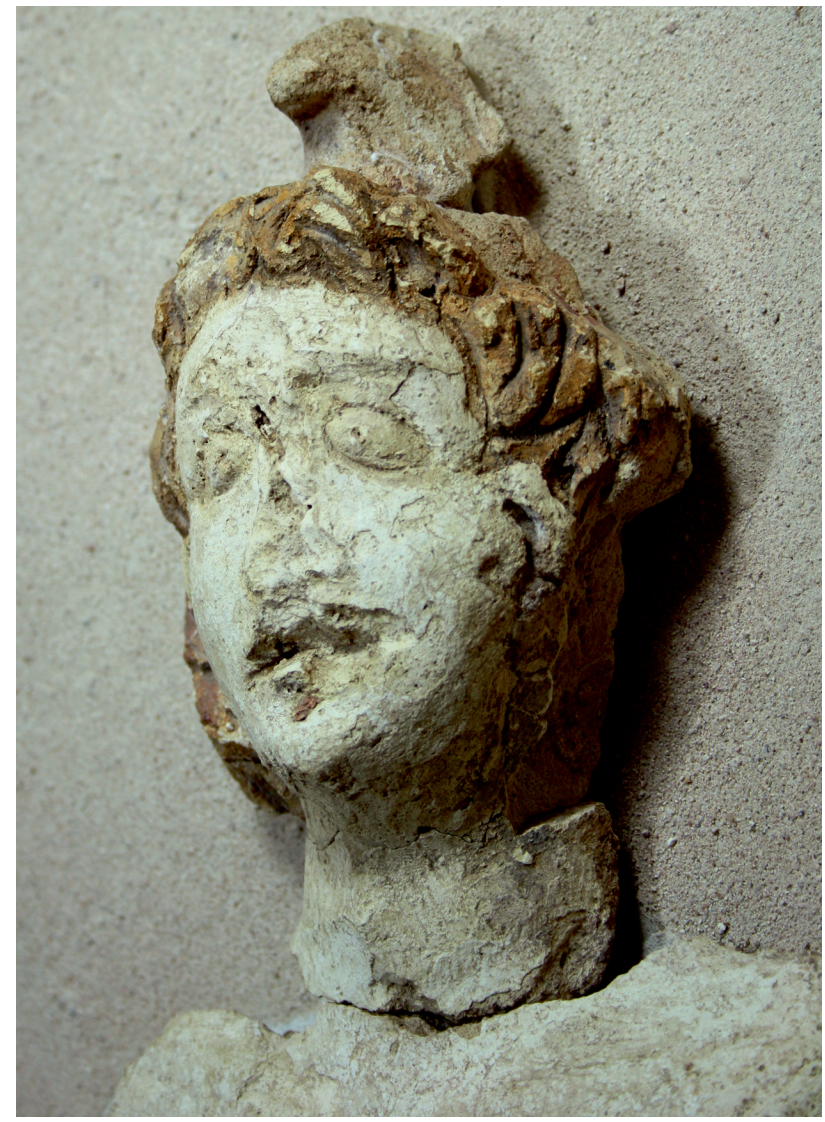

A Fig. 32. Vieux, Maison au grand Péristyle, salle XV, détail du visage de l'Attis (cliché J. Boislève, CG14).

où l'artisan a joué non seulement sur le relief des moulures, mais aussi et surtout, a conçu une structure préalable à la pose de l'enduit pour créer des profondeurs impossibles à obtenir avec le seul travail d'un enduit appliqué sur un plan lisse. En effet, à Autun, l'étude des revers a permis de montrer que l'ensemble de l'enduit est posé sur une armature de tubuli qui ne sont nullement dévolus à l'évacuation des fumées d'un système d'hypocauste ${ }^{19}$ (Boislève y Allag 2011), mais ont uniquement un but décoratif. Ils permettent de créer les volumes des arcades et l'épaisseur des piliers qui les supportent, dégageant au passage niches et caissons en creux. Ce travail qui amène l'artisan à construire, à l'échelle de toute une pièce, haute de $5,75 \mathrm{~m}$, une telle substructure traduit assez la recherche de monumentalité souhaitée pour ce décor et la volonté de pousser encore plus loin l'illusion d'une structuration architecturale.

Parmi les décors de ce groupe on note l'utilisation d'un répertoire décoratif assez commun. Arcs moulurés et pilastres ou colonnettes sont les éléments les plus fréquents comme en témoignent, en plus des exemples déjà

(19) La disposition des tubuli connue par les empreintes au revers de l'enduit, indique que les conduits n'étaient pas fonctionnels puisque certains rangs disposés horizontalement venaient obstruer les tubulures verticales. D'autre part, l'artisan utilise des matériaux en grande partie récupérés (certains ont des traces de chauffe et d'autres non, au sein d'un même rang), parfois cassés. L'examen des tubuli récupérés en même temps que les enduits, montre aussi que certains étaient comblés de mortier. 


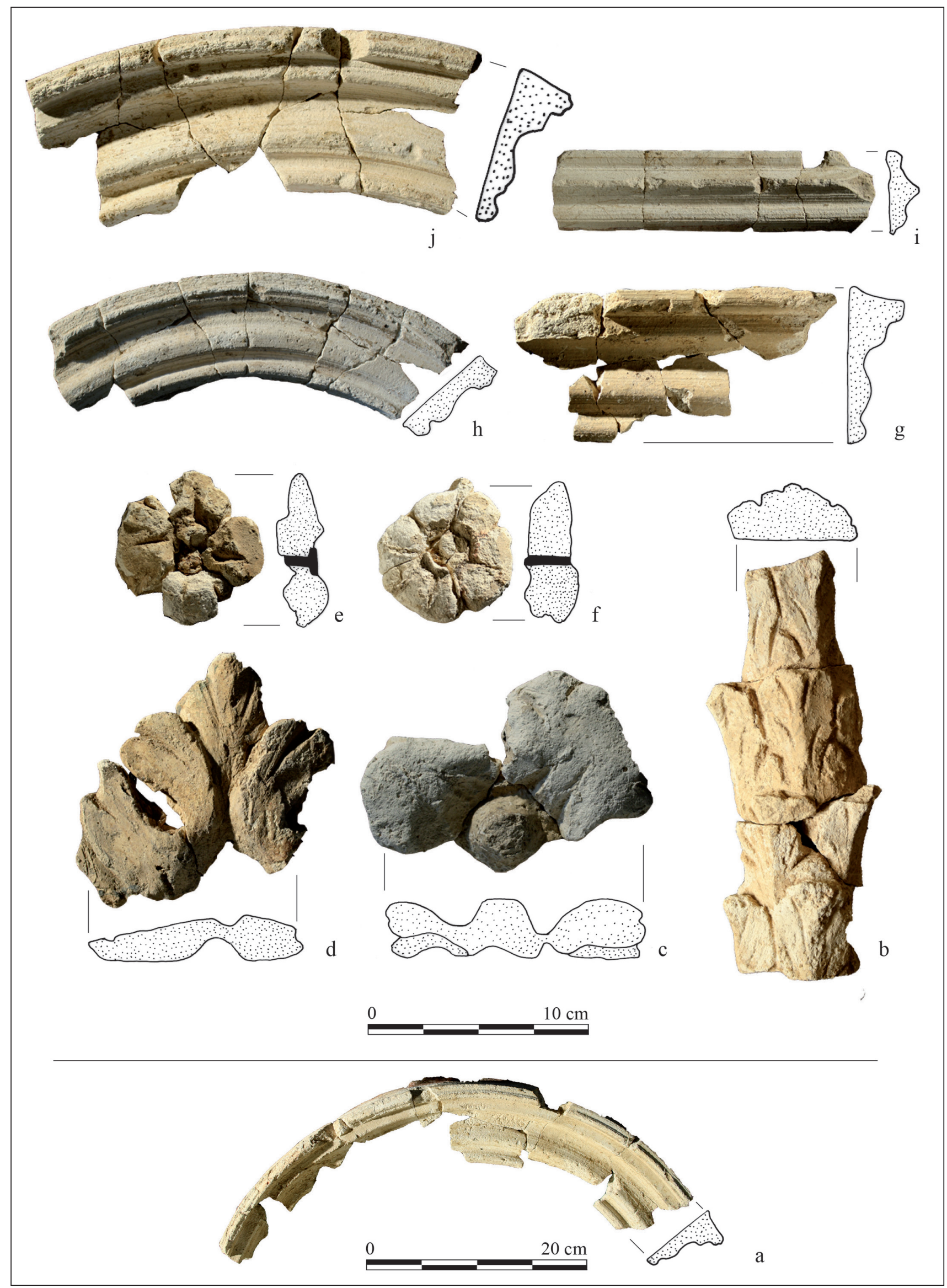

\ Fig. 33. Vieux, Maison au grand Péristyle, salle XV, éléments de stucs divers (cliché J. Boislève, CG14). 
cités (cf. supra), les arcatures de la villa de Karadennec en Saint-Frégant (Finistère) (Sanquer y Galliou), le fragment de pilastre cannelé des thermes de Mirebeau (Côte-d'Or) (Allag et al. 2011 : 512), ou encore les colonnettes de la villa de Pont-de-Poitte à Vicourt (Jura) (Barbet y Gandel 1998).

Les motifs estampés, le plus souvent des rangs d'oves, sont particulièrement développés sur les moulures d'arcades et de fronton où ils permettent de faire un lien évident avec les frises présentes sur les entablements des véritables architectures. On notera d'ailleurs l'aspect atypique, de ce point de vue, des décors de Mané-Véchen ou l'estampage est une technique totalement absente. Pilastres et colonnettes sont généralement cannelés (Mirebeau, Bavilliers, Maladières), plus rarement rudentés (Mané-Véchen, salle BF). Les chapiteaux font le plus souvent l'objet d'un soin particulier comme l'exemplaire très finement travaillé de CharlevilleMézières (Allag et al. 2011 : 511) ou ceux figurés de Vicourt. Les motifs végétalisants y trouvent leur place comme la palmette à Bavilliers, les feuillages d'Autun (fragments de provenance imprécise conservés au Musée Rolin, Frizot 1977), ou ceux traités en peinture à Mané-Véchen ${ }^{20}$.

Si pour certains décors, comme à Kéradennec, à Autun ou à Bavilliers, ce cadre architecturé fonctionne seul et structure la paroi, il peut sur d'autres ensembles, comme à
Mané-Véchen, constituer un environnement permettant de mettre en avant des éléments figurés.

\subsection{Les décors figurés}

Le stuc permet un travail en trois dimensions particulièrement apprécié pour imiter la sculpture en haut-relief et évoquer ainsi les plus riches créations en marbre. Souvent, lors des fouilles les plus anciennes, seuls les visages ou quelques "beaux" éléments facilement identifiables ont été conservés, nous privant du cadre décoratif qui les accompagnait. Le décor de la salle BF à Mané-Véchen est donc à ce jour l'ensemble le plus complet ${ }^{21}$ et amène un éclairage nouveau sur les nombreux éléments isolés ou hors contexte connus par ailleurs.

Le modelage des figures, qu'il s'agisse de personnages ou d'autres types de représentations (végétaux, animaux,...) est en soit beaucoup plus élaboré et varié que les éléments estampés ou obtenus à l'aide de gabarits. En effet, par définition, chaque figure est unique.

La figuration vise souvent à représenter des divinités tels l'Attis de Vieux, les Hermès, Éros, Silènes et autres personnages secondaires de Mané-Véchen. Ailleurs, les identifications sont souvent plus complexes mais on suppose une

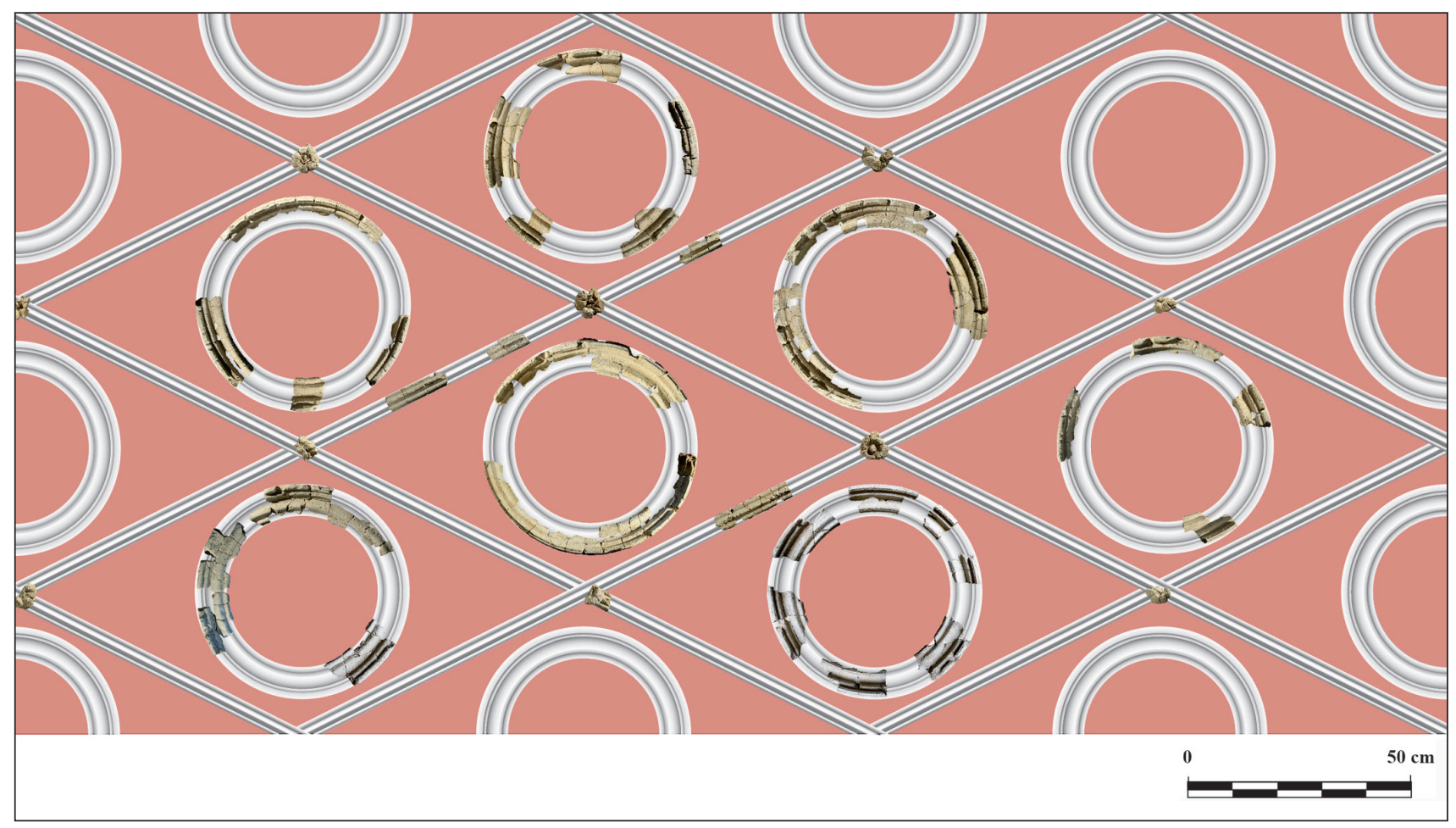

A FIg. 34. Vieux, Maison au grand Péristyle, salle XV, restitution hypothétique du décor de plafond (Dao, clichés et restitution J. Boislève, CG14).

${ }^{(20)}$ Signalons qu'en plus des feuillages peints, de petits masques lunaires prenaient place sur les pilastres sans que nous puissions préciser leur emplacement exact.

${ }^{(21)}$ Les décors de la villa de Vicourt, qui présentent également une multitude d'éléments figurés et architecturés devraient offrir, sous réserve de remontages suffisants, des données importantes sur ce type de décor. Leur étude et leur publication sont toujours attendues. 


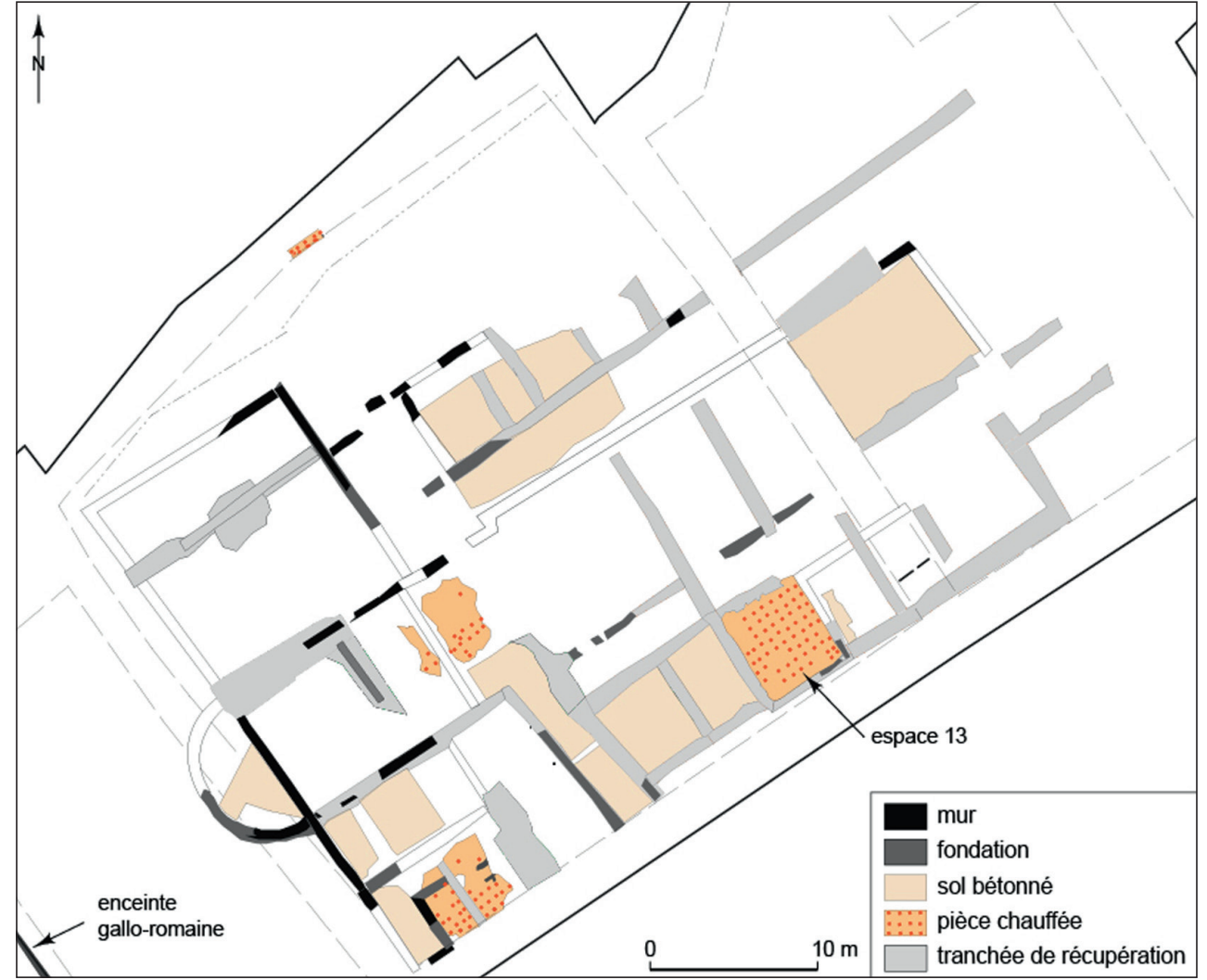

FIG. 35. Autun, nouvel hôpital, plan du site, état du grand bâtiment de la fin du III ${ }^{\mathrm{e}}$ s. (d'après $\mathrm{Ph}$. Bet). représentation de Mars et Vénus à Curçay-sur-Dive (Vienne) (Allag y Blanc 2006) tandis que les traits enfantins de la petite tête isolée de Clermont-Ferrand (fig. 44) identifieraient volontiers un Amour. À Argentomagus (Coulon 2002) la tête aux traits accentués, nez épaté et bouche lippue, et à la barbiche doit-être un dieu Pan et non une "tête négroïde"comme le pense l'auteur, d'autant que des cornes, incomplètes, paraissent pointer dans la chevelure (fig. 45).

Ces personnages sont traités à des échelles très diverses et il n'est pas certains que tous correspondent à des représentations en pied. Toutefois, les plus grandes d'entre elles, à Vieux et à Mané-Véchen avoisinent la taille humaine. Néanmoins, l'ensemble de la Salle BF confirme la présence de divers personnages d'échelles très variables, au sein d'un même décor. Pour autant, ils ne paraissent pas composer des tableaux à personnages multiples ou des plans successifs justifieraient le recours à des échelles dégressives.

Ces personnages peuvent être en fort relief sur la paroi. Il en est ainsi de l'Attis de Vieux ou des plus grandes figures de Mané-Véchen où le traitement de certains plis de vêtement, ou encore la présence d'orteils, particulièrement proéminents, prouvent que l'ensemble du personnage, de la tête aux pieds, se détache nettement de la paroi pour tendre vers le très haut-relief voire même certaines parties traitées en ronde-bosse. À l'inverse, pour d'autres figures, l'artisan choisi de ne mettre en saillie qu'une partie du corps, le plus souvent la tête, comme si le personnage semblait s'extraire progressivement de la paroi. II en va ainsi pour le torse de faune de Mané-Véchen dont l'épaule gauche est bien plus proéminente que la droite. Le procédé donne aussi un effet de mouvement à la figure. Il est probable qu'une partie des têtes isolées, connues sur divers sites de Gaule étaient ainsi mise en avant par rapport à un corps traité avec un relief moindre.

La facture et la finition de ces figures est aussi très variable d'un site à l'autre, révélant des savoir-faire ou des goûts très différents. Ainsi, les personnages de Mané-Véchen tendent vers un naturalisme remarquable. Le soin apporté au modelage et la finesse de finition des traits du visage vise à donner aux figures un réalisme étonnant et les rapproche ainsi des grandes sculptures classiques. Proportions des membres, rendu du volume et du modelé des muscles, finesse des détails jusque dans la représentation des ongles,... sont autant d'éléments qui concourent à cette finalité. On retrouve le même type de finition à Argentomagus ou sur un ensemble de la villa de Noyal-Châtillon-sur-Seiche (Ille-etVilaine) ${ }^{22}$, beaucoup plus fragmentaire mais dont quelques éléments figurés révèlent une certaine similitude avec les stucs de Mané-Véchen (fig. 46).

${ }^{(22)}$ Stucs inédits observés lors d'un inventaire réalisé par J. Boislève et $F$ Labaune-Jean. Le site partiellement fouillé par A. Provost fera prochainement l'objet d'une fouille préventive menée par l'Inrap et qui pourrait apporter les éléments complémentaires pour ce décor stuqué. 


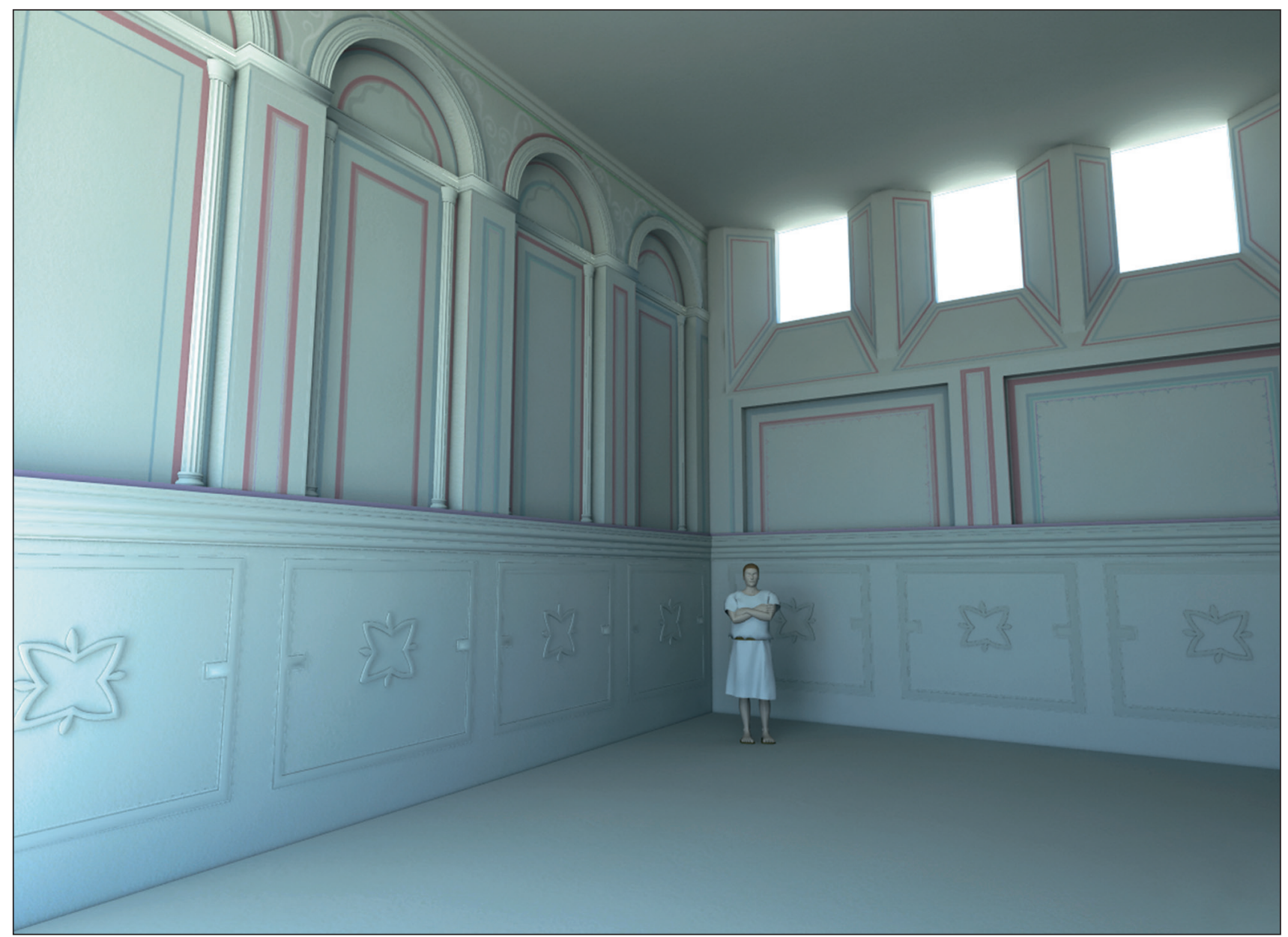

\ FIg. 36. Autun, nouvel hôpital, restitution en 3D du décor (archéotransfert/ausonius).

À l'opposé, certains décors présentent une facture d'apparence beaucoup plus grossière, où les traits sont moins détaillés, les volumes plus sommaires et où le travail à la spatule reste davantage perceptible. L'ensemble donne aux figures une expressivité plus marquée puisque seuls les traits primordiaux sont dégagés. Ainsi, le visage de l'Attis de Vieux présente deux yeux en amande assez globulaires sans davantage de détails pour les paupières. À Vicourt, le travail est encore plus expressif avec un modelage dont les coups de spatules demeurent volontairement visibles. Ainsi, sur un des masques de cet ensemble, les cheveux sont évoqués par de vifs coups de couteau aux incisions marquées, et les yeux paraissent disproportionnés. Aucun lissage ou badigeon de surface ne vient finir le travail, contrairement aux têtes de Mané-Véchen où nous avons pu observer ce procédé pour adoucir les traits et masquer les traces d'outil.

Outre les représentations humaines, on observe quelques figurations animales. Elles semblent plutôt accompagner des scènes mythologiques comme la panthère bondissante de la salle BD ou la tête d'équidé de la salle BF de Mané-Véchen. À
Alésia ${ }^{23}$, une belle tête de taureau, malheureusement isolée, pourrait être l'indice d'une scène de sacrifice ou d'un culte oriental.

Parmi les éléments figurés, l'évocation du monde végétal revient assez souvent avec le thème du rinceau de vigne qui est particulièrement fréquent. Les petites grappes de raisins, formées toujours selon la même technique de petites boulettes enfoncées dans une base de mortier frais, se retrouvent ainsi sur les décors de Vicourt, de Curçay-sur-Dive, mais aussi dans les villae de Cujasseix à Rougnat (Creuse) et de la Guyomerais à Noyal-Châtillon-sur-Seiche.

Elles s'accompagnent souvent de feuillages souvent luxuriants dont la découpe peut être plus ou moins stylisée.

\subsection{Les décor de voûte et de plafond}

L'étude des stucs de Mané-Véchen, Autun et Vieux, révèle des éléments de décor de quatre nouveaux plafonds qui constituent d'ailleurs l'essentiel du corpus. En effet, si en Italie, le stuc trouve essentiellement place sur les surfaces

(23) Découverte en 1914 lors de la fouille du cimetière Saint-Père (n. ${ }^{\circ}$ inv. 2007.1.227). 


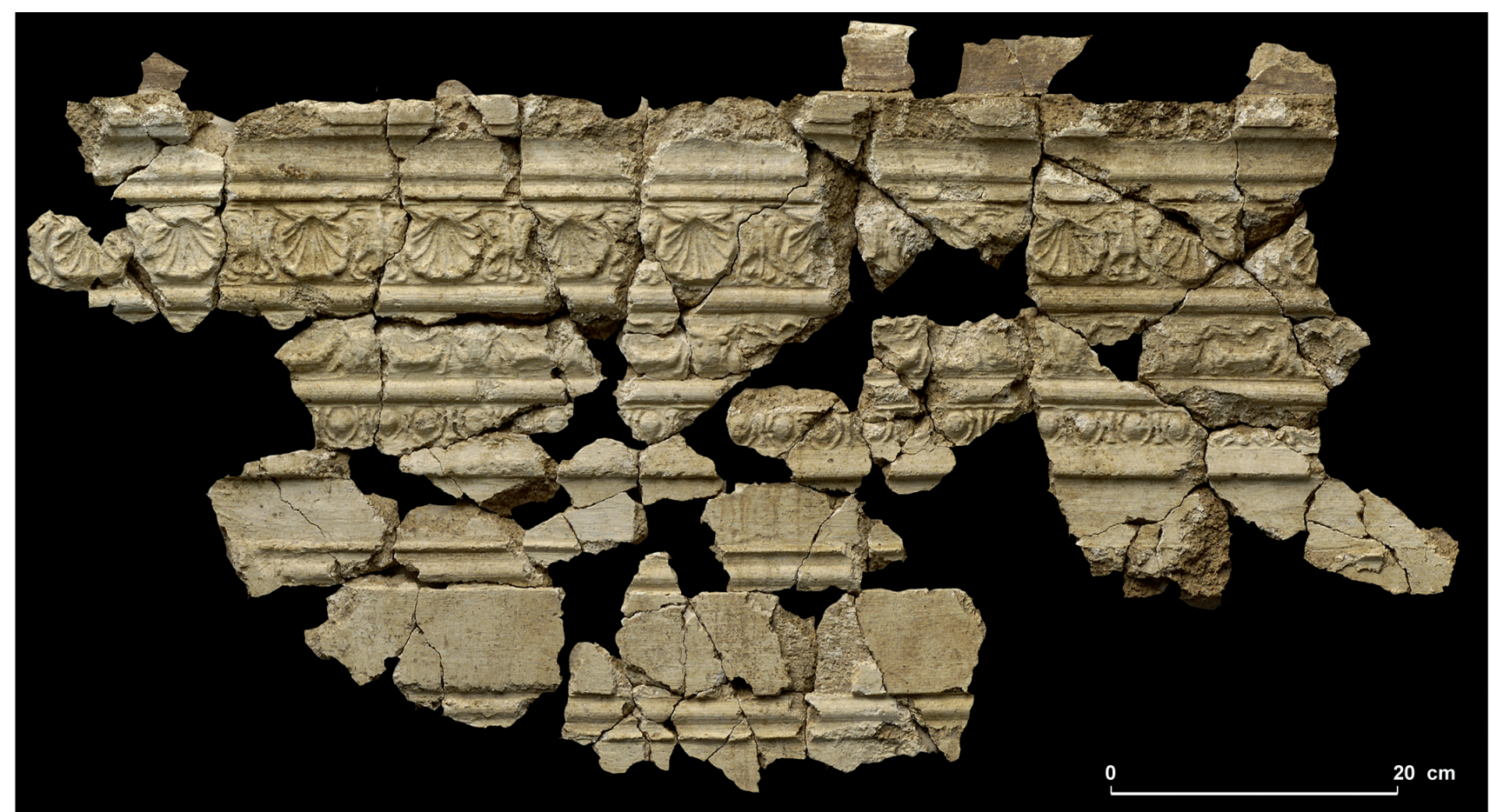

\ FIg. 37. Autun, nouvel hôpital, corniche de couronnement de la zone inférieure (cliché ph. Delangle, CEPMR).

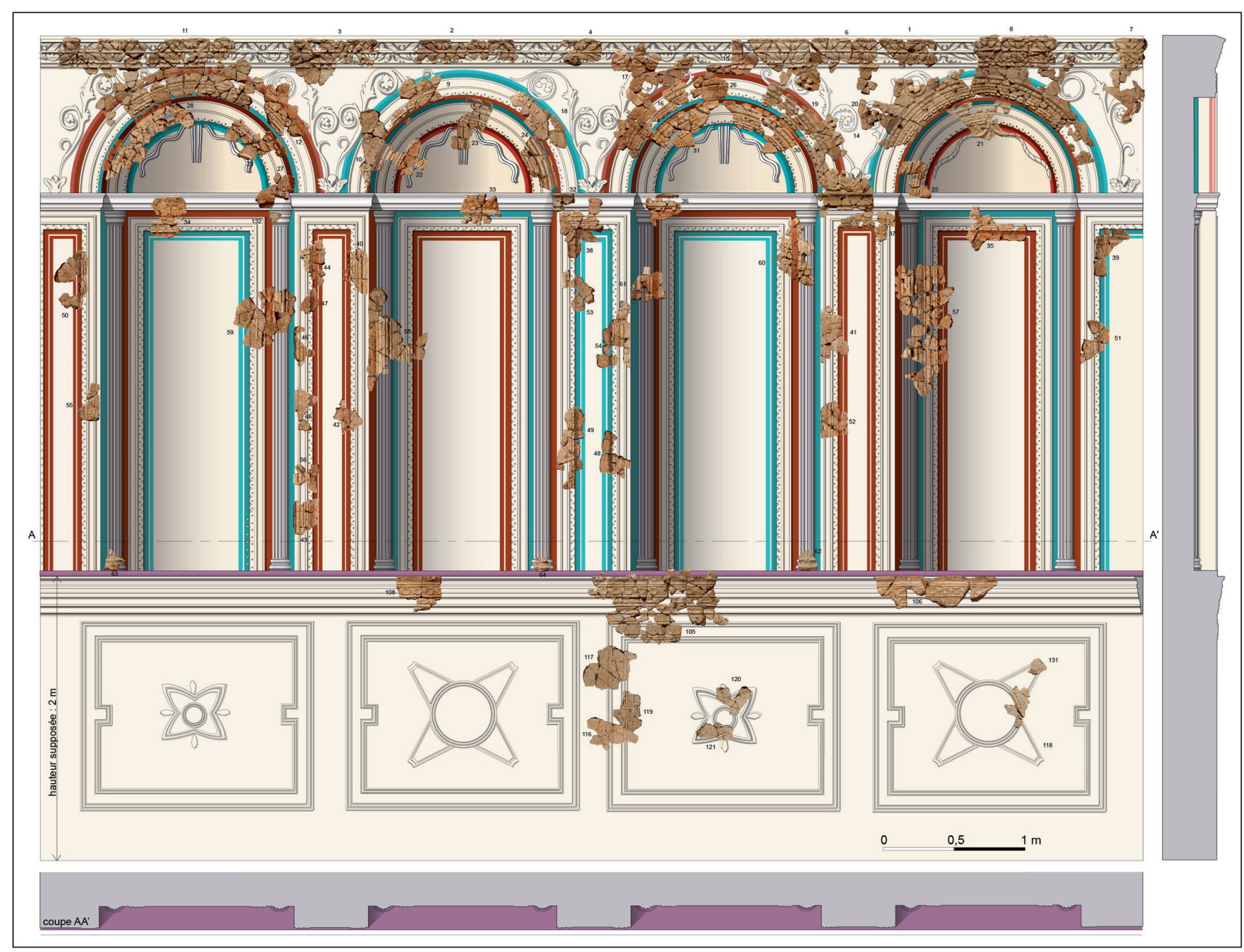

\ FIg. 38. Autun, nouvel hôpital, restitution du décor du mur A (DAO J.-F. Lefèvre, clichés ph. Delangle, restitution J. Boislève, CEPMR). 


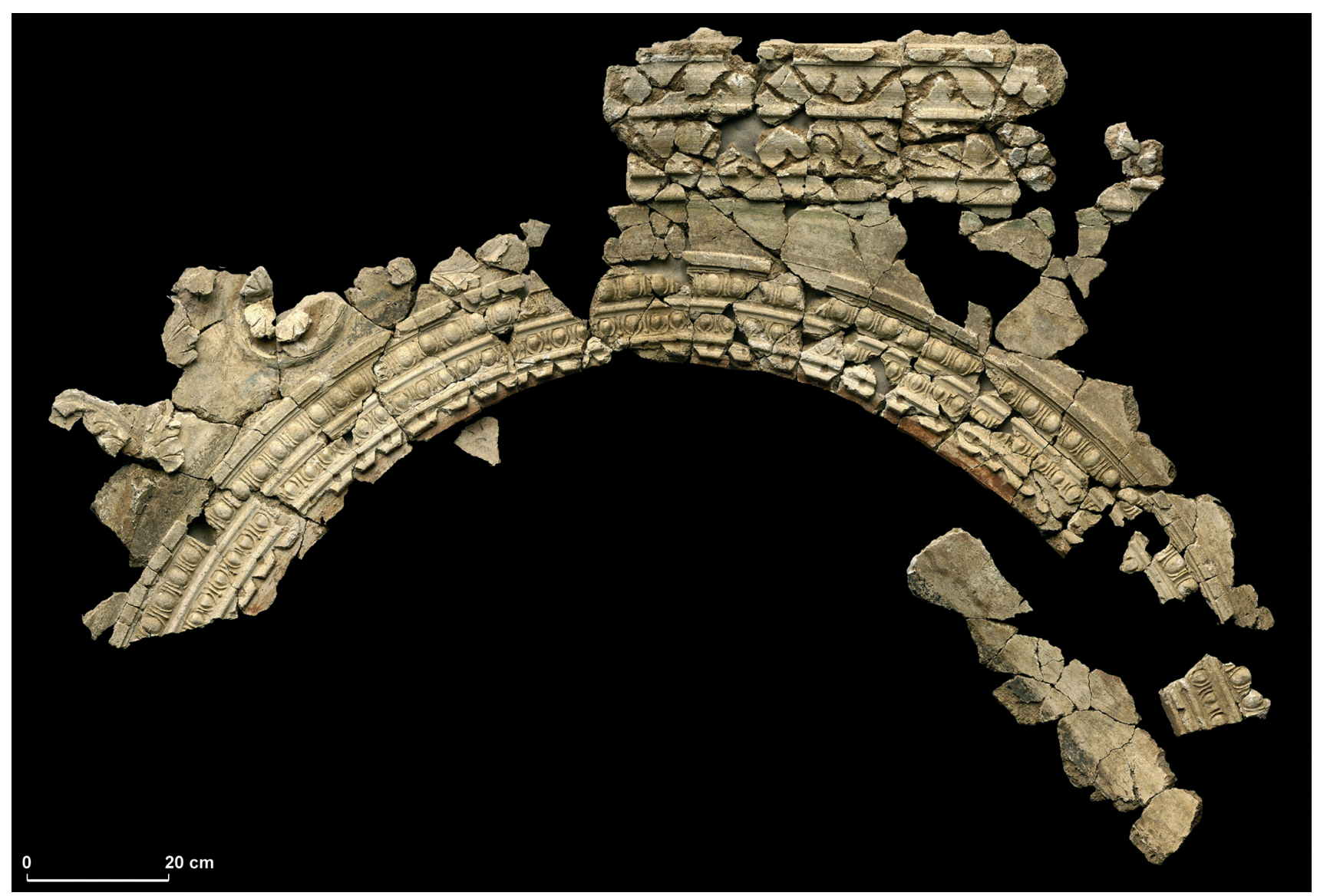

^ FIg. 39. Autun, nouvel hôpital, arcade (cliché ph. Delangle, CEPMR).

de voûte, ces décors sont très méconnus en Gaule. Malheureusement, malgré ces nouveaux apports, la restitution des décors demeure problématique. II semble pourtant qu'il faille privilégier des décors à réseau à Autun et à Vieux. Dans le premier cas, le motif de pelte ainsi que les moulures droites évoquent volontiers une composition sur la base d'une trame géométrique, d'autant que les éléments sont assurément répétés sur plusieurs plaques. À Vieux, les stucs rattachés à la pièce XV correspondent aussi certainement à une composition en réseau comme en témoigne la mutlitude de moulures en arc de cercle qui définissent des médaillons circulaires prenant probablement place en remplissage de losanges dégagés par une trame matérialisée par une moulure lisse avec fleurons aux intersections. Toutefois, la restitution de l'ensemble pourrait être plus complexe que nous ne le proposons car les éléments de colonnette de feuilles qui ne semblent pas trouver place sur le décor mural devraient dès lors appartenir au plafond. Dans la même domus, quelques autres éléments de stucs, définissant également des médaillons avec une moulure légèrement différente, pourraient aussi révéler des plafonds stuqués dans la pièce VIII et le portique sud. Toujours sur la base d'une trame à réseau, mais appartenant cette fois à un décor de voûte, l'ensemble exhumé sur le site de la clinique du Parc à Autun (Allag et al. 2011 : 516) présente une composition d'octogones adja- cents dégageant des carrés. Les encadrements sont obtenus par une moulure estampée d'oves stylisés et des cabochons à trois pétales marqués d'une incision centrale prennent place aux angles, masquant sans doute les raccords de moule à cet endroit. Les compositions à réseau sont les plus courantes pour orner les plafonds, qu'ils soient peints ou stuqués. Elles imitent simplement les caissons de l'architecture de pierre et sans doute de bois. À cette fin, le stuc offre un potentiel bien plus important puisque le relief crée la parfaite illusion. Ce type de composition semble être inscrit durablement dans les modes décoratives romaines et n'être jamais tombé en désuétude durant tout la période impériale.

Les deux plafonds de Mané-Véchen relèvent sans doute d'un autre style de composition. Dans la salle BF, la multitude d'éléments de feuillages, plus ou moins stylisés, de formes variées et très plats plaident en faveur d'une organisation plus libre où la végétation est luxuriante et dominante, sans doute un vaste rinceau de vigne comme le suggère les multiples grappes de raisins. La surface n'est toutefois pas dépourvue de structuration comme en témoigne les moulures droites qui définissent sans doute des encadrements, peut-être pour les petites scènes figurées dont l'une évoque les amours d'un satyre avec une nymphe ou une ménade.

Dans la salle BD les quelques indices anciennement découverts révèlent un plafond aussi riche avec là encore quelques 


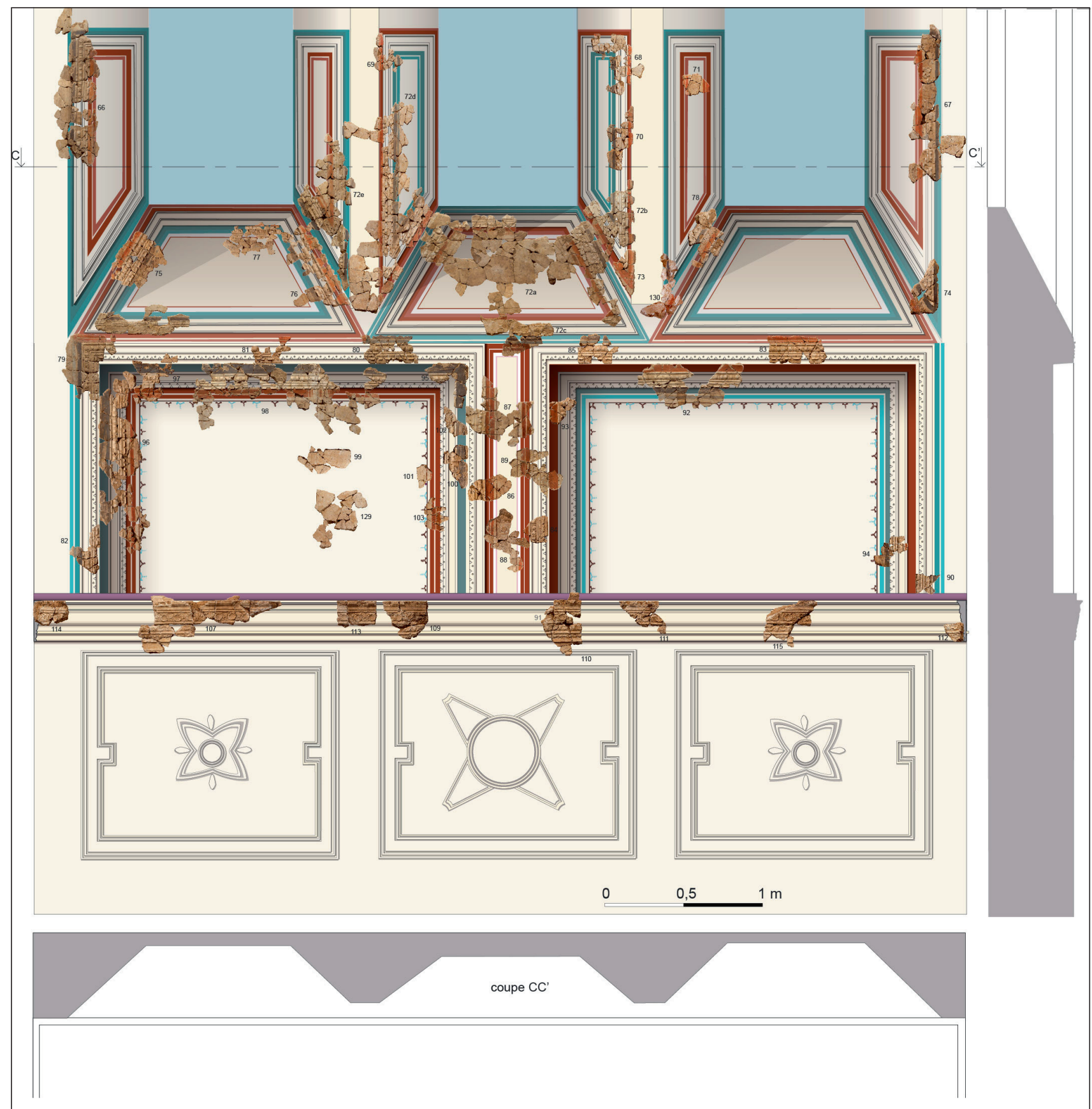

A FIg. 40. Autun, nouvel hôpital, restitution du décor du mur B (DAO J.-F. Lefèvre, clichés ph. Delangle, restitution J. Boislève, CEPMR).

éléments figurés. Ces deux décors constituent à ce jour les seuls cas de scènes figurées sur plafond avérés en Gaule.

\section{QUELQUES ASPECTS TECHNIQUES}

D'un point de vue technique, l'examen des décors de ces trois sites apporte aussi son lot de nouveautés.

Si on retrouve sans surprise les techniques bien connues de l'estampage et du gabarit qui permettent de répéter un motif et de définir le profil d'une moulure ou corniche, on observe également des usages moins fréquents, jusqu'alors inconnus ou encore dont le procédé est mieux éclairé par ces ensembles plus complets.

Ainsi, dans la fixation du relief nous observons des pratiques très variées d'un site à l'autre et qui correspondent plus aux habitudes de tel ou tel artisan qu'à des besoins liés à l'importance du relief mis en place. À Autun, malgré le relief assez important de certaines corniches, aucun système de renfort de fixation par des chevilles ou des clous n'a été observé. L'artisan a simplement aménagé la surface de pose pour les corniches et les colonnettes. La couche d'épiderme n'a pas été posée sous la corniche sommitale et a été striée à l'emplacement de l'imposte et des colonnettes. Ainsi, la 


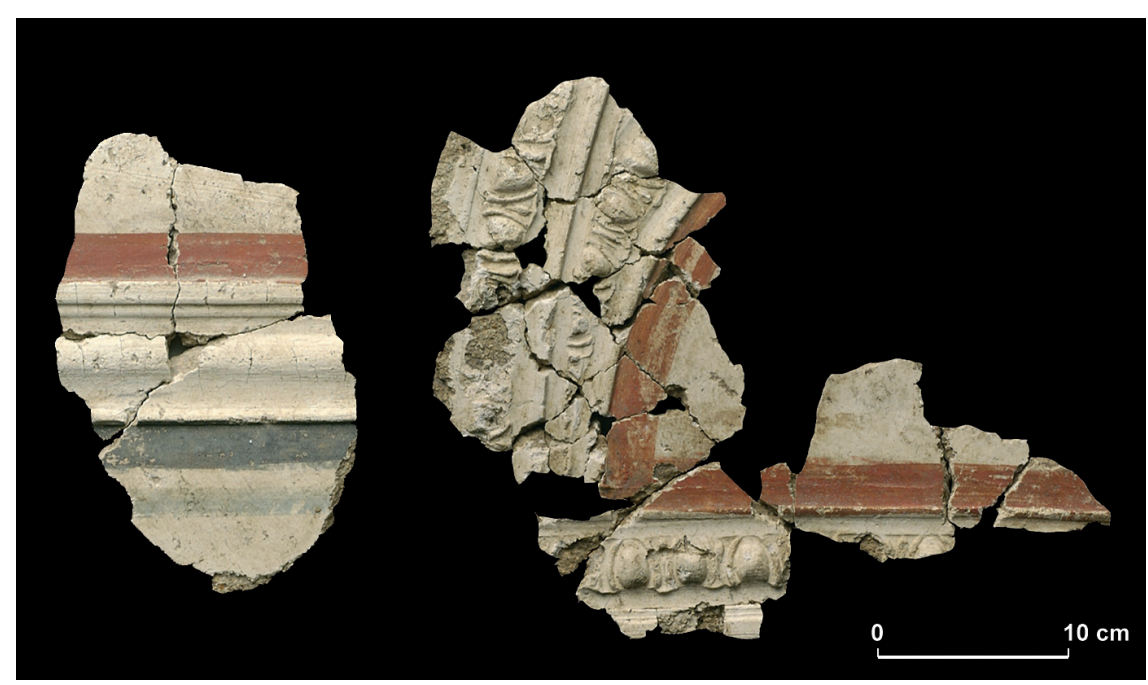

4 FIg. 41. Autun, nouvel hôpital, éléments du décor de plafond (clichés ph. Delangle, CEPMR).

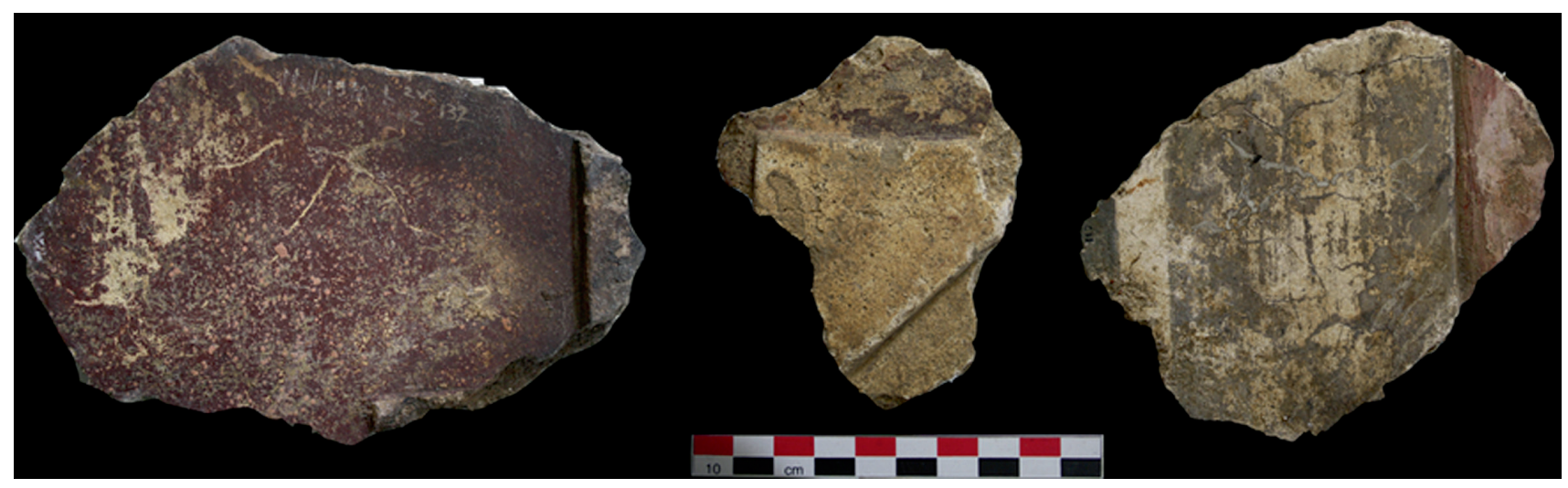

৯ FIg. 42. Corseul, éléments du décor stuqué (clichés J. Boislève).

surface rugueuse paraissait suffisante pour l'adhérence du stuc. Pour les moulures d'encadrement les plus fines, aucun dispositif particulier n'intervient et la matière est posée directement sur la couche d'épiderme. À Vieux en revanche, l'artisan a davantage craint la chute des éléments en saillie et a donc renforcé leur fixation par la pose de clous assez nombreux. Ils sont ainsi présents tout au long des colonnettes de feuilles et au niveau des moulures définissant les médaillons circulaires de la pièce XV. Dans la pièce III, on observe aussi l'empreinte de quelques clous au niveau des bandeaux définissant le contour des scuta de la zone inférieure. En plus des clous métalliques de section carrée, l'artisan a préparé la surface en la rendant plus rugueuse par des stries en croisillons. À Mané-Véchen enfin, les pratiques sont différentes d'une pièce à l'autre, ce qui traduit sans doute l'intervention de différents ateliers. Dans la salle $A B$, la surface de pose qui correspond à la couche d'épiderme, est striée par quelques incisons irrégulières à l'endroit des reliefs les plus légers (motifs des bandeaux inférieurs et médian). En revanche, elle est totalement ôtée à l'endroit des corniches intermédiaires dont la tenues est par ailleurs renforcée par des chevilles en bois ou des clous comme le suggèrent les empreintes de section carrée observées tous les 5 à $7 \mathrm{~cm}$. Dans la salle $B F$, où les imposantes figures atteignent jusqu'à $9 \mathrm{~cm}$ d'épaisseur, ce sont des chevilles en os (fig. 47) qui ont été préférées pour la fixation du stuc. II s'agit de simples esquilles d'os dont la longueur a été adaptée à l'épaisseur du relief à soutenir. Ce procédé n'est pas inconnu mais avait été vu par C. Allag (Allag y Blanc 2005 : 113-114) comme le signe d'une particularité locale du Poitou, sur la base d'exemples repérés à Mairé (Deux-Sèvres) et à Poitiers (Vienne). Cette hypothèse est donc infirmée par le décor de Mané-Véchen mais aussi par celui de Noyal-Châtillon-sur-Seiche où plusieurs fragments conservent une cheville d'os à leur revers (fig. 46).

Pour ce qui est de la création du relief, plusieurs pratiques sont à noter. À Autun tout d'abord, nous découvrons la création d'une véritable armature préalable à la pose de l'enduit et destinée à apporter au mur le relief voulu pour le décor. Ainsi, piliers, arcades et caissons sont obtenus par la pose de tubuli, qui ne sont nullement destinés à l'évacuation des fumées d'un système de chauffage mais ont bien pour seule fonction la mise en place du relief décoratif. Le conduit est donc détourné de son usage premier et sert uniquement de matériau de construction qui permet d'obtenir le relief de 15 à $20 \mathrm{~cm}$ nécessaire pour évoquer une architecture imposante. L'usage détourné des tubuli était déjà identifié pour 


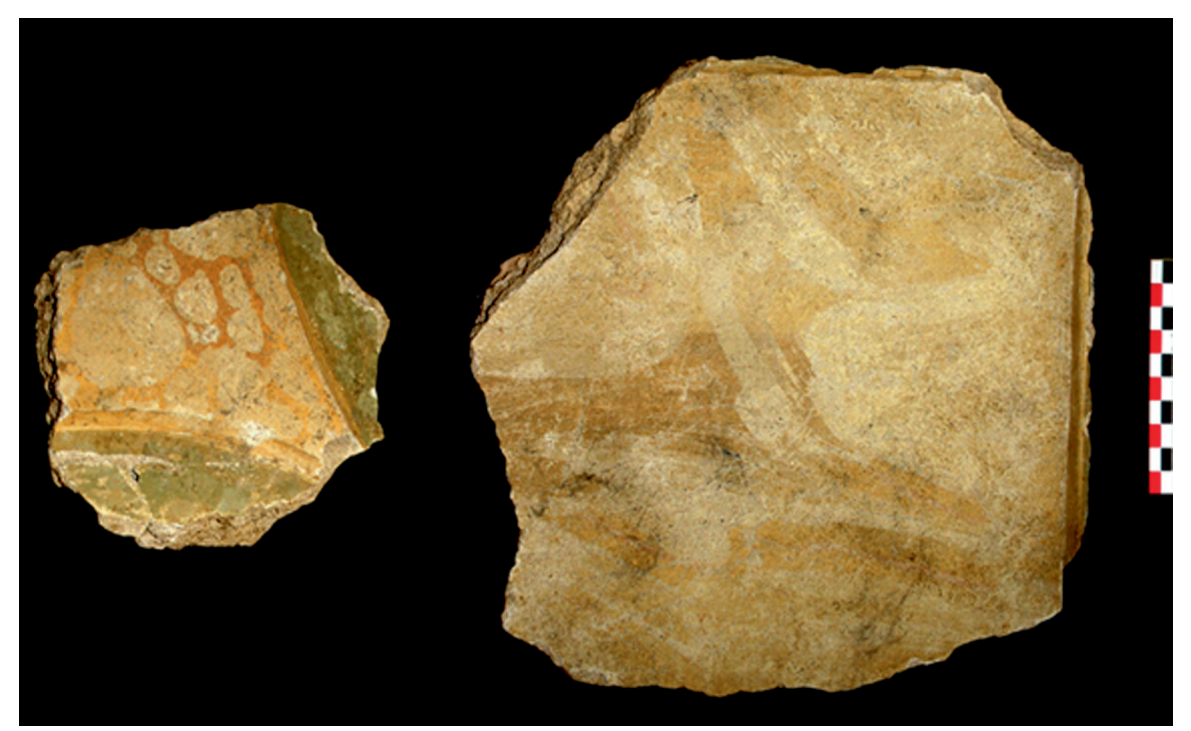

4 Fig. 43. Argentomagus, éléments du décor stuqué (clichés J. Boislève).

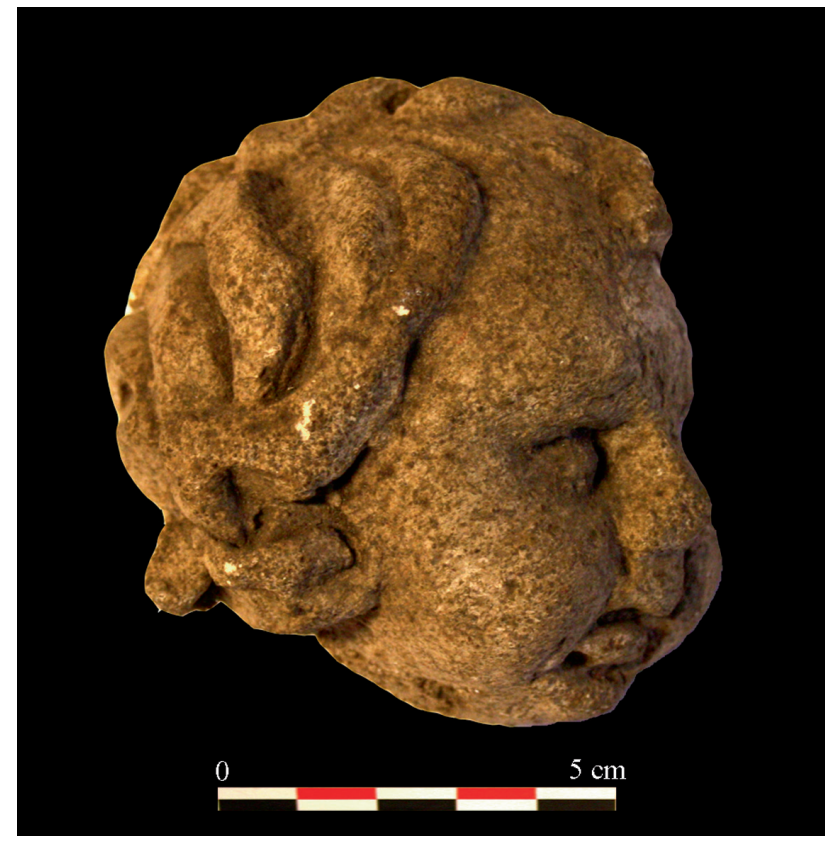

A Fig. 44. Clermont-Ferrand, tête enfantine (Eros ?) (cliché J. Boislève).

servir d'armature à des voûtes peintes, comme à Lisieux ou au Thillay (Val-d'Oise), mais jamais pour un usage mural à des fins strictement décoratives.

Le relief est ensuite développé de façon classique par l'ajout d'une ou plusieurs couches de mortier successives. On remarque que le tuileau intervient assez souvent pour créer l'âme des corniches qui est parfois, comme à Mané-Véchen, renforcée par l'ajout de fragments de céramique.

À Autun, l'observation d'empreintes carrées sur le replat supérieur d'une corniche révèle la pose d'une baguette de bois qui servait de butée et de guide pour tirer le gabarit en garantissant l'horizontalité du geste.

L'âme des corniches est souvent préprofilée, c'est-àdire d'ores et déjà dégrossie selon un profil proche du pro-

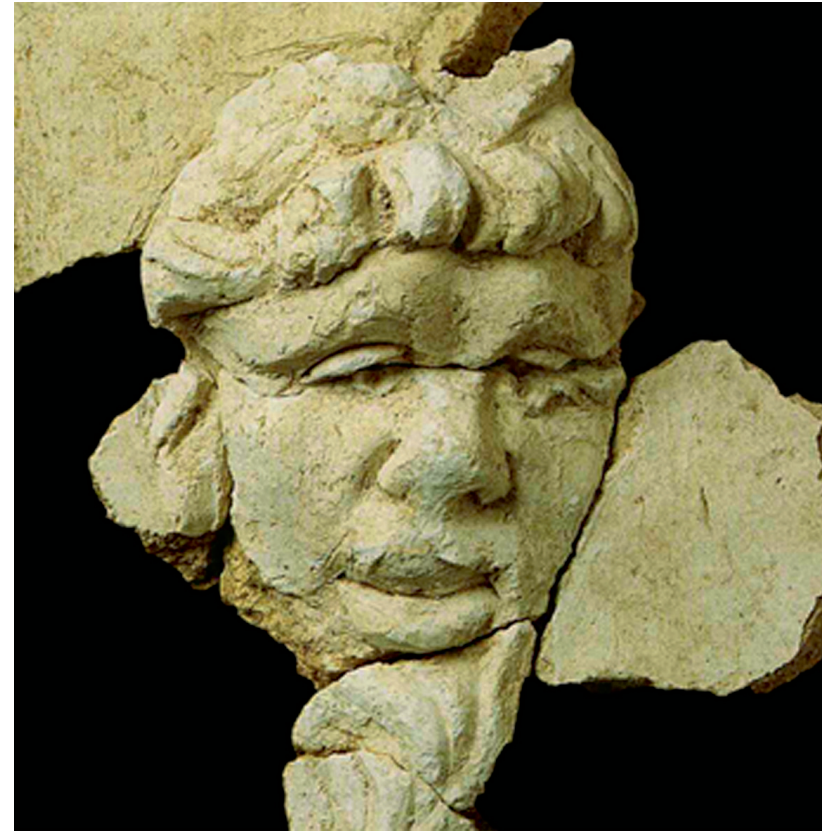

$\Delta$ Fig. 45. Argentomagus, tête de Pan ou de satyre (extrait de Coulon 2002).

fil final, sans doute pour réduire l'épaisseur de la dernière couche, généralement blanche et plus chargée en chaux ou en poudre de marbre, matériau plus coûteux que le mortier de base. Pour les reliefs modelés, le décor de la salle BF de Mané-Véchen apporte un degré inconnu de la préparation d'un visage. Au profit de la séparation des couches de mortier, nous avons pu observer l'esquisse préparatoire modelée par l'artisan sur la couche de mortier servant d'âme. Les traits principaux du visage y sont nettement esquissés (fig. 48), tel un tracé préparatoire en peinture.

Toujours à Autun, l'observation de la corniche sommitale révèle un procédé nouveau. Le relief est principalement monté en mortier sableux gris mais, sous la couche blanche d'épiderme, l'artisan a appliqué une fine couche de 


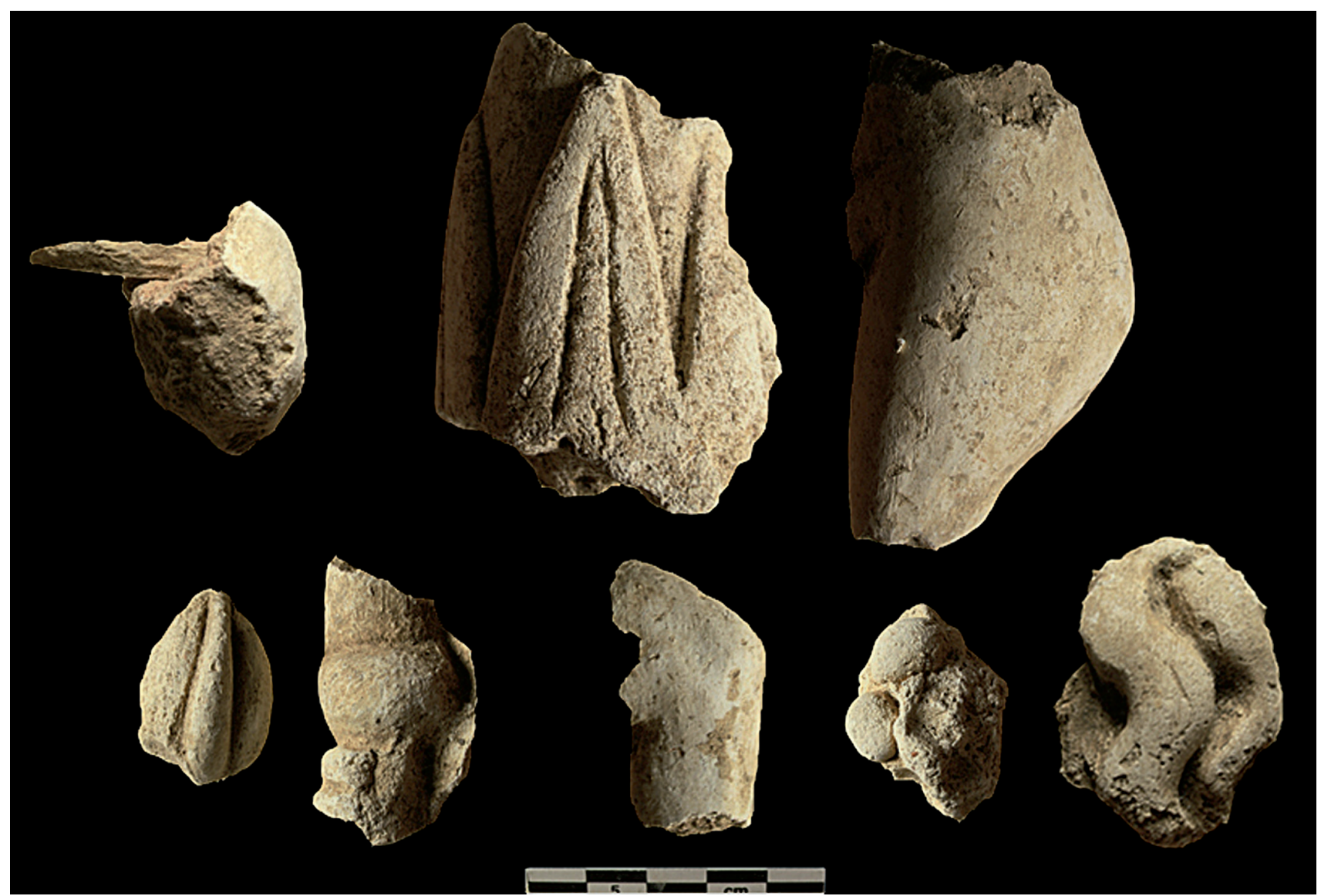

\ FIg. 46. Noyal-Châtillon-sur-Seiche, éléments du décor stuqué (décor figuré et végétalisant, fragment avec cheville en os) (clichés J. Boislève).

mortier de tuileau, rose, qui n'apporte que peu d'épaisseur à la corniche. Son intérêt réside plutôt dans sa couleur car le motif de la corniche est travaillé au couteau par évidements dans la couche de surface blanche. Ainsi, aux endroits où l'artisan enlève de la matière, il laisse réapparaître le rose de la couche sous-jacente. Cette astuce, qui peut sembler anodine, rappelle la technique du sgraffito jusqu'alors inconnue dans l'Antiquité mais développée au XVIle s. C. Allag et N. Blanc proposent de voir un autre exemple de cette technique sur le chapiteau de Charleville mais la volonté de faire apparaître la polychromie sousjacente nous semble moins évidente. En effet dans ce cas, toute l'âme du chapiteau est montée en tuileau ce qui ne permet pas, comme à Autun, de caractériser assurément la volonté de retrouver cette couleur en surface, et les évidements tiennent, à notre sens, plus de la recherche de profondeur sur ce chapiteau, qui cherche clairement à imiter la ciselure de la pierre, que de l'idée de faire apparaître une couleur sous-jacente.

Enfin, le plafond de la salle BF de Mané-Véchen apporte le second exemple de dorure à la feuille sur stuc, le premier cas étant constitué de trois fragments de moulure provenant du sanctuaire de Tintignac à Naves (Corrèze) (Maniquet et al. 2012). L'analyse révèle l'utilisation d'or natif aminci en feuille particulièrement fine qui était posée sur une assiette d'ocre rouge. Si en peinture l'usage de la feuille d'or semble réservé à rehausser quelques petits zones du décor comme les feuilles d'une couronne ou le bracelet d'un personnage, en stuc, l'emploi semble plus large et donne au relief l'aspect d'un objet ciselé dans le métal précieux. La technique est par exemple développée sur la volta dorata de la Domus aurea où toutes les moulures, feuilles, oves et autres modillons étaient dorés pour mieux se détacher sur un fond peint en rouge et bleu, des tonalités qu'on retrouve donc sur le plafond de Mané-Véchen.

\section{CONSIDÉRATIONS CHRONOLOGIQUES}

Les décors de stucs trouvent leurs fondements à l'époque hellénistique. En Italie, à partir du ler s. ap. J.-C., l'artisanat s'émancipe et développe ses propres formes, essentiellement destinées à l'ornementation des voûtes. Progressivement, le stuc gagne la paroi mais se cantonne souvent à une zone dans un dialogue où la peinture colorée des fonds tranche avec la blancheur du relief.

En Gaule, les décors de stuc demeurent parmi les plus mal documentés. Quelques exemples d'orthostates ou d'appareils de maçonnerie de l'architecture sont connus dans le sud de la Gaule, par exemple à l'lle Sainte-Margue- 


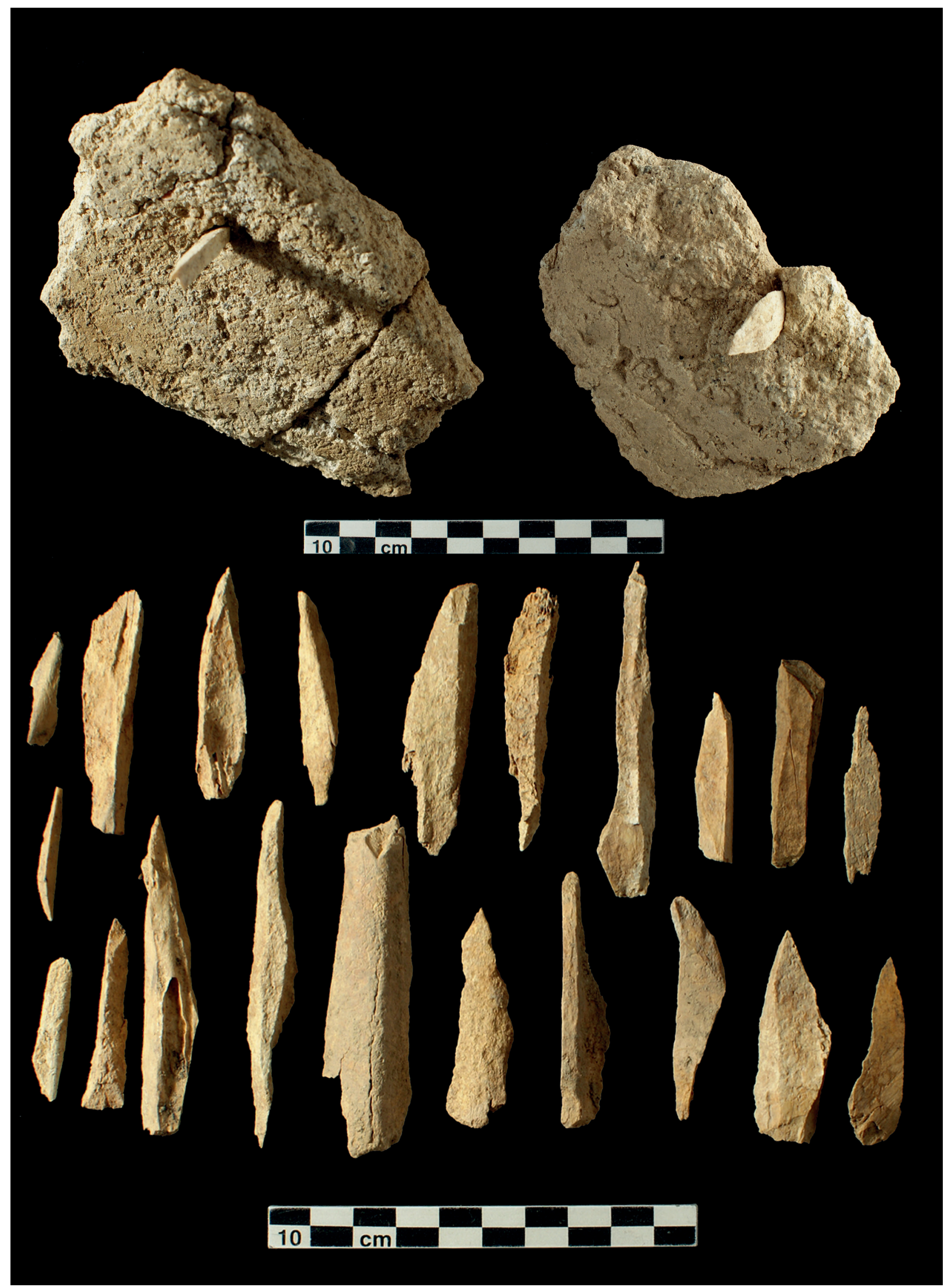

\ FIg. 47. Mané-Véchen, salle BF, chevilles en os et stucs avec cheville en place (clichés J. Boislève). 


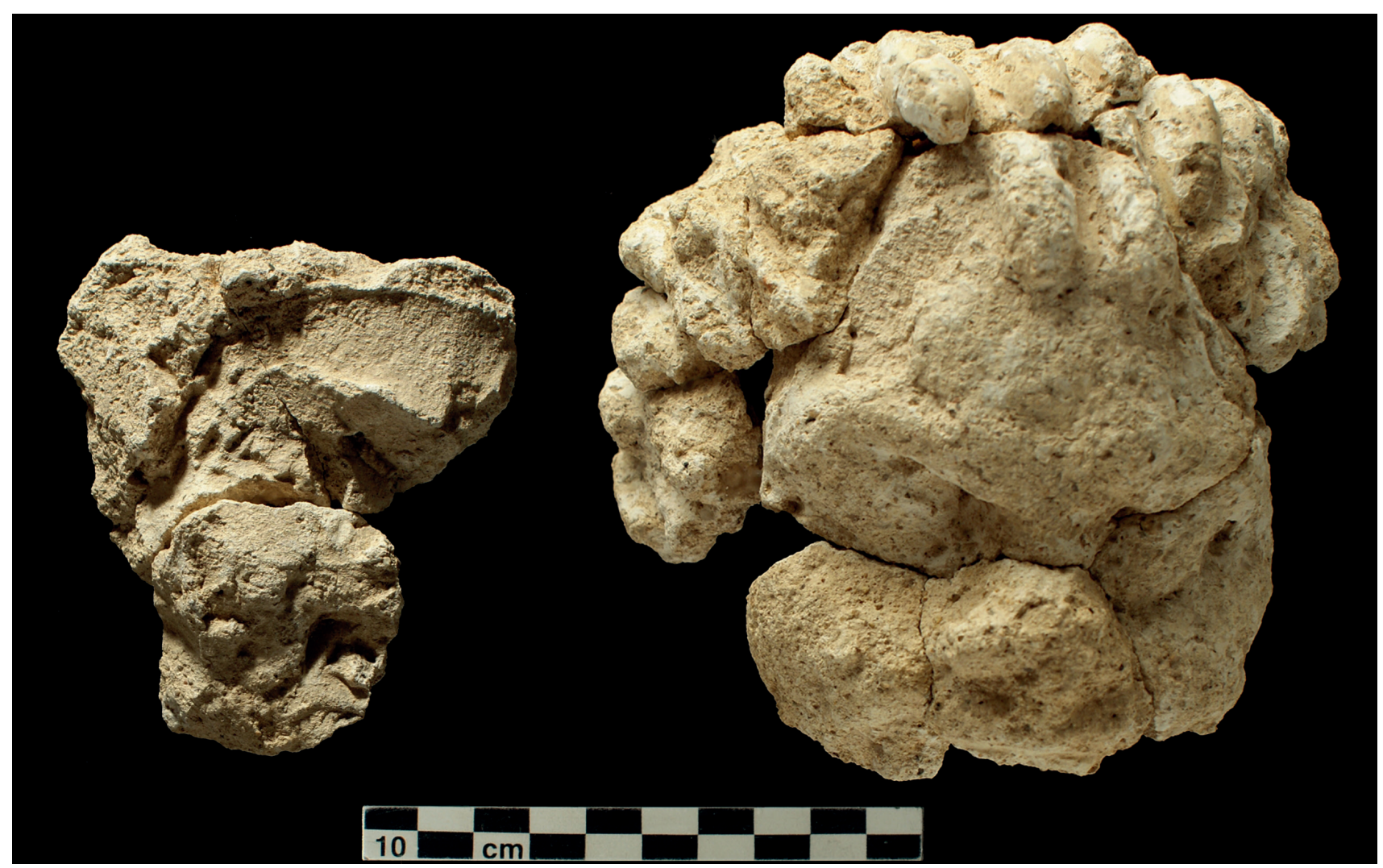

\ FIG. 48. Mané-Véchen, salle BF, tête de satyre et esquisse préparatoire dans le mortier sous-jacent (clichés J. Boislève).

ritte ou à Vaison-la-Romaine (Vaucluse). Sous influence directe de I'Italie toute proche, ils se rattachent au Style structural ou au ler style pompéien. Le décor de la salle $A B$, qui reprend un système d'orthostates et, en zone supérieure, de compartiments qui peuvent rappeler une disposition en carreaux et boutisses, pourrait être interprété comme un retour de ce ler style. Toutefois il s'agit plutôt d'une variante des imitations de placages de marbres dont le renouveau florissant de l'ère sévérienne offre une multitude d'exemples. Certains de ces décors s'enrichissent du relief, comme nous l'avons vu à Vieux et Mané-Véchen qui sont tous deux datés de cette période. Les décors d'argentomagus et de Corseul plus incomplets et encore inédits correspondent à la même mode.

De manière plus générale, il apparaît que les décors à dominante stuquée connus en Gaule sont très majoritairement datés de la seconde moitié du II $\mathrm{s}$. ou du III $\mathrm{s}$. définissant ainsi une phase de renouveau et d'expansion de cet artisanat dans cette province. Les éléments figurés connaissent un engouement certains au sein de ces décors où le vocabulaire architectural, plus habituel, est toujours très présent. Par ailleurs, les reliefs de cette époque semblent plus prononcés et traduisent une volonté de sortir davantage de la paroi en mettant mieux en avant le motif. Les grands personnages de Mané-Véchen et de Vieux ne sont certainement pas des cas isolés et il est probable que de prochaines découvertes complèteront cette série. Enfin, on peut suivre cet engoue- ment jusqu'à la fin du III s. ou le début du IVe siècle où le décor d'Autun apporte un nouveau jalon stylistique pour mieux comprendre le maintien d'un artisanat du stuc durant l'Antiquité tardive et le haut Moyen Âge.

\section{CONCLUSIÓN}

Nous l'avons vu, les vestiges conservés dans ces trois sites jettent un éclairage nouveau sur l'artisanat du stuc antique en Gaule et révèlent des décors complexes qui ne peuvent être perçus que dans le cadre de fouilles où un prélèvement adéquat et exhaustif a été mené. Ils traduisent à la fois la tradition et la filiation par rapport à I'Italie mais aussi l'émancipation et l'indépendance prise par les artisans pour renouveler ces décors et leur apporter un vocabulaire créatif ou du moins remanié au sein de compositions innovantes. Malgré la faible quantité de décors composant le corpus, les divers points de découvertes sur le territoire semblent montrer un certain engouement pour ces progrès stylistiques. L'époque sévérienne, qui installe une nouvelle phase d'expansion économique et de stabilité politique après des périodes de troubles, constitue donc le cadre de renouveau de l'artisanat du stuc en Gaule. On perçoit également que ces décors sont réservés aux plus riches bâtiments auxquels ils confèrent une monumentalité considérable, captant la lumière et parant d'un univers foisonnant n'importe quel mur des plus communs. • 


\section{BIBLIOGRAPHIE}

Allag, C. y BARTEL, M. 1985 : "Les peintures murales de Lisieux". En Peintures murales en Gaule. Actes des séminaires de I'AFPMA, Lisieux 1982, Bordeaux 1983. (BAR International Series 240) : 29-38.

AlLAG, C. y BLANC, N. 2006 : "Vouneuil et la tradition des stucs antiques". En C. Sapin (dir.) : Stucs et décors de la fin de l'Antiquité au Moyen $\hat{A} g e\left(V^{e}-X I /{ }^{e}\right.$ siècles). Actes du colloque international tenu à Poitiers du 16 au 19 septembre 2004. (Bibliothèque de l'Antiquité tardive publiée par l'Association pour l'Antiquité tardive, 10). S.I. : 105-114.

Allag, C., Blanc, N. y Palazzo-Bertholon, B. 2011 : "Le décor de stuc en Gaule (le-VIIIe siècle)". En Balmelle et al. 2011 : 509-523.

ANDRÉ, P. 2003 : "Le trésor monétaire du Mané-Véchen-en-Plouhinec (Morbihan)". Les dossiers du Centre régional d'archéologie d'Alet $31: 11-22$.

Balmelle, C., Éristov, H. y Monier, F. (dir.) 2011 : Décor et architecture en Gaule entre l'Antiquité et le haut Moyen-Âge : mosaïque, peinture, stuc. Actes du colloque de Toulouse, 9-12 octobre 2008. (Aquitania, supplément 20). Bordeaux.

BARBEt, A. 2008 : La peinture murale en Gaule romaine. Editions Picard. Paris.

BARBet, G. y Gandel, P. 1998 : "À Vicourt, Jura, les insolites décors d'une villa gallo-romaine". Archéologia 346 : 42-45.

BerTHIER, G. 1980 : "Les peintures du temple de Genainville". En Peinture murale en Gaule. Actes des séminaires de l'AFPMA, Lyon-NarbonneParis-Soissons, 1979. (Publication du Centre de recherches sur les techniques gréco-romaines 9). Dijon : 127-134.

BEt, PH. 2006 : "Le site gallo-romain du nouvel hôpital d'Autun". Dossiers archéologie et sciences des origines 316 : 78-85.

BILleREY, R. 2009 : "Bavilliers, l'établissement gallo-romain et ses abords. Permanence de la présence humaine des origines au XIX siècle" ; Bulletin de la société belfortaine d'émulation 100 : 25-210.

BoIsLĖVE, J., collab. LeFĖVRE, J.-F. 2006 : La villa de Mané-Véchen en Plouhinec (Morbihan), étude des peintures de la salle $A B$. Rapport d'étude inédit. CEPMR de Soissons.

BoISLĖVE, J. 2007 : "Un ensemble de stucs exceptionnel". En P. ChardronPicault (dir) : Hommes de feu, hommes du feu : I'artisanat en pays Eduen. Catalogue de l'exposition au musée Rolin. Autun : 186-195.

- 2010a : "Décor de Stucs : I'ensemble exceptionnel du nouvel Hôpital d'Autun". En P. Chardron-Picault (dir.) : Aspects de l'artisanat en milieu urbain : Gaule et occident romain. Actes du colloque international d'Autun, 20-22 septembre 2007. (Revue Archéologique de I'Est, supplément 28). Dijon : 219-229.

- 2010b : "Mané-Véchen, dorures et stucs d'une villa maritime". Archéologia 475 : 36-49.

- "Un important décor architectural en stuc à Autun". En Balmelle et al. 2011 : 525-538.

BolstėVE, J., collab. LeFĖVRE, J.-F. y GroetembriL, S. 2009 : La villa de ManéVéchen en Plouhinec (Morbihan), étude des stucs de la salle BF. Rapport d'étude inédit. CEPMR de Soissons. 2 vol.

BoISLĖVE, J. 2012 : "La maison au Grand Péristyle à Aregenua (Vieux - Calvados), une relecture du programme décoratif peint et stuqué". En J. Boislève, K. Jardel y G. Tendron (dir.) : Décor des édifices publics civils et religieux en Gaule durant l'Antiquité, ler - IV s. ap. J.-C., peinture, mosaïque, stuc et décor architectonique. Actes du colloque de Caen, 7-8 avril 2011 XLV. Mémoire APC, Chauvigny : 135-153.

BOISLĖVE, J. sous presse : "L'utilisation du relief dans les décors de la villa gallo-romaine de Mané-Véchen (Morbihan)". En Actes du colloque de I'AFPMA, séminaire de Narbonne 2010. (Pictor, 1, collection de I'AFPMA).

BoIsLĖVE, J. y ALLAG, C. 2011 : "Un décor stuqué monumental du BasEmpire à Autun". Gallia 68-2 : 195-235.

BoIsLĖVE, J. y collab. Allonsius, C. 2006 : "Un exceptionnel décor de stucs provenant du site du Nouvel Hôpital". Dossier archéologie et sciences des origines $316: 86-88$.

BoIsLĖVE, J. y LABAUNE-JEAN, F. 2011 : "Quelques peintures murales romaines et autres éléments décoratifs à Carhaix-Vorgium (Finistère)". Arémorica $4:$ 125-137.

BoIsLÈVE, J. y PROVOSt, A. 2011 : "Les stucs de la villa maritima de ManéVéchen, anciennes découvertes et nouveaux décors". En Balmelle et al. $2011: 539-552$.

BoIsLĖVE, J., LABAUnE-JeAn, F. y Dupont C. 2011 : "Coquillages, les décors marins d'Armorique". Archéologia 486 : 24-35.

ColleCtIF 1991 : Archéologie chez vous, Grésivaudan : pays d'Allevard et de Goncelin. Catalogue d'exposition du musée dauphinois, n. ${ }^{\circ} 9$. Grenoble.

CoUlon, G. 2002 : Argentomagus, du site gaulois à la ville gallo-romaine. Hauts lieux de l'Histoire. S.l.

FLECHER, J.-F. 1980 : "Les peintures murales du Mont-de-Gif (commune d'Arnouville-les-Gonesse, Val-d'oise). En Peinture murale en Gaule. Actes des séminaires de l'AFPMA, Lyon-Narbonne-Paris-Soissons, 1979. (Publication du Centre de recherches sur les techniques gréco-romaines 9). Dijon : 121-126.

FrIzot, M. 1977 : Stucs de Gaule et des provinces romaines. Motifs et techniques. (Publication du centre de recherches sur les techniques gréco-romaines 7). Dijon.

Maniduet, Ch., GroetembriL, S. y DuphiL, V. 2012 : "Le programme ornemental du sanctuaire de Tintignac (Naves, Corrèze)". En J. Boislève, K. Jardel, G. Tendron (dir.) : Décor des édifices publics civils et religieux en Gaule durant I'Antiquité, ler - IVe s. ap. J.-C., peinture, mosaïque, stuc et décor architectonique. Actes du colloque de Caen, 7-8 avril 2011. Mémoire XLV APC, Chauvigny : 245-266.

Provost, A. 2007 : "La villa maritime de Mané-Véchen en Plouhinec (Morbihan)". Arémorica $1: 85-100$.

Sanquer, R. y Galuiou, P. 1970 : "Le "Château" gallo-romain de Keradennec en Saint-Frégant (Finistère)". Annales de Bretagne 77 : 183224.

VIPARD, P. 1998 : La Maison du "Bas de Vieux" : une riche habitation romaine du quartier des thermes d'Aregenua (Vieux, Calvados). Guide à l'usage des visiteurs. Edition du Service Départemental d'Archéologie du Calvados. Caen.

- 2002 : La cité d'Aregenua (Vieux, Calvados), Chef-lieu des Viducasses : état des connaissances. Exé productions. Paris. 
